Portland State University

PDXScholar

Winter 3-9-2015

\title{
Supporting the Aging Workforce: The Impact of Psychosocial Workplace Characteristics on Employees' Work Ability
}

Jennifer Rae Rineer

Portland State University

Follow this and additional works at: https://pdxscholar.library.pdx.edu/open_access_etds

Part of the Social Psychology Commons

Let us know how access to this document benefits you.

\section{Recommended Citation}

Rineer, Jennifer Rae, "Supporting the Aging Workforce: The Impact of Psychosocial Workplace Characteristics on Employees' Work Ability" (2015). Dissertations and Theses. Paper 2216.

https://doi.org/10.15760/etd.2213

This Dissertation is brought to you for free and open access. It has been accepted for inclusion in Dissertations and Theses by an authorized administrator of PDXScholar. Please contact us if we can make this document more accessible: pdxscholar@pdx.edu. 
Supporting the Aging Workforce: The Impact of Psychosocial Workplace Characteristics on Employees' Work Ability

by

Jennifer Rae Rineer

A dissertation submitted in partial fulfillment of the requirements for the degree of

\author{
Doctor of Philosophy \\ in \\ Applied Psychology
}

Dissertation Committee:

Donald Truxillo, Chair

Todd Bodner

Leslie Hammer

Margaret Neal

Portland State University

2015 


\begin{abstract}
It is estimated that by $2020,25 \%$ of the US labor force will be aged 55 or older. Along with this demographic shift, Americans and employees in other industrialized nations are now working longer than before, either out of preference or financial necessity. Therefore, it is essential that we understand how to support employees so that they can continue working in a healthy, happy, and productive manner as they age. The construct of work ability (the extent to which people perceive they can meet the mental and physical demands of their jobs) has the potential to guide research and practice on how best to support employees throughout the lifespan. However, though studied extensively in the occupational health literature, work ability has only recently gained attention in the Industrial/Organizational Psychology and Occupational Health Psychology literatures. This study helps to further integrate work ability into our field and theoretically ground the construct using the Job Demands-Resources model (Demerouti, Bakker, Nachreiner, \& Schaufeli, 2001). Specifically, this study examined psychosocial characteristics of the work environment (age diversity climate, team cohesion, organizational justice, and leader-member exchange) that were expected to buffer against the negative effects of increased age and poor health on work ability. The interaction between team cohesion and poor health had a significant effect on work ability. While the other hypothesized interaction relationships were unsupported, ancillary analyses showed that both team cohesion and age diversity climate do relate positively to work ability, even after controlling for age and health. These findings highlight the importance of a positive social work environment in supporting employees' work ability throughout the
\end{abstract}


lifespan. Suggestions for future research include examining additional psychosocial predictors and behavioral outcomes of work ability, as well as conducting intervention studies aimed at increasing work ability by improving social aspects of the work environment. 


\section{Acknowledgments}

I would like to thank my doctoral program advisor and dissertation chair, Dr. Donald Truxillo, for his insightful feedback and guidance in conducting my dissertation research, and more broadly for his invaluable mentorship throughout my graduate school career. I would also like to thank my dissertation committee members Drs. Leslie Hammer and Todd Bodner not only for their contributions to my dissertation, but also for being wonderful teachers to me over the years. Finally, I would like express my appreciation for Dr. Margaret Neal, whose unique perspective on my committee as an expert on aging undoubtedly strengthened this research.

The data utilized in this dissertation were collected as part of the Safety and Health Improvement Program (SHIP), a three-year intervention study aimed at improving the safety and health of construction workers through supervisor training and facilitated work-group sessions. SHIP was funded through the Oregon Healthy Workforce Center (www.ohsu.edu/ohwc), a National Institute for Occupational Safety and Health (NIOSH) Total Worker Health Center of Excellence (Grant: U19OH010154). 
Table of Contents

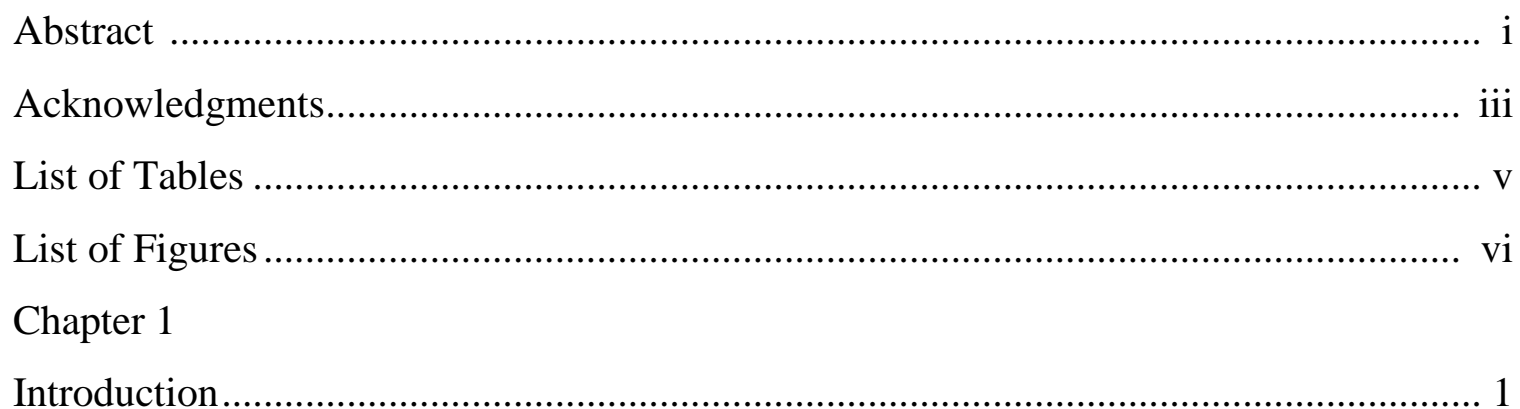

Chapter 2

The Work Ability Construct and Its Measurement ..................................................11

Chapter 3

The Job Demands-Resources Model and Its Application to Work Ability .....

Chapter 4

Antecedents and Moderators of Work Ability within the JD-R Framework

Chapter 5

Hypotheses

Chapter 6

Method.

Chapter 7

Results

Chapter 8

Discussion 79

References

Appendix A - Work Ability Index

Appendix B - Questionnaire Items 


\section{List of Tables}

Table 1

Examples of Work Ability Measurement Tools and Strategies

Table 2

Means, Standard Deviations, and Intercorrelations of Study Variables .101

Table 3

Main and Moderating Effects of Age Diversity Climate on the Relationships Between

Age and Work Ability and Health and Work Ability ............................. 102

Table 4

Main and Moderating Effects of Organizational Justice and Leader-Member Exchange on the Relationships Between Age and Work Ability and Health and Work Ability ........103

Table 5

Ancillary Analysis

Results................................................................... 104

Table 6

Main Effects of Concurrent Predictors of Work Ability. 105 


\section{List of Figures}

Figure 1

Proposed Model

106

Figure 2

Work Ability House

Figure 3

Graph Depicting Interaction between Age Diversity Climate and Health

Figure 4

Graph Depicting Interaction between Team Cohesion and Health

Figure 5

Graph Depicting Interaction between Leader-Member Exchange and Health 110 


\section{Chapter 1: Introduction}

The twenty-first century workforce is aging, with increasing percentages of workers aged 55 and older (Loeppke et al., 2013). This is due to the combined effects of a number of social and demographic trends. Globally, the general population is aging. By 2040, people aged 65 and older are estimated to account for $14 \%$ of the total population (Kinsella \& Wan, 2008). In the United States specifically, life expectancy has increased from age 70 to age 78 over the past 50 years, thanks to advancements in medicine, technology, and public health (Centers for Disease Control and Prevention, 2012). By 2060, individuals aged 65 and older are expected to account for one in five Americans, compared to one in seven today (U.S. Census Bureau, 2012). Concurrently, there has been a decline in fertility rates, leading to fewer young workers entering the workforce (Kinsella \& Wan, 2008). It is estimated that by $2020,25 \%$ of the U.S. labor force will be aged 55 or older (Stanford Center on Longevity, 2013). This increase in older workers is partly attributable to the impact of the "Baby Boomer" generation; this group, born between 1946 and 1964, began turning 65 in 2011 and accounts for about one quarter of the population (U.S. Census Bureau, 2012).

Along with these demographic changes, Americans and employees in other industrialized nations are now working longer than before, either out of preference or financial necessity. Many countries are concerned about labor shortages that are expected to occur when the Baby Boomer generation retires. Further, it will be difficult for many nations to financially support increased numbers of retirees. Accordingly, employees are being encouraged to work longer. Eleven Organisation for Economic Co-Operation and 
Development (OECD) countries, including Australia, France, Denmark, Korea, and the United States, plan to increase pension ages by 2050 (Brandon, 2010). Additionally, many workers are making the decision to keep working later in life because the economic downturn of recent years has prevented them from saving the money they need to support themselves in retirement.

The aging of the workforce presents new challenges for employees, organizations, and societies, as increased age is related to a variety of changes in worker functioning. Aging affects all parts of the body. Generally, individuals are physically strongest at age 20-30; physical strength gradually declines between ages 30 and 50, and then deteriorates more quickly after age 50 (Millanvoye, 1998). Age is also related to declines in bone density, balance, exercise capacity, hearing ability, and visual acuity, and increases in conditions such as coronary artery disease (Silverstein, 2008). Increased age is also related to an increased prevalence of work-limiting disabilities; such disabilities affect only $3.4 \%$ of workers age $18-28$ but $13.6 \%$ of workers over age 60 (National Research Council, 2004).

Age is also related to a variety of declines in cognitive functioning. There is a negative relationship between age and certain abilities like fluid intelligence (e.g., working memory, abstract reasoning, and attention; Horn \& Cattell, 1967; Schaie \& Willis, 1993). Older individuals also tend to experience reduced spatial abilities and have more difficulty processing complex stimuli (Silverstein, 2008). These sorts of cognitive declines may have negative consequences for both employee well-being and performance, especially with regard to certain types of work. For example, jobs high in 
task variety (defined as the degree to which the job demands a wide range of tasks; Morgeson \& Humphrey, 2006), while beneficial for younger workers (Zaniboni, Truxillo, Fraccaroli, McCune, \& Bertolino, 2011), may be detrimental to older workers, negatively affecting their satisfaction, engagement, and performance (Truxillo, Cadiz, Rineer, Zaniboni, \& Fraccaroli, 2012). A study by Zaniboni, Truxillo, and Fraccaroli (2013) provided empirical support for the differential effects of task variety on employees of different ages; task variety had a stronger relationship with work-related burnout and turnover intentions for older workers as compared to younger workers.

However, it is important to note that aging at work does not need to be viewed only as a problem to be addressed; instead, we must consider that age can come with advantages to both employees and organizations (Baltes \& Finkelstein, 2011). For example, there is a positive relationship between age and crystallized intelligence or experiential knowledge (Kanfer \& Ackerman, 2004). Research has shown that older adults have more of this type of education- and experience-based domain knowledge than younger adults (Ackerman, 2000), which could lead to positive relationships between age and well-being and performance for certain types of jobs. Further, individuals can compensate for declines in fluid intelligence by selecting goals and utilizing selfregulatory strategies that allow them to take advantage of their accumulated crystallized intelligence (Selective Optimization with Compensation [SOC] Theory; Baltes \& Baltes, 1990). For example, jobs high in autonomy (or control over how one does one's work) may lead to increased satisfaction, engagement, and performance for older workers who have accumulated greater work experience and job knowledge. 
Further, non-ability traits that change throughout adulthood can also make older employees more valuable to organizations. For example, generativity motives, focused on caring for others and giving back to society and future generations, seem to arise in midcareer (McAdams, de St. Aubin, \& Logan, 1993; Kanfer \& Ackerman, 2004), and can inspire older workers to be effective mentors for younger employees (Allen, 2007) and thrive in jobs in which there are opportunities to both give and receive social support (Rineer, Truxillo, Hammer, \& Bodner, 2012). These positive effects of age on workers are borne out by the meta-analytic finding that older workers can have higher levels of certain types of work performance (e.g., Ng \& Feldman, 2008).

The aforementioned discussion highlights the fact that while age-related changes are inevitable, they do not necessarily lead to inability to work, or reduced job performance (Ng \& Feldman, 2008; Silverstein, 2008). Employers should, to the extent possible, adapt the work environment to support the needs of workers of all ages. When strategies for successful aging are in place, organizations can reap the benefits of the experience of older workers (Baltes \& Finkelstein, 2011; AARP, 2002).

The best way to support aging workers, however, is a complicated issue, as the ability of employees to continue working in a healthy and productive way is dependent on both the individual and the particular job in which he or she works. An understanding of the fit between aging workers' abilities and their job demands will allow organizations to assess the extent to which employees are continuing to thrive, or conversely, the extent to which changes may be needed to ensure the continued well-being and effectiveness of older workers. 
The concept of work ability, designed to address this need, was conceived in the 1980s and further developed by researchers at the Finnish Institute of Occupational Health throughout the 1990s (Ilmarinen, 2001). Work ability refers to an employee's perception of his or her physical and mental capacity to perform his or her work (Ilmarinen, 2007, 2009; Tuomi et al., 1997). It is described as a match between the personal resources of an employee and the demands of his or her job (Ilmarinen, 2009). When job demands consistently exceed a person's resources, work ability decreases (Weigl, Muller, Hornung, Zacher, \& Angerer, 2013).

The work ability construct holds promise in helping organizations to quantify the successful aging of its employees. It also has important policy implications for determining when an employee can or should retire or move into different roles. Popular among researchers in the Nordic countries and Europe, the concept of work ability has been shown to relate to a variety of important work outcomes. For example, work ability has shown an association with disability pensions and mortality (Tuomi et al., 1997), selfreported productivity at work (Tuomi et al., 2001), early retirement (Feldt, Hyvonen, Makikangas, Kinnumem, \& Kokko, 2009), mental and physical health perceptions, turnover intentions, stress, and disability (Ahlstrom, Grimby-Ekman, Hagberg, \& Dellve, 2010; Camerino et al., 2006).

The relationship between work ability and personal characteristics such as age and health has been established in the occupational health and medicine literature in Europe; generally speaking, work ability is positively related to health and negatively related to age (e.g., Pohjonen, 2001; Tuomi et al., 1997). Yet, despite the potential of the 
work ability construct to guide organizational research and practice on supporting older workers, there has been a lack of research concerning psychosocial predictors of work ability that could buffer against the personal demands of increasing age and declining health. Investigation of these types of variables is important, as they are often under the control of organizations. Identifying group- and individual-level psychosocial variables that affect work ability can provide leverage to organizations to help them support their employees' functioning as they age. To date, only a few studies (e.g., Feldt et al., 2009; McGonagle, Fisher, Barnes-Farrell, \& Grosch, in press; Weigl et al., 2013) have specifically addressed the issue of psychosocial antecedents of work ability.

In this dissertation, I utilize data from a larger study, the Safety and Health Improvement Program (SHIP), to investigate psychosocial moderators in the relationships between age, health, and work ability. SHIP is a NIOSH-funded intervention study aimed at improving work-life and safety support for construction workers conducted through the Oregon Healthy Workforce Center, a NIOSH Center of Excellence. Specifically, I use SHIP data to test a model of the psychosocial antecedents and moderators of work ability (see Figure 1.) I investigate selected group-level factors (i.e., group-level age diversity climate and team cohesion), as well as individual-level factors (i.e., perceptions of organizational justice and leader-member exchange) in terms of their impact on the relationships between age and work ability and health and work ability. Here, I briefly introduce the theoretical basis for this model, which is then further developed in later chapters of this dissertation.

\section{Overarching Framework: Job Demands-Resources Theory}


In this dissertation, I build on the work of McGonagle and colleagues (in press) by utilizing the Job Demands-Resources (JD-R; Bakker \& Demerouti, 2007; Demerouti, Bakker, Nachreiner, \& Schaufeli, 2001) model as the basis for my hypotheses. According to the JD-R model, all working conditions, as well as individual characteristics, can be classified as either demands or resources. Demands are challenging to the individual, while resources facilitate goal achievement and help people to recover after energy expenditure. Demands and resources have both direct and interactive effects on individual health and work outcomes. In this study, I am conceptualizing age and poor health as demands that lead to reduced work ability. The primary focus of this dissertation is on the psychosocial workplace factors (i.e., group-level age diversity climate and team cohesion, and individual-level organizational justice and leader-member exchange), which I hypothesize will act as job resources and buffer against the negative effects of aging and declining health on work ability.

\section{Contribution}

This study makes a number of significant contributions to the occupational health psychology literature as well as the literatures on work ability and the aging workforce. Although certain physical job characteristics such as ergonomics and physical workload have been shown to relate to work ability (e.g., van den Berg, Elders, de Zwart, \& Burdorf, 2009), much less work has been conducted on potential psychosocial predictors. Yet the limited research that has investigated the effects of psychosocial variables shows promise. For example, Weigl and colleagues (2013) found that job autonomy positively relates to work ability, and Feldt and colleagues (2009) identified not only job control but 
also organizational commitment and general organizational climate as factors related to favorable work ability trajectories. Most recently, McGonagle, Fisher, Barnes-Farrell, and Grosch (in press) found that the job resources of autonomy, coworker support, and supervisor support were related to work ability, albeit much less strongly than the personal resources of health and sense of control.

Feldt and colleagues (2009) concluded that more attention should be given to psychosocial work conditions in organizations to prevent poor work ability. Similarly, McGonagle and coauthors recommended that future research examine additional job resource variables to better understand how to improve work ability. In this way, a major contribution of this dissertation is to further integrate work ability into the psychology literature by examining key psychosocial variables that can impact work ability, at both the group and individual levels. These antecedents can eventually inform work ability interventions, increasing the ability of aging employees to successfully meet the demands of their jobs and preventing their early exit from the workforce.

Specifically, this study makes three major contributions regarding psychosocial moderators that may weaken the negative effects of age and declining health on work ability. First, it examines the impact of group-level variables (i.e., age diversity climate and team cohesion) on work ability. This is a significant addition to the literature, as it demonstrates the extent to which work ability is affected not only by the individual and the job itself, but also the social context in which the job is enacted. Second, this study will demonstrate the effects of justice and leader-member exchange on work ability. This is of particular practical value, as both justice and leader-member exchange can be 
affected by organizations. If these variables are shown to affect the age-work ability and health-work ability relationships, this will give organizations a leverage point for improving work ability by instituting and enacting fair practices and improving supervisor-subordinate relationships. Third, by utilizing JD-R theory, this study helps to build a unifying, theoretically-based framework within which to organize both existing and future research on work ability. Taken together, these contributions lead to a fuller understanding of how to support employees in meeting the demands of their jobs, allowing them to continue working successfully as they age and potentially experience declines in their health.

Finally, this study is of enhanced value because of the sample utilized (construction workers and their crew leaders from two public works organizations in the Pacific Northwest). Construction workers (particularly older construction workers, who are represented in our sample) belong to a work sector and demographic group that the National Occupational Research Agenda (NORA Construction Sector Council, 2008) has identified as under-studied. As mentioned earlier, the general workforce is aging, and the construction industry is no exception. In 1985, the average construction worker was approximately 36 ; in 2010 , that age jumped to approximately 41 and may continue to rise (CPWR, 2013). The economic downturn in the construction industry has made it more likely that older workers will retain their jobs and retire at a later age. This is of concern, as construction jobs are among the most physically demanding and dangerous (Choi, 2009). Thus, among this workforce sub-population in particular, it is important that we 
increase our understanding of how to support employees' work ability throughout the lifespan.

\section{Overview}

In the next chapter, I give a review of the work ability construct, including its history and measurement. Subsequently, I review the JD-R model and each of the proposed antecedents (age and health) and moderators (age diversity climate, team cohesion, organizational justice, and leader-member exchange) of work ability, and provide a theoretical rationale for their hypothesized relationships with work ability. Next, I describe the method of the study and analyses conducted. Finally, I describe the results and conclude with a discussion, including an interpretation of the findings, implications for research and practice, potential limitations, and suggestions for future research. 


\section{Chapter 2: The Work Ability Construct and Its Measurement}

As stated in the previous chapter, work ability refers to individuals' ability to meet the mental and physical demands of their job. However, a concise, uniform definition of work ability does not currently exist, and this can provide a challenge to those seeking to enhance knowledge of work ability through rigorous scientific research. Even the name "work ability" can cause confusion, as many researchers (particularly those outside of occupational health) are unfamiliar with the term. The lack of consistency in conceptualization is largely due to the fact that work ability does not belong to one particular branch of science; rather, it is utilized by a wide range of stakeholders, including health care practitioners, institutes for pensions and rehabilitation, employers, workers, researchers, and legislators. The more work ability has been studied and utilized, the more multidimensional and diverse its conceptualization has become (Ilmarinen, Gould, Jarvikoski, \& Jarvisalo, 2008). Further, the research on work ability has been largely atheoretical, which means that there has not been a unifying framework to tie the extant research together.

Yet, despite this lack of clarity, there is some consensus around various aspects of work ability and its application. For example, there seems to be agreement that work ability cannot be analyzed solely with regard to characteristics of the worker. Rather, the nature of the work and the work environment must also be taken into account (Makitalo \& Palonen, 1994). This chapter provides a review of the ways in which work ability is currently defined and utilized and will serve to synthesize the existing literature on work ability. 


\section{Background}

Developed in Finland in the early 1980s (van den Berg et al., 2009), the work ability concept was created in order to support work participation and promote the health and functional competencies of employees by helping to identify individual and workplace factors that enhance effective functioning across the lifespan. The concept and measurement of work ability is also useful for detecting deteriorating work ability as early as possible. When declining work ability is detected, it allows for changes to be made within both the individual and the work environment that can prevent work disability (Ilmarinen et al., 2008).

As described in an editorial piece by Ilmarinen (2009), the construct of work ability (and its measurement tool, the Work Ability Index, or WAI) was designed to address the basic question of how long employees are able to work and to what degree being able to work is dependent on job content and work demands. These questions were being asked in Finland in the 1980s because of the social, economic, and employment contexts that were at play. Specifically, job-dependent retirement ages, ranging from 5363 were common among Finnish municipal occupations, and employees had a broad range of early-retirement options. As work disability costs increased, societal concerns around the increased occurrence of work disability and the shortening of work careers increased, particularly in relation to the sustainability of retirement systems. In order to address these concerns, Tuomi, Ilmarinen, and colleagues formed a multidisciplinary study group to develop and validate a measure of work ability, the WAI (Ilmarinen, 2009). This group consisted of experts in the fields of occupational physiology, 
psychology, medicine, epidemiology and biostatistics (Finnish Institute of Occupational Health, 2011).

\section{The Work Ability Index}

The Work Ability Index (WAI) was designed to take a new, positive approach to the aforementioned societal concerns and consists of seven items. The first question asks respondents to rate their present work ability compared with their lifetime best. The second (consisting of two items) requires respondents to rate their work ability in relation to the demands of their job. Question 3 asks about the employee's number of diagnosed diseases. (The survey includes a checklist of a wide range of 50 possible diseases, including musculoskeletal diseases [e.g., sciatica, arthritis], cardiovascular diseases [e.g., hypertension], respiratory diseases [e.g., chronic bronchitis, asthma], mental disorders [e.g., depression, insomnia], digestive diseases [e.g., liver disease, gastric ulcer], endocrine and metabolic diseases [e.g., diabetes, thyroid disease], and blood diseases [e.g., anemia]). The fourth question asks one's subjective estimation of work impairment due to disease, and the fifth measures absences due to sickness over the past year. The sixth question asks respondents to provide their own prognosis of their work ability two years from now, and the seventh pertains to mental resources. The full listing of items from the WAI is presented in Appendix A.

The Finnish researchers began conducting studies with the WAI in 1981, utilizing a sample of over 6,000 municipal employees aged 45-58. They then repeated these studies with the same participants in 1985, 1991, and 1997. One of the most important findings of this longitudinal study was the extent to which the work ability trajectory 
varied amongst participants. Although work ability generally declines with age and significantly declined for $30 \%$ of participants over the course of the longitudinal study, it also remained about the same for $60 \%$ of participants and even improved among $10 \%$ (Tuomi et al., 1997). This was the case for both men and women and for jobs with physical demands, mental demands, or both. These results suggest that while age tends to be correlated with decreased work ability, this decline (or at least a significant rate of decline) is not inevitable for all workers.

Regression analysis indicated that factors related to work demands, work organization and workplace community, and individuals' health and lifestyle, explained both the decline and improvement of work ability during aging (Tuomi, Huuhtanen, Nykyri, \& Ilmarinen, 2001). Regarding work demands, poor work postures, hectic work environment, poor physical climate, tool failure and substandard work rooms were associated with poor work ability, while improvements in work and tasks, as well as in work environment and tools, positively influenced work ability. Work organization and workplace community factors negatively related to work ability included uninspiring work, poor management, and lack of autonomy, while opportunities to utilize work experience were positively related to work ability. Physical exercise during free time and artistic hobbies were positively related to work ability, while being overweight was negatively related.

Based on these findings, the Finnish research and social partners agreed it was important to pursue the maintenance and promotion of work ability in workplaces. The WAI was then utilized among private, municipal, and government employees, and 
occupational health professionals, physicians, and nurses were trained in the use of the WAI by the Finnish Institute of Occupational Health. In the 1990s, the WAI gained international traction when Austrian and Dutch research groups began utilizing translated versions of the diagnostic tool. Today, the WAI is available in nearly 30 languages (Ilmarinen, 2009).

Reliability and validity. Considering the widespread research use of the WAI, relatively little research has been conducted regarding its reliability and validity. De Zwart, Frings-Dresen, and Duivenbooden (2002) concluded that the questionnaire has “acceptable" test-retest reliability, using a four-week interval between WAI measurements. They found that $25 \%$ of their 97 subjects reported the exact same score at both time points, and that $95 \%$ of the differences in individuals' scores between the two time points were less than 6.86 points, which was twice the standard deviation. However, no specific reliability estimate was provided.

Eskelinen, Kohvakka, Merisalo, Hurri, and Wagar (1991) provided validity evidence for the WAI, showing that self-reported work ability, according to WAI scores, was similar to clinical assessments of work ability. Nygard, Eskelinen, Suvanto, Tuomi, and Ilmarinen (1991) investigated the convergent validity of objectively measured functional capacity and WAI scores and found that mental capacity correlated less with work ability than physical capacity did. (Physical capacity objectively measured cardiorespiratory capacity, oxygen consumption, heart rate, and musculoskeletal capacity [mobility, flexibility, etc.], while mental capacity measured fine motor speed, auditory short-term memory, visuomotor speed, visuoconstructive ability, visual search, and 
verbal concept formation.) Although functional capacity test scores were correlated with WAI scores, the relationships were small. At best, functional capacity explained $16 \%$ of the variance in work ability. The authors explained that this was likely the result of a mismatch between the content of the functional capacity tests and requirements of actual work tasks. The predictive validity of the WAI was reported by Liira and colleagues (2000), who found that WAI scores at baseline were highly predictive of use of disability pensions four years later.

Overall, more rigorous research is needed to provide improved reliability and validity evidence for the work ability construct. This should occur as work ability becomes further integrated into the I/O and OHP literatures, as the journals in these fields often require that such information be published.

\section{Other Measures of Work Ability}

Although the WAI is the most common measure of work ability, it is not the only one. Alternate measures have been developed largely due to the length and complexity of the WAI, which measures a variety of different constructs and contains 60 items. The single-item Work Ability Estimate (first used in the Mini-Finland Health Examination Survey in the 1980s) asks participants to evaluate their work ability regardless of whether or not they are currently employed. Respondents report that they are either 1) completely fit for work, 2) partially disabled for work, or 3) completely disabled for work (Gould et al., 2008). Work ability is also commonly measured using a Work Ability Score, which is simply the first question of the Work Ability Index (one's present work ability compared to lifetime best). 
Other shortened variations of the WAI have also been used in research and have demonstrated acceptable psychometric properties. For example, Palermo, FullerTyszkiewicz, Walker and Appannah (2013) used a four-item scale measuring perceived current work ability and predicted work ability two, five, and ten years in the future. The authors found that the scores on their scale were correlated with other measures such as health and well-being in the expected directions among a sample of public sector workers. The internal reliability of their scale was .69. McGonagle and colleagues (in press) utilized a four-item measure of work ability. They used three items from the WAI (work ability compared to lifetime best, and work ability in relation to physical and mental job demands), as well as a fourth item measuring work ability in relation to interpersonal demands. In their three studies, the authors found reliabilities for the fouritem scale ranging from .75 to .90 . In this dissertation, I will use a two-item version of the WAI (based on the second question on the full-length questionnaire), which assesses a person's perceived ability to meet the physical and mental demands of their job. This shortened measure was utilized by Weigl and colleagues (2013); in their sample, the reliability of the two-item scale was .78.

Work ability is also sometimes assessed without the use of survey assessments and can be evaluated based on the person's own views or based on judgments made by health care or other professionals (Ilmarinen, et al., 2008). Sometimes individuals are assessed as having sufficient work ability if they are not on long-term sick leave. Work ability has also been measured by the number of days a person has been on sick leave in the past year (van den Berg et al., 2009; Lindberg, Vingård, Josephson, \& Alfredsson, 
2006). Most recently, Tengland (2013) has recommended a more flexible, qualitative interview approach to measuring work ability. See Table 1 for examples of work ability measurement tools and strategies.

As noted above, there are a variety of ways in which work ability is currently measured. Importantly, the various measures tap into various aspects of a person's health, well-being, functional capacity, and work life. Further, many of the metrics used to assess work ability, including the WAI, are quite subjective in nature. However, some work ability researchers purport that estimation of work ability by the individual themselves (as opposed to objective criteria or expert evaluation) is necessary because of its complexity (Ilmarinen, Gould, Jarvikoski, \& Jarvisalo, 2008). Subjective assessments have, in fact, been shown to predict future work disability (defined as receiving a work-related disability pension; Alavinia, De Boer, Van Duivenbooden, Frings-Dresen, \& Burdorf, 2009).

\section{Models of Work Ability}

Although the measurement of work ability (most commonly assessed with the WAI) has remained largely unchanged since its initial development in the 1980s, the conceptualization of work ability as a construct has changed over time. Initially, work ability was viewed as a health-based concept; namely, does the employee have the physical and mental health resources to meet the demands of his or her job? However, over time, there has been a shift toward a more holistic and versatile view of work ability which recognizes that work ability is affected and promoted by a variety of factors. According to Ilmarinen (2009), the definition of work ability also depends on the point of 
view from which it is considered (i.e., occupational health, rehabilitation, or social security).

Balance model. In occupational health, work ability is conceptualized as a balance between a person's resources and work demands. Resources include health and functional abilities, education and competence, and values and attitudes, while work demands refer to aspects of the work environment (including management), and the contents, demands, and organization of work. This balance model is based on the stressstrain concept (Rohmert \& Rutenfranz, 1983), which states that occupational stress creates strain within the individual, and that this strain is regulated by the individual's resources. According to this model, balance can be reached by either supporting the development of individuals' resources or by restructuring work demands and conditions to better suit individuals (Ilmarinen et al., 2008).

It is important to acknowledge that both personal resources and work demands are constantly changing. Although personal resources change with age and life circumstances, work demands change with both internal and external developments, such as globalization, new technology, and organizational restructuring. These increasingly dynamic conceptualizations of work ability acknowledge that work ability is related to life outside, as well as inside, of work. Improving aspects of non-work life can be helpful to improving work ability. Studies have shown that participation in both work and family roles can buffer individuals from the effects of stress in one of the roles (Greenhaus \& Powell, 2006). For example, research has shown that the relationship between work stress and impaired well-being is weaker for individuals who have a more satisfying, high- 
quality family life (Barnett, Marshall, \& Pleck, 1992). Additionally, lower work-family conflict is related to decreased psychological strain, physical health problems, depression, and burnout (Allen, Herst, Bruck, \& Sutton, 2000), all of which could affect one's ability to meet the demands of his or her job. Further, culture and society provide the framework, services, infrastructure, and rules within which employees' work ability can be supported (Ilmarinen, 2009).

Multidimensional model: coping at work, control over one's work, and participation in the work community. The multidimensional model of work ability was developed in 2001 by the Rehabilitation Foundation in Finland (Järvikoski, Härkäpää, \& Mannila, 2001). The major difference between the multidimensional model and the balance model is that the multidimensional model focuses on individual prerequisites for functioning in worklife. According to this approach, an individual's ability to cope at work, have control over his or her work, and participate in the work community are necessary for sufficient work ability. As with the balance model, each dimension (of coping, control, and participation) is examined based on the relationship between individuals' resources and the demands of the work or work environment.

In their model, Järvikoski and colleagues (2001) identified the aspects of the worker, work, and work environment likely to affect the critical dimensions of coping, control, and participation. They also delineated organizational practices related to the three dimensions that are likely to impact work ability. In the multidimensional model, coping at work is hypothesized to be affected by the individual's physical and mental capacity and the physical and mental strain of the work processes or work conditions. 
Organizations can increase opportunities for successful coping at work by optimizing the distribution of work tasks among employees and improving work conditions and processes to minimize work-related strain.

Control over one's work is affected by occupational skills and competence at the individual level. It is also determined by the cognitive prerequisites and skills required for work processes, possibilities to affect work, and opportunities to learn and develop at work. Employees' work control can be enhanced when organizations optimize occupational roles and their cognitive and skill prerequisites, provide proper equipment, and give employees opportunities to influence their work, learn, and develop.

Participation in the work community is affected by general skills in work-life and social competence, skill in applying for work, and interests at the individual level.

Participation in the work community is also influenced by prerequisites for surviving in the work community, opportunities to socially participate, social support, and diversity of work roles. Organizations can encourage participation in work-life through their attitudes and values (e.g., acceptance of diversity), the atmosphere of the work community, and practices concerning recruiting and promoting careers.

\section{Holistic model: individual resources, work, family, close community and}

society. Developed by the Finnish Institute of Occupational Health, the holistic model (another multidimensional model of work ability) is often depicted in the form of a work ability "house" (see Figure 2). An individual's resources form the foundation of the house (the first three floors). The first floor represents health and functional capacity, the second comprises competence (knowledge and skill), and the third incorporates values, 
attitudes, and motivation. The fourth floor represents "work", and consists of the conditions, content, and demands of the work, work community and organization, and leadership (supervision and management). Work ability is represented by the roof of the house, which balances on the foundation of the work and individual resource floors. The work ability house is also affected by its surroundings, which are identified as family and close community (friends, relatives, acquaintances) proximally, and society, or the external operational environment, distally. While the balance model, multidimensional model, and holistic model do not mention the use of any particular instrument for measuring work ability, they were developed by researchers who typically utilize the WAI in their research.

Summary. Although work ability research refers to these different models (the balance model, multidimensional model, and holistic model; Ilmarinen et al., 2008), it is important to note that the differences among them are minimal. All three utilize the concept of work ability as the balance between a person's resources and the demands of his or her work and work environment. The main difference between the balance model and the holistic model (which is considered a multidimensional model) is the explicit acknowledgment of the role of contextual factors on work ability in the holistic model. While work ability research refers to multidimensional conceptualizations of work ability, empirical research has not explicitly tested these models in their entirety.

\section{Individual Differences and Work Ability}

One of the most common findings among studies of work ability is that work ability tends to decline with age (Goedhard, Rijpstra, \& Puttiger, 1998; Monteiro, 
Ilmarinen \& Filho, 2006; Tuomi et al., 1991). This is unsurprising, as health is related to age, and the WAI contains several health-related items. However, good health is not always related to high work ability, and poor health does not necessarily indicate low work ability (Ilmarinen, 2009). Not surprisingly, the relationship between work ability and age has been found to be job-dependent. For men between the ages of 51-58, there is a faster decline in WAI scores for those in physical (e.g., installation) and mixed (e.g., transport) jobs as compared to those that are more mentally demanding (e.g., administration). Women over 50 also experience greater declines in WAI scores if they are in physically demanding jobs as opposed to mixed (e.g., nursing) or mentally demanding jobs (e.g., teaching). The following section reviews research related to individual differences and work ability, including demographic factors, physical and mental health, other personal resources, and work attitudes.

Demographic variables. In addition to age, work ability has been shown to relate to a number of other individual differences, including education, employment status, and marital status. Level of work ability has been shown to increase as education increases (Martelin, Sainio, Koskinen, \& Gould, 2008), because education increases the possibilities for maintaining work ability. For example, education decreases the likelihood of occupying jobs heavy in physical labor and increases the likelihood that employees have control over their work. Results of the Finnish Health 2000 study also demonstrated a relationship between work ability and employment status (Martelin, Sainio, Koskinen, \& Gould, 2008). The proportion of men and women reporting limited work ability was found to be smallest among those working full time (8\%). Those 
working part-time were more than twice as likely to report limited work ability (18\%). Individuals who were not employed experienced, by far, the worst work ability, with about $30 \%$ reporting limited work ability. The exception was women who took care of their households or family members, whose work ability was similar to that of part-time employees. Regarding marital status, those who were married or cohabitating perceived their work ability to be better than those who are single, widowed, or divorced. This is likely because marital status is a rough proxy for one's access to social support (Pensola \& Jarvikoski, 2008).

Physical and mental health. According to the Finnish Health 2000 survey, good health is essential for good work ability (Koskinen, Martelin, Sainio, \& Gould, 2008). This study showed that the Work Ability Estimate is strongly related to self-rated health. In fact, respondents who rated their health to be average estimated their work ability to be limited six times more often than those who perceived they were in good health. Further, those who rated their health as poor estimated their work ability to be limited 15-20 times more often than those who perceived themselves as healthy. Of the many diseases examined in the Finnish Health 2000 survey, depression and back disorders were the most critical sources of work ability problems among those who were employed. Related to health, lifestyle factors, such as smoking and physical activity during leisure time, have also been shown to impact work ability (van den Berg et al., 2009). Functional capacity (physical, mental and social) is another important determinant of work ability (Sainio, Koskinen, Martelin, \& Gould, 2008). In particular, even relatively minor mobility difficulties are related to lower work ability, even among those whose jobs are not very 
physically demanding. Problems in social functioning, such as managing interactions with others, are also related to reduced work ability.

Other personal resources. In addition to health, a study by Palermo and colleagues (2013) showed that the personal resources of self-reported coping ability and self-efficacy are positively correlated with work ability. Interestingly, older workers in their study reported significantly higher levels of coping ability than their younger counterparts. The authors noted that this may explain the small effect size of the negative relationship between age and work ability in their sample. In other words, perhaps age was not related to greater declines in work ability because of older workers' increased ability to cope with stress.

This explanation is in accordance with previous research which demonstrates how age and emotion are related. For example, according to Blanchard-Fields, Stein, and Watson (2004), older adults use more emotion-focused regulation strategies aimed at minimizing negative affect than younger or middle-aged adults. Additionally, $\mathrm{Ng}$ and Feldman (2010) found that increased age is positively related to a variety of job attitudes, including job satisfaction, satisfaction with coworkers and supervisors, interpersonal trust at work, organizational commitment, and perceived organizational support. Further, Soto, John, Gosling, and Potter (2011) found that neuroticism tends to decrease with age. These trends regarding personality and affect throughout the lifespan help to explain why older workers may experience less stress, which can buffer against the negative impact of age and health problems on work ability. 
Work attitudes. Attitudes toward work have also been identified as factors affecting work ability (Gould \& Polvinen, 2008). Cynicism, a characteristic of burnout, is negatively related to work ability, while professional self-esteem, job satisfaction, and organizational commitment are positively related to work ability (Gould \& Polvinen, 2008; Feldt et al., 2009). Generally, more positive attitudes toward work are related to higher work ability. It is important to note that many of the studies regarding work ability and attitudes are cross-sectional. Therefore, it is possible that good work ability can cause positive attitudes, or vice versa. It is also possible that both self-rated work ability and self-rated work attitudes are influenced by a person's generally positive or negative mindset.

Because, generally speaking, age and poor health have been shown to negatively affect work ability, and (as discussed in Chapter 1) employees are now working later in life and in spite of declining health, I will be examining these two personal characteristics in terms of their main effects on work ability. My focal hypotheses, then, will investigate the buffering potential of positive workplace characteristics in ameliorating the negative effects of older age and declining health on work ability.

\section{Work and Organizational Factors and Work Ability}

Many studies have shown that positive aspects of the work environment, such as opportunities for development, are related to enhanced work ability, while stressful work demands are related to decreased work ability (Goedhard \& Goedhard, 2005; Tuomi et al., 1997; Tuomi, Vanhala, Nykyri, \& Janhonen, 2004). The Finnish Health 2000 study examined a variety of work and organizational factors and their relation to work ability 
(Seitsamo, Tuomi, Ilmarinen, \& Gould, 2008). Results showed that of the physical work demands, heavy physical work, strenuous work with hands, and poor work postures were the strongest indicators of work ability. Individuals were more likely to report limited work ability if they had physically demanding jobs. The relationship between physical work demands and limited work ability was stronger for individuals in their late 50s and 60s than for younger workers. Mental strain of work, defined by mental exhaustion, mental workload, and a feeling of being mentally drained, was also found to be strongly related to diminished work ability.

Autonomy and opportunities for self-development have also been identified as factors related to work ability. Lack of autonomy (minimal opportunities to make independent decisions and to influence one's work) has been found to relate to poor work ability (Pohjonen, 2001; Tuomi et al., 2001; Tuomi et al., 2004). This may be due to the fact that an absence of control at work can prevent feelings of mastery and does not allow employees to adjust to changing or stressful job conditions or changes in their own abilities (Hackman \& Oldham, 1976; Weigl et al., 2013). Some research has indicated that this relationship is stronger among men than women (Seitsamo, Tuomi, Ilmarinen, \& Gould, 2008).

Different aspects of self-development may also be more strongly related to work ability for men and women. Limited opportunities to develop specialized skills have been shown to be particularly related to limited work ability for men, while limited opportunities to learn new things are more strongly related to an increased risk of limited work ability among women (Seitsamo et al., 2008). Other psychosocial factors that have 
been shown to relate to work ability include supervisor and coworker support (Seitsamo et al., 2008) and supportive organizational climate (Feldt et al., 2009). Palermo and colleagues (2013) found organizational nurturance (a feminine dimension of organizational culture) and subordinate-rated leadership effectiveness to be positively related to work ability.

\section{Outcomes Related to Work Ability}

Perhaps the research interest in work ability can be traced to its usefulness in predicting important work and retirement outcomes. For example, WAI scores have been shown to predict long-term sickness absence (Alavinia et al., 2009; Kujala et al., 2006) as well as intentions to leave a particular occupation (e.g., nursing; Camerino et al., 2006). Moderate to poor work ability has also been shown to predict later receipt of disability pension (Alavinia et al., 2009). One of the most important issues regarding work ability is its relationship with retirement, as it has been shown to predict retirement intentions (Heponiemi et al., 2008; McGonagle et al., in press)

Research has also shown that work ability is related not only to retirement intentions, but also to the actual age of retirement. A study by Feldt, Hyvonen, Makikangas, Kinnunen, and Kokko (2009) identified five different trajectories of managers' work ability over a ten-year period: work ability consistently excellent, work ability good but slowly declining, work ability declined from good to poor, work ability improved from moderate to good, and work ability consistently poor. The mean retirement age was highest (61.3 years) in the most favorable trajectory groups and was nearly 6 years younger (55.4 years) in the least favorable work ability group ("work 
ability consistently poor"). In this study, young age, higher management position, high job control, supportive organizational climate, and high organizational commitment at baseline were identified as significant predictors of the positive development of work ability. The authors concluded that aging and lower-level managers are at risk of unfavorable work ability trajectories, and that more attention should be paid to their psychosocial work conditions in order to prevent poor work ability and subsequently, early retirement.

\section{Work Ability in the Industrial/Organizational and Occupational Health Psychology Literatures}

The research in this chapter shows that studies of work ability have been useful in identifying individual and organizational factors that are related to employees' ability to meet the demands of their job. However, it is evident that rigorous research is needed to better understand the psychological underpinnings of this important construct. The mainstream Industrial/Organizational and Occupational Health Psychology literatures have begun to take notice of the work ability construct and respond to this call, identifying its psychosocial antecedents, with three recent studies relating work ability to a number of psychological variables. First, Weigl and colleagues (2013) found a threeway interaction between age, job control, and use of Selection, Optimization, and Compensation (SOC; Baltes \& Baltes, 1990) strategies. (SOC strategies refer to selecting goals and priorities based on personal motives and preferences or perceived loss of resources; optimized use of means [e.g., practicing and modeling behaviors or increasing effort; Freund \& Baltes, 2002] to pursue selected goals, and compensating for age-related 
losses by utilizing new strategies.) Specifically, they found that the negative relationship between age and work ability was weakest for those who implemented more SOC strategies and had greater job control.

In a second study, Palermo and colleagues (2013) found through path analysis that organizational nurturance (feminine qualities of organizational culture) and vocational strain indirectly predicted work ability, with work satisfaction mediating these relationships.

Third and most recently, McGonagle and colleagues (in press) used the JD-R model to examine the effects of job demands (role overload, role conflict, time pressure, conflictual contact, negative environmental conditions, physical demands, and unfavorable body positions), job resources (autonomy, coworker support, and supervisor support), and personal resources (health status, sense of control, emotional stability, consciousness, and positive affectivity) on work ability (directly) and absence, disability leave, and retirement (indirectly). They found, through relative importance analysis, that health and sense of control were most strongly related to work ability perceptions, but suggested that other job-related resources be examined in the future.

Despite the aforementioned studies, the relationship between work ability and many work-related psychosocial variables remains unknown. For instance, at the group level, the relationships between work ability and aspects of the social context of work, such as team cohesion and age diversity climate have yet to be studied. It is important to investigate the impact of social environment factors on work ability, particularly because older workers tend to pursue more social and emotional goals than their younger 
counterparts (as per Socioemotional Selectivity Theory; Carstensen, 1991). Therefore, the social context of work is liable to affect employees' ability to meet their job demands as they age.

Similarly, perceptions of organizational justice and leader-member exchange likely affect one's interpretation of the quality of his or her social environment, impacting motivation. Employees treated in a just manner are more likely to exert increased effort on the job, because they perceive that these efforts are valued by the organization, while those in high leader-member exchange relationships are more likely to have the support and resources needed to meet the demands of their jobs. Conducting research on these psychosocial factors is necessary for determining how to support employees' work ability throughout the lifespan, which can eventually inform organizational work ability interventions. This dissertation addresses these gaps, contributing to our understanding of work ability in an I/O and OHP framework.

In the next chapter, I review the Job Demands-Resources Model and its application to work ability. This provides the framework in which I develop my focal hypotheses, which state that the psychosocial workplace characteristics of age diversity climate, team cohesion, organizational justice, and leader-member exchange are expected to buffer the negative effects of age and poor health on work ability. 


\section{Chapter 3: The Job Demands-Resources Model and Its Application to Work Ability}

While different models of work ability have been proposed, they have been largely atheoretical, making it difficult to identify the mechanisms through which work ability can be improved. In order to become further integrated into the $\mathrm{I} / \mathrm{O}$ and $\mathrm{OHP}$ literatures, this line of research is in need of a sound theoretical basis, as theory will provide a unifying framework in which researchers can describe, explain, and predict behavior. In this dissertation I expand on the work of McGonagle and colleagues (in press) and apply the Job Demands-Resources Model to the concept of work ability to address this gap in the literature.

\section{Job Demands-Resources Model}

The Job Demands-Resources Model (JD-R) is an expanded version of Karasek's (1979) earlier Job Demands-Control (JD-C) model. The JD-C model showed that jobs that are high in demands (workload, time pressure) and low in control (decision latitude) are related to high strain and low job satisfaction. According to the JD-C model, enhanced job control was thought to buffer the negative effects of job demands on employee physical and mental health. Social support (Karasek \& Theorell, 1990) was later added to the model as a factor that can mitigate the effects of high demands on strain. While the JD-C model became very popular in the job design and stress literatures, its disadvantage was its narrowness in scope; the only positive work characteristics considered were control, and later, social support.

According to the JD-R model, while every occupation has its own specific risk factors associated with job stress, all working conditions can be classified in one of two 
general categories: job demands and job resources (Bakker \& Demerouti, 2007;

Demerouti et al., 2001). Job demands refer to "physical, psychological, social, or organizational aspects of the job that require sustained physical and/or psychological (cognitive and emotional) effort or skills and are therefore associated with certain physiological and/or psychological costs" (Bakker \& Demerouti, 2007, p. 312). Examples of job demands include high work pressure, emotionally demanding work, and unfavorable working conditions. Job demands are not inevitably negative but may be perceived as stressful and lead to strain if the employee has not recovered from previous effort expenditure (Meijman and Mulder, 1998) and does not have the resources to meet those job demands.

Job resources refer to physical, psychological, social, or organizational aspects of the job that are functional in achieving work goals, reduce job demands and the associated physiological and psychological costs, or stimulate personal growth, learning, and development (Bakker \& Demerouti, 2007). Job resources can be present at different levels of the work environment and come from various sources at the organizational-, interpersonal-, and work-levels. Resources at the organizational level can include pay, career opportunities, and job security. At the interpersonal level, social support from peers, supervisor support, and team climate can serve as resources. Characteristics of the work, such as autonomy and role clarity, as well as task characteristics such as task significance and skill variety can also serve as work resources (Bakker \& Demerouti, 2007). 
A more detailed explanation of the resources concept within the JD-R model is available in the well-established Conservation of Resources (COR) theory (Hobfoll, 1989). Specifically, COR theory is useful in understanding why resources are critical to positive individual (and subsequently, organizational) outcomes. The basic tenet of COR theory is that people strive to obtain, retain, protect, and foster the things that they value. Stress occurs when individuals' resources are threatened with loss or are actually lost, or when individuals fail to gain sufficient resources following significant resource investment. According to the JD-R model, job resources buffer against the potential negative effects of job demands. This makes sense in the context of COR theory; job demands, though not necessarily perceived as negative, require effort (or, in other words, investment of resources). Therefore, in order for individuals to avoid experiencing workrelated stress, they must have enough resources to compensate for the resource depletion inherent in facing one's job demands.

The psychosocial moderators examined in the present study are expected to act as resources for employees (e.g., they will be helpful in meeting job demands), thus improving employees' perceived work ability. Age diversity climate should act as a resource because it has positive effects on desirable cognitive and affective states (e.g., it enhances work motivation; Boehm, Kunze, \& Bruch, 2014; Kopelman, Brief, \& Guzzo, 1990), having a positive effect on work ability. Similarly, team cohesion is a largely affective construct, referring to the degree to which members enjoy being a part of their team and desire to remain in it. This positive team environment serves as a resource, as it can help to provide both instrumental and emotional support (Bakker \& Demerouti, 
2007) to individual members and thus support their belief that they are able to continue to work. Organizational justice and leader-member exchange should also act as resources in a work environment. They signal to employees that they are supported and valued (by the organization's policies and practices, and by their supervisors, respectively), which increases motivation to continue to work and their perceived ability to stay at work. The role of these group- and individual-level moderators as job resources are further developed and explained in the next chapter.

The JD-R model has received considerable support demonstrating the buffering potential of job resources (e.g., Bakker, Hakanen, Demerouti, \& Xanthopoulou, 2007; Johnson \& Hall, 1988; Van Vegchel, De Jonge, \& Landsbergis, 2005; Xanthopoulou, Bakker, Dollard, Demerouti, Schaufeli, Taris, \& Schreurs, 2007). I describe two studies here as examples. First, Bakker, Demerouti, and Euwema (2005) found that low job resources combined with high job demands significantly added to the prediction of burnout. Specifically, they found that work overload, emotional demands, physical demands, and work-family conflict did not result in high levels of burnout if employees also experienced autonomy, received feedback, had social support, or had a high-quality relationship with their supervisor. Similarly, Xanthopoulou, Bakker, Demerouti, and Schaufeli (2006) found that autonomy, support, and opportunities for professional development reduced the impact of physical job demands and patient harassment on burnout. Relevant to the present study, this study showed that there are factors that can reduce the effects of stressors, such as a supportive work team. 
Research has also shown that, in addition to aspects of the work environment that serve as demands or resources, personal characteristics are also at play in the JD-R model. Xanthopoulou, Bakker, Demerouti and Schaufeli (2007) found that the personal resources of self-efficacy, organizational-based self-esteem (feeling confident and highly regarded within the organizational context), and optimism, together with job demands and job resources, contribute to explaining variance in well-being outcomes. Resources are considered not only necessary for dealing with demands, but are also important in their own right because they are a means to achieving new resources and protecting other valued resources. This is in accordance with the well-established COR theory, which again states that humans fundamentally strive to accumulate and maintain resources (Hobfoll, 2001). While personal resources have been integrated into the JD-R model, personal demands have not been examined to date. However, in a recent review chapter on the JD-R model, Schaufeli and Taris (2014) noted that future research should expand the model to include personal demands, which they termed "personal vulnerabilities." In other words, in addition to job demands, there are personal factors - in the case of the present study, advanced age and poor health - that can lead to negative outcomes for workers.

While the original JD-R model was designed to predict dimensions of burnout, namely, exhaustion and disengagement, (Demerouti et al., 2001), later studies have expanded the model to other domains to include other individual and organizational outcomes, such as motivation, strain (Bakker \& Demerouti, 2007), ill health and organizational commitment (Hakanen, Bakker, \& Schaufeli, 2006), and in-role and extra- 
role performance (Bakker, Demerouti, \& Verbeke, 2004). Demands and resources affect strain, motivation, and other organizational outcomes through two different underlying psychological processes (Bakker \& Demerouti, 2007). The first is the health impairment process. Poorly designed jobs or chronic job demands deplete employees' mental and physical resources, leading to decreased energy and health problems. The second is the motivational process: job resources can be either intrinsically or extrinsically motivating. Resources are intrinsically motivating when they fulfill basic human needs, such as growth and development, and extrinsically motivating when they are instrumental to achieving work goals (Deci \& Ryan, 1985; Bakker \& Demerouti, 2007).

The moderating factors of age diversity climate, team cohesion, organizational justice, and leader-member exchange are expected to affect work ability through both processes mentioned above, ameliorating the negative impact of demands, and serving as motivational forces. To elaborate, first, it is anticipated that these factors will buffer against the personal demands of older age and declining health. While those who are older and/or experience health problems may have to expend a greater amount of resources to meet their job demands, the positive psychosocial factors which are the focus of this study should protect against these potentially negative effects and prevent chronic resource depletion. Second, these positive aspects of the work environment are expected to increase motivation by providing employees with the resources and support needed to help ensure that their efforts will lead to goal achievement and optimal performance.

Work ability fits logically into a JD-R model, as it is often conceptualized as a balance between one's resources and work demands (Ilmarinen et al., 2008). It is also 
beneficial to utilize the JD-R model in our understanding of work ability because of its flexibility and widespread applicability. One of the main advantages of the JD-R model is that it can take into account the different demands and resources present in various occupations and roles. This is important, as work ability is a construct of relevance for all employees, regardless of the nature of their work, and which can vary depending on the interface between the individual and his or her job.

Weigl and colleagues (2013) utilized the JD-R model in developing their hypothesis that increased job control should relate to improved work ability. They note that, according to the concept of work ability (e.g., Ilmarinen, 2009), contextual features of work prospectively influence employees' work ability. They explicitly state that this idea is in accordance with the JD-R model commonly used in organizational psychology.

A recent series of three studies by McGonagle and colleagues (in press) provides further support for the application of the JD-R model to the study of work ability. The authors tested a model in which job demands (role overload, role conflict, time pressure, conflictual contact, negative environmental conditions, and unfavorable body positions) were hypothesized to negatively affect work ability, while job resources (autonomy, coworker support, and supervisor support) and personal resources (health, sense of control, positive affectivity, conscientiousness, and emotional stability) were expected to positively affect work ability. Further, in accordance with the JD-R model, high levels of job resources were hypothesized to buffer the expected negative relationship between job demands and perceived work ability. 
The authors tested their hypotheses using three independent samples. Sample 1 was from the Health and Retirement Study (HRS), a national, longitudinal survey of Americans age 51 and older. Sample 2 consisted of working American adults from Amazon's Mechanical Turk (MTurk). (MTurk is an online crowdsourcing platform which researchers can use to access survey respondents.) Sample 3 included employees from six manufacturing companies in the Northeast U.S. Overall, the authors found that the particular job resources and job demands in their study had only minimal main effects on work ability - of the job demands, only unfavorable body positions, time pressure, and negative environmental conditions were significantly related to work ability, and the results were inconsistent across the three samples. Unfavorable body positions related to perceived work ability in Samples 1 and 3, and time pressure and negative environmental conditions related to work ability only in Sample 3. Among the job resources, only autonomy was significantly related to work ability in Sample 1, and this was not replicated in Samples 2 and 3. The researchers also failed to find support for the interactive effects of job demands and resources on work ability. The most robust findings were that the personal demands of health and sense of control were related to work ability in all three samples.

Regardless of the fact that the particular job demands and job resources examined by McGonagle and colleagues were not found to substantially predict work ability (particularly when compared to the personal resources of health and perceived control), this study builds an important foundation for the study of work ability within the $\mathrm{I} / \mathrm{O}$ literature. First, it underscores the need for I/O psychologists to improve the 
understanding of the work ability construct through integration with psychological and organizational theory. Second, it demonstrates that the application of the JD-R model for understanding work ability is theoretically sound, as the authors did find that unfavorable body positions and time pressure (job demands) and autonomy (a job resource) related to work ability.

Lastly, the authors called for future research on additional job resources that may demonstrate a more significant impact on work ability than those examined in their study. This dissertation responds to that call by building on the framework put forth by McGonagle and colleagues by investigating job resources that have yet to be examined for their impact on work ability (within a JD-R model or otherwise). While McGonagle and colleagues focused equal attention on job demands, job resources, and personal resources, I am focusing my attention primarily on job resources, as I believe they are more practical leverage points for change from an organizational perspective, and the construct of job demands is already inherent in the measure of work ability we are using in this study. Further, I will examine team-level resources, age diversity climate and team cohesion, which were not examined by McGonagle et al. but have been shown to have consistent effects on turnover and performance (Boehm, Kunze, and Bruch, 2014; Evans \& Dion, 1991).

In the following chapter, I use the JD-R model to expand on the work of McGonagle and colleagues to explain how certain psychosocial factors within the work environment have the potential to help employees to meet their job demands (e.g., maintain higher work ability), despite personal vulnerabilities that are generally 
associated with lower work ability. In particular, I discuss how group-level age diversity climate and team cohesion, as well as individual-level organizational justice and leadermember exchange, will serve as resources in the JD-R model, buffering against the negative effects of age and poor health on work ability. 
PSYCHOSOCIAL CHARACTERISTICS AND WORK ABILITY

Chapter 4: Antecedents and Moderators of Work Ability within the JD-R

\section{Framework}

As stated in Chapter 1, the three specific contributions of this study are to 1)

examine the impact of group-level variables (e.g., age diversity climate and team cohesion) on work ability; 2) demonstrate the effects of individual-level leader-member exchange and justice perceptions on work ability; and 3) develop the theoretical framework (JD-R model) for understanding how psychosocial workplace variables can impact work ability. These three aims support the overarching goal of better understanding, and thus being able to impact, aspects of the work environment that lead to improved work ability. To this end, I am using the JD-R framework to delineate factors within the work environment (not yet studied in McGonagle and colleagues' (inpress) model of work ability) that will likely act as resources to buffer against personal demands to positively impact work ability.

\section{Antecedents: Personal Vulnerabilities}

In the preceding chapter, I reviewed the JD-R model, which states that characteristics of the work environment, as well as personal characteristics, can be categorized as either demands or resources. In this dissertation, "demands" are differentiated into two types and thus included in two parts of the study model. First, personal demands, or "personal vulnerabilities" (Schaufeli \& Taris, 2014), are conceptualized as predictors, which will have significant and direct effects on work ability. Second, the concept of work demands is inherent in the measurement and conceptualization of work ability (the outcome variable in this study), as work ability is 
defined as one's ability to meet the demands of his or her job (Tuomi et al., 1997). Thus, I argue that personal vulnerabilities (demands) hinder one's ability to meet his or her jobs demands (e.g., relate to decreased work ability), but that these relationships are moderated by various group- and individual-level psychosocial work characteristics (see Figure 1). I begin this chapter by describing how the personal vulnerabilities of increased age and poor health are likely to affect work ability using a JD-R approach.

Age. When examining the effects of age on work-related outcomes, it is important to define what is meant by age. Because of its concreteness and simplicity, chronological age has been the predominant age construct used in research and policy-making (Settersten \& Mayer, 1997). However, it is really a marker for other variables of interest such as changes to the self-concept (including changes in motivation and personality over time), cognitive functioning, and employee health and disability. Because the measurement of simple chronological age does not take into account differences in life experiences, social and cultural influences, and individuals' own interpretations of their aging processes (Adams, 1971), there are limitations regarding the conclusions that can be drawn based on chronological age alone.

Furthermore, as people grow older, variability among similarly-aged individuals increases (Dannefer, 1987), and simple chronological age becomes less useful as an index for understanding the key variables in the older worker (Settersten \& Mayer, 1997). To address these limitations, a number of researchers have developed various measures of subjective age, such as cognitive age (Barak \& Stern, 1986), which refers to one's perceptions of how old the person feels, looks, and behaves, and relative age, defined as 
how old one feels compared to others in a particular context (Settersten \& Mayer, 1997). Although these subjective age constructs can be useful to understanding the developmental and contextual experiences of employees throughout the lifespan, I am focusing on chronological age in this dissertation. Chronological age is a much more practical construct for organizational decision-makers, and a main goal of the current study is to provide insight into the workplace characteristics that buffer against declining work ability so that organizations can take action and intervene in the process. However, it is important in discussions of chronological age not to overgeneralize the conclusions made, as individual differences in health, personality, and ability are surely present in every age group.

With that said, the aging process is complex, and for this reason, age can act either as a personal demand or a personal resource. With regard to physically demanding work (such as construction), age likely acts as an additional demand, as physical strength begins deteriorating after age 30 (Millanvoye, 1998). This means that, generally speaking, it will require more effort for an older person, compared to a younger person, to complete the same physical task. Age will also act as a personal demand in the sense that it relates to physical decrements such as declines in bone density, balance, exercise capacity, hearing ability, and visual acuity (Silverstein, 2008). According to the JD-R model, demands are associated with physiological and/or psychological costs. Because of the physical changes that come with aging, older age places increased demands on employees because they have to exert increased effort to compensate for losses in their physical abilities. 
Age is also a personal demand in that it is associated with certain declines in cognitive functioning. Because of the negative relationship between age and fluid intelligence abilities (e.g., working memory, abstract reasoning, and attention; Schaie \& Willis, 1993), older workers may have to put forth more effort to successfully perform certain types of work, such as jobs high in task variety that require performance of a wide range of tasks (Zaniboni et al., 2011). However, age can also act as a personal resource, because it is associated with increased crystallized, or experiential knowledge (Horn \& Cattell, 1967). Because of their extensive experience, older workers may be able to capitalize on knowledge and expertise they have accumulated over their working lives, if opportunities for job crafting are present. While job crafting opportunities are likely beneficial for all employees, older workers in particular have acquired the knowledge and skills needed to redesign their jobs to fit their changing needs and abilities (Truxillo et al., 2012).

Generally, age has been shown to have only weak main effects on job performance (Ng \& Feldman, 2008). While age has exhibited slightly negative relationships with certain types of performance (such as performance in training programs), it has also been shown to relate to enhanced performance in other realms, such as organizational citizenship behaviors and safety compliance (Ng \& Feldman, 2008). Age has also been shown to relate to more positive job attitudes, such as job satisfaction and organizational commitment (Ng \& Feldman, 2010). However, age is more likely to relate to negative outcomes in work situations with limited autonomy (Truxillo et al., 2012), which tends to be the case in blue collar jobs and those that are 
heavy in physical labor (as in our sample of construction workers). This is because jobs low in autonomy do not give employees the freedom necessary to make adjustments to their work strategies to compensate for age-related changes.

Moreover, while age has shown relatively weak relationships with job performance, the (negative) relationship between age and work ability is quite wellestablished. Advanced age is not always related to poor work ability. In fact, McGonagle and colleagues (in press) found that age was significantly (negatively) related to work ability in only one of their three samples. However, large-scale longitudinal studies have shown that, on average, age is related to declines in work ability, and that the rates of decline are greater for those with more physically-demanding jobs (Ilmarinen, Tuomi, \& Klockars, 1997; Tuomi et al., 1991). Thus, in this study, I expect age to act as a personal vulnerability (disadvantage) in this JD-R model of work ability. Given this presumed relationship between age and work ability, I focus in this study on moderators of the agework ability relationship that may exacerbate or mitigate the relationship between age and work ability (as opposed to the main effect of age on work ability).

Health. Both mental and physical health have demonstrated significant main effects on work ability in longitudinal research (Ilmarinen, Tuomi, \& Klockars, 1997; van de Vijfeijke et al., 2013). In fact, some measures of work ability (including the full-length Work Ability Index) include health issues as part of the measure (although this makes the assessment very lengthy - up to 60 items - and thus somewhat impractical). Health is a major factor that influences retirement decisions (Shultz \& Wang, 2007), because health problems can lead to constraints on an employees' ability to perform effectively on the 
job (Wang \& Shultz, 2010). In their study examining the effects of a variety of job demands, job resources, and personal resources on work ability and work withdrawal behaviors (absences, disability leave, and retirement), McGonagle and colleagues found health status to be one of the two strongest predictors of these outcomes. (The other was sense of control.) Mental and physical health can affect performance in a variety of ways, the most common of which will be discussed here.

Chronic pain, which is related to many health problems, negatively affects employees' performance in multiple ways (Byrne and Hochwarter; 2006). Chronic pain, defined as physical discomfort lasting more than six months (Hurwitz, Morganstern, \& Chiao, 2005), is related to a variety of neurocognitive problems, including difficulties with focusing, problem solving, decision making, and abstract thinking, all of which prohibit individuals from successfully completing work tasks. Also, chronic pain often causes physical and mental fatigue, which make it difficult for many sufferers to initiate and maintain levels of goal-directed behavior necessary for high performance (Byrne and Hochwarter; 2006; Hamilton, Karoly, \& Kirtzman, 2004). Even physical health problems which may not cause pain on a regular basis or in an immediate way, such as hypertension or cancer, are related to reduced productivity because of the time required to manage these health problems (Goetzel et al., 2004).

Mental health issues, such as depression and anxiety, also affect job performance. A longitudinal study comparing depressed individuals to controls as well as those with physical health problems (in this case, rheumatoid arthritis), found that the group of depressed individuals had significantly greater deficits than the other two groups in 
managing mental-interpersonal, time management, and output tasks (Lerner et al., 2006). Another study of the effects of depression and anxiety on individual and organizational work outcomes found that individuals with depression and/or anxiety experienced both psychological and physical symptoms that impact their performance. Psychological symptoms include poor concentration, emotional distress, and difficulties with decisionmaking, while physical symptoms include nausea, headaches, dizziness, trembling, insomnia, and fatigue. These symptoms lead to loss of social networks and isolation, increased accidents on the job, and impaired work performance, all of which contribute to reduced productivity and poor staff morale at the organizational level (Haslam, Atkinson, Brown, \& Haslam, 2005).

In addition to reduced productivity while at work, individuals with common mental disorders, such as depression and anxiety, have much higher rates of sickness absence than those without these mental health issues. In fact, in many Western countries, mental disorders are the second most common cause of sickness absence after musculoskeletal disorders (Koopmans et al., 2011). Depression and anxiety also lead to both long- and short-term disability, as well as increased turnover (Haslam et al., 2005).

For the aforementioned reasons, it is clear that health problems inhibit individuals' work ability by impeding effective functioning and leading to both presenteeism and absenteeism. (Presenteeism refers to being present at work, but with reduced efficiency [usually because one is sick], whereas absenteeism refers to actual physical absence from work.) Therefore, health issues are expected to act as "personal vulnerabilities" in this JD-R model of work ability. For this reason, I am looking at factors in the person and in 
the environment that may mitigate the effects of health on work ability, that is, that may support or impede a person's work ability.

\section{Group-Level Moderators of the Effects of Age and Health on Work Ability}

According to the JD-R model, while the demands of workplace stressors or personal vulnerabilities can lead to negative outcomes, positive aspects of the work environment can help buffer against these negative effects. The group-level work characteristics of age diversity climate and team cohesion, as well as the individual perceptions of organizational justice and leader-member exchange, are expected to counter against the personal vulnerabilities of age and (poor) health outlined above. Their functions as resources in the JD-R model of work ability are described in the following paragraphs.

Age diversity climate. Age diversity climate is a specific type of general diversity climate. General diversity climate refers to employees' shared perceptions that an employer utilizes fair employment practices and socially integrates underrepresented employees into the work environment (McKay, Avery, \& Morris, 2008). Most studies of diversity climate cite Mor Barak, Cherin, and Berkman's (1998) study as foundational for their work. Mor Barak and colleagues explain that diversity climate is rooted in social identity theory (Tajfel, 1982), which posits that social structures and individual identity are connected through the meanings people attach to their memberships in identity groups, such as racial, ethnic, gender, or age groups. These meanings then shape the way individuals interact with those both within and outside their own identity groups. This 
social identification leads to activities that are congruent with this identity and support for institutions that embody the identity.

According to Mor Barak and colleagues (1998), the overall diversity environment in an organization is comprised of two components: an individual dimension (individuals' views and prejudices toward people who are different from them) and an organizational dimension (management's policies and procedures specifically affecting minority groups, such as discrimination or preferential treatment in promotion decisions). Diversity climate has been shown to relate to important work-related outcomes. Using a diversity climate scale based on the one developed by Mor Barak and colleagues, McKay and colleagues (2007) found that diversity climate perceptions accounted for $15 \%, 7 \%, 7 \%$, and $4 \%$ of the variance in turnover intentions for Blacks, White men, White women, and Hispanics, respectively. The relationship between diversity climate perceptions and turnover intentions was mediated by organizational commitment. Diversity climate has also been shown to moderate the relationship between race and sales performance. McKay, Avery, and Morris (2008) found that racial-ethnic performance disparities disfavoring Blacks and Hispanics were largest in stores with less supportive diversity climates and smallest in stores with highly pro-diversity climates.

Age diversity climate is defined as employees' shared perceptions of an organization's diversity-related policies, practices, and procedures with respect to age specifically (Boehm, Kunze, \& Bruch, 2013; Gelfand, Nishii, Raver, \& Schneider, 2005). According to Boehm et al. (2014), age diversity climate covers, in practice, employees' collective impression that their organization favors an age-diverse workforce and takes 
active steps to recruit, promote, and retain employees of all age groups. Age diversity climate has been shown to affect both performance and turnover intentions through its effect on social exchange relationships (Boehm et al., 2014).

Organizations with a strong, positive age diversity climate are more likely to be perceived as just, trustworthy, investing in their employees, and having a long-term orientation. These are characteristics of social exchange relationships, which involve mutual investments between both parties as well as a concern for the interest of the other party in the relationship (Blau, 1964; Shore et al., 2011). According to Blau (1964), social exchanges involve mutual obligations such that, when one party does something good for another, there is an expectancy of some future return. Because a positive age diversity climate fosters positive perceptions of high social exchange, it should not only increase employees' willingness to contribute to organizational goals but also positively affect their willingness to support colleagues (Takeuchi, Lepak, Wang, \& Takeuchi, 2007; Boehm et al., 2014). This likely increases work ability, as it involves increased motivation as well as support from coworkers, both of which are instrumental in meeting job demands.

According to Kunze, Boehm, and Bruch (2011), a poor age diversity climate may negatively affect organizational outcomes because employees associate it with age discrimination. In this way, poor age diversity climate may lead to reduced work ability for those who perceive that employees in the company are unfairly disadvantaged because of their age. McKay, Avery, and Morris (2008) provided rationale as to why perceived discrimination impacts performance. When individuals perceive discrimination 
against members of their social identity group (in this case, their age group), they may develop coping strategies, including self-limiting behavior and psychological disengagement, to protect their self-images from identity threats. These coping behaviors, whether conscious or subconscious, can hinder individuals from being able to meet the demands of their jobs.

Two studies in particular have provided strong evidence for the effects of age diversity climate on both individual and organizational outcomes. In the first, Kunze, Boehm, and Bruch (2011) examined the effect of perceived age discrimination climate on collective affective commitment and performance among 8,651 employees from 128 companies. In accordance with their hypotheses, the authors found that company-level age discrimination climate (defined as an organization-level variable that refers to unfair, age-related treatment against any age group) was related to organization-level affective commitment (staying with a company out of desire, as opposed to need or felt obligation), which then predicted operational and organizational company performance. In the second study (conducted with a sample of 14,260 employees in 93 companies), Boehm, Kunze, and Bruch (2014) found that age-inclusive HR practices were positively related to organization-level age diversity climate, which then predicted collective perceptions of social exchange (directly) and firm performance and lower collective turnover intentions (indirectly).

In accordance with the aforementioned findings, in the present study I conceptualize age diversity climate as a moderator of the effects of age and health on work ability. Further, I am following the example of Boehm et al. (2014) in focusing on 
age diversity climate, as opposed to their earlier study (Kunze et al., 2011), which focused on age discrimination climate. While these constructs are both important, and obviously closely related, I want to focus on the positive aspects of the work environment that organizations can leverage to improve work ability. Therefore, within the JD-R model, I am hypothesizing that positive age diversity climate will serve as a resource, which will buffer against the negative effects of age and health problems on work ability.

Team cohesion. Team cohesion is defined as the degree to which members are attracted to their team and desire to remain in it (Cartwright, 1968; Michalisin, Karau, \& Tangpong, 2007). Because team cohesion develops largely out of trust, it too leads to enhanced performance as predicted by Social Exchange Theory (Mach, Dolan, \& Tzafrir, 2010). Positive feelings, perceptions, and expectations about the goodwill of other team members foster an obligation on the part of employees to reciprocate (Lewis \& Weigert, 1985), resulting in greater effort.

Team cohesion has, in fact, been shown to relate to both performance and other individual and work-related outcomes. A meta-analysis examining the relationship between group cohesion (which is synonymous with team cohesion) and performance found that the correlation between the two was moderately strong and positive $(r=.42$; Evans \& Dion, 1992). Team cohesion has also been shown to buffer against potentially harmful aspects of the social work environment. Interestingly, team cohesion has been found to ameliorate the negative effects of workplace drinking climate (perceptions of coworker social drinking and attitudinal support for job-related drinking; Bennett \& Lehman, 1998). Bennett and Lehman (1998) found that high drinking climate and 
individual job stress were negatively related to team cohesion and that high drinking climate (greater occurrence and acceptance of drinking within the workgroup) combined with low cohesion resulted in increased vulnerability regarding job stress, job withdrawal, health problems, work accidents, and absences.

Additionally, individuals who are part of a cohesive team are more likely to experience higher levels of social support, which are beneficial for effective workplace performance. According to Bakker and Demerouti (2007), social support is a straightforward resource, because it is functional in achieving work goals. Instrumental support from coworkers can help to get work done in a timely manner, which may then alleviate the impact of work overload (high demands) on strain (Van der Doef \& Maes, 1999). Additionally, according to the stress-buffering hypothesis, social support protects employees from the emotional consequences of stressful experiences (Cohen and Wills, 1985). These higher levels of social support are likely to be particularly helpful to aging employees, as well as those with health concerns, because they have these personal vulnerabilities that make them experience their work as being more demanding.

The Input-Mediator-Output-Input model of teamwork (IMOI; Ilgen, Hollenbeck, Johnson, \& Jundt, 2005) also provides a framework within which to understand the impact of team cohesion on group functioning. This model describes the cyclical way in which mediating characteristics and processes turn team inputs (like individual characteristics and resources, as well as task demands) into outputs (e.g., performance), which then feed back into the process as inputs. Team cohesion is similar to the mediating characteristic of "bonding" in the IMOI model, which is described as reflecting 
a strong sense of rapport, desire to stay together, and positive affective feelings team members have toward one another and the team (Ilgen et al., 2005). Bonding has been shown to be of importance for effective team functioning, particularly when task interdependence is high (Beal, Cohen, Burke, \& McLendon, 2003). Similarly, team cohesion is likely to have positive effects on work ability, in part because of its affective nature. Positive affect is related to improved performance through its relationship with motivation (i.e., increased expectancy and instrumentality; Erez \& Isen, 2002). Those experiencing more positive emotions are more likely to believe that their efforts will lead to achievement of their goals, and that those goals will lead to desired outcomes. Thus, in the present study, team cohesion is expected to moderate the relationships between age and work ability, and between health and work ability, such that team cohesion will lessen the negative impact of increased age and poor health on work ability.

\section{Individual-Level Moderators of the Effects of Age and Health on Work Ability}

Organizational justice. Organizational justice (Greenberg, 1987) refers to employees' perceptions of fairness in organizations along with their associated behavioral, cognitive, and emotional reactions. Perceptions of justice are important because they signify that employees believe their treatment in the workplace is not only equitable, but also ethical and moral (Cropanzano, Bowen, \& Gilliland, 2007). Justice has been shown to predict performance through its effect on relationships. When supervisors treat their subordinates in a just manner, this leads to higher-quality relationships, which in turn enhance subordinate motivation and performance (Cropanzano, Prehar, \& Chen. 2002; Rupp and Cropanzano, 2002). This same motivation, as well as the perceived 
support inherent in being treated in a just manner, should improve subordinates' work ability.

Organizational justice has also been shown to relate to a number of important individual outcomes, including job satisfaction, withdrawal (Colquitt, Conlon, Wesson, Porter, \& Ng, 2001), and turnover intentions (Aryee, Budhwar, \& Chen, 2002). A metaanalysis by Colquitt and colleagues (2001) examined the differential relationships between the different types of organizational justice and critical work-related outcomes. In particular, distributive justice (perceived outcome fairness) was shown to relate strongly to outcome satisfaction, job satisfaction, and organizational commitment (positively), and withdrawal (negatively). Procedural justice (perceived process fairness) demonstrated similar relationships with those outcome variables, and also related moderately (and positively) to performance. Because both types of justice have been linked to important attitudinal and behavioral outcomes, I am including both in this study.

Relevant to this dissertation, a study by Armstrong-Stassen and Schlosser (2011) provided a model for understanding the relationship between justice and withdrawal among older workers in particular. The researchers found that older workers' perceptions of procedural and interpersonal justice were related to perceptions of belonging (perceived insider status), which in turn affected their desire to remain with the organization. These feelings of belonging, as well as affecting desire to remain directly, may also affect it indirectly through work ability. Belonging has been conceptualized as an aspect of social support that is related to increased emotional support-seeking and decreased stress (Ingledew, Hardy, \& Cooper, 1997). This decreased stress is likely to 
improve work ability, as those in a more positive mental state will have more resources available to meet the demands of their job.

The relationship between justice and health can also help to explain why organizational justice would affect work ability. A meta-analysis by Robbins and colleagues (2012) describes the relationship between organizational injustice and employee health. These researchers explained that perceived injustice (with regard to outcome, process, and interpersonal treatment fairness) is a stressor, which can cause strain (Kahn \& Byosiere, 1992). This can be understood within the framework of the Effort-Reward Imbalance Model (Siegrist, 1996), which states that a lack of balance between rewards received and efforts put forth is experienced as stressful and results in strain. This can lead to decreases in mental health, resulting in outcomes such as anxiety, depression, or burnout. Worsened mental health can then cause decreases in physical health through negative health behaviors (e.g., overeating, lack of exercise). Employees who experience strain due to injustice at work may be more likely to engage in behaviors such as drinking alcohol and smoking and may live more sedentary lifestyles (Kivimaki et al., 2005).

Research has also shown that strain resulting from perceptions of organizational injustice can lead to insomnia (Greenberg, 2006). Declines in mental health (specifically, sustained stress) can also impact physical health directly through physiological mechanisms (e.g., weakening of the immune system due to changes to the central nervous system; Cohen \& Herbert, 1996; Robbins et al., 2012). Because health is an important resource for effective functioning, and organizational justice has been shown to impact 
health, organizational justice is likely to act as an important resource in predicting work ability.

As seen in the above paragraphs, organizational justice affects key work-related outcomes in two major ways. First, it affects critical work-related attitudes and behaviors, such as organizational commitment and performance. Second, organizational justice impacts employees' mental and physical health (because injustice is perceived as stressful and can lead to strain, which can have a sustained, negative impact on health if the perceived injustice is continual). For these reasons, I expect that organizational justice will act as a resource in a JD-R model of work ability, countering the negative effects of older age and poor health on work ability.

Leader-member exchange. According to Leader-Member Exchange theory (Dansereau, Graen, \& Haga, 1975; Graen \& Uhl-Bien, 1995), leaders develop differential relationships with each of their followers, which are based on contribution, affect, loyalty, and professional respect (Liden \& Maslyn, 1998). Both leader and follower have mutual influence within the dyad, and these relationships are formed through a process of role taking, role making, and routinization (Bauer \& Green, 1996). Trust is critical to higher-quality leader-member exchange relationships, which have been shown to lead to a variety of positive individual and organizational outcomes. High-quality leader-member exchange relationships, also characterized by liking, latitude, attention, mutual obligation, and reciprocity (Graen \& Uhl-Bien, 1995) are related to turnover intentions and actual turnover, satisfaction with supervisor, overall satisfaction, organizational commitment, role clarity, reduced role conflict, justice perceptions, and job performance (Gerstner \& 
Day, 1997; Dulebohn, Bommer, Liden, Brouer, \& Ferris, 2012). Leader-member

exchange has been considered a type of supervisor support, and even explicitly

categorized as a resource in a JD-R model predicting employee attitudes (van Emmerick, Bakker, \& Euwema, 2009).

According to leader-member exchange theory, followers in high-quality leadermember exchange relationships demonstrate improved performance because their leaders provide increased support, encouragement, and consideration (Howell \& Hall-Merenda, 1999). These same characteristics should lead to increased work ability because followers in high-quality leader-member exchange relationships are better equipped, through supervisor support, to meet the demands of their jobs. Bakker and Demerouti (2007) explained the mechanisms through which supervisor support can act as a resource in the

JD-R model: a high quality relationship with one's supervisor may alleviate the influence of job demands (e.g., work overload, emotional and physical demands) on job strain, because leaders' appreciation and support put demands in another (more positive) perspective. Additionally, leaders' appreciation and support may also help employees to cope with their job demands, facilitate performance, and act as a protector against poor health (Vaananen et al., 2003).

\section{Summary: Moderators of the Effects of Age and Health on Work Ability}

In this chapter, I have described the personal and workplace characteristics which are expected to affect work ability through their roles as either demands or resources according to the JD-R model. The personal demands of age and health problems are expected to exhibit negative relationships with work ability, while the moderators of age 
diversity climate, team cohesion, organizational justice, and leader-member exchange are expected to buffer against these negative effects. In the following chapter, I explicitly state the hypotheses that I test in this dissertation. 


\section{Chapter 5: Hypotheses}

In the previous chapter, I used the JD-R model to explain how certain characteristics within the work environment are expected to buffer against the personal vulnerabilities of advanced age and poor health, leading to improved work ability. I explained how the group-level characteristics of age diversity climate and team cohesion and the individual-level characteristics of organizational justice and leader-member exchange are expected to act as resources in a JD-R model of work ability. Here, I explicitly state the hypotheses I am testing in this dissertation based on the theoretical rationale that I outlined in Chapter 4.

\section{Main Effects (Personal Vulnerabilities)}

Age. Although the aging process is complex and can act as both an advantage or disadvantage with regard to work-related outcomes, previous research has shown that it generally relates negatively to work ability (e.g., Ilmarinen et al., 1997, Tuomi et al., 1991). Further, while the relationship between age and cognitive abilities is nuanced, the relationship between age and physical ability is more straightforward, with strength declining after age 30 (Millanvoye, 1998), and physical decrements such as declines in hearing and vision becoming more prevalent after middle age (Silverstein, 2008). Particularly because this study is being conducted among construction workers, whose jobs are heavy in physical labor, I expect to find a negative main effect of age on work ability.

H1: Increased age will be negatively related to work ability. 
Health. Both mental and physical health have been consistently shown to predict work ability (e.g. Ilmarinen et al., 1997, Tuomi et al., 1991). In their study of work ability in a JD-R framework, McGonagle and colleagues found health to be one of the strongest predictors of work ability, demonstrated to be more predictive than job demands. Health is critical for effective functioning and affects employees through multiple pathways, including the cognitive deficits associated with physical discomfort and pain, as well relationships with both absenteeism and presenteeism (Haslam et al., 2005; Koopmans et al., 2011). For these reasons, I expect that prior findings will be replicated in this study, and that poor health, a detriment to employees, will demonstrate a negative main effect on work ability.

H2: Poor health will be negatively related to work ability.

\section{Group-Level Moderators}

Below I describe the moderating effects that each of the resources examined in this study should have on age and health's effects on with work ability. However, one could also expect that they will have main effects on work ability as well. Although these main effects are not the focus of this dissertation, these main effects will be tested as part of the moderation analyses.

Age diversity climate. As explained in Chapter 4, positive age diversity climate refers to employees' collective impression that their organization favors an age-diverse workforce and takes active steps to recruit, promote, and retain employees of all age groups (Boehm et al., 2014). Age diversity climate should act as a resource in a JD-R model of work ability because it signals to employees that their organizations are just, 
trustworthy, and invest in them. This increases commitment (Kunze et al., 2011), which then positively impacts performance. Age diversity climate is anticipated to interact with age and health because employees who work in a more positive age diversity climate are more likely to be valued and provided with resources and opportunities to succeed, regardless of age, and in the face of health challenges. For these reasons, I expect that age diversity climate will buffer against the negative effects of age and declining health on work ability.

H3A: Age diversity climate will moderate the relationship between age and work ability. Under conditions of lower age diversity climate, the negative relationship between age and work ability will be stronger, while under conditions of higher age diversity climate, the negative relationship between age and work ability will be weaker.

H3B: Age diversity climate will moderate the relationship between health and work ability. Under conditions of lower age diversity climate, the negative relationship between poor health and work ability will be stronger, while under conditions of higher age diversity climate, the negative relationship between poor health and work ability will be weaker.

Team cohesion. As noted in the previous chapter, team cohesion refers to team members' affective response to their team (Cartwright, 1968) and has been shown to affect performance (Evans \& Dion, 1992). Team cohesion also helps to buffer against potentially stressful aspects of the work environment, since it is related to increased levels of social support. It is expected that team cohesion will interact with age and health 
because those in more cohesive teams should perceive more support and assistance from their teammates to compensate for changes in abilities related to older age and decreasing health. Therefore, as a resource in the JD-R model, I expect that team cohesion will buffer against the negative effects of increased age and poor health on work ability. H4A: Team cohesion will moderate the relationship between age and work ability. Under conditions of lower team cohesion, the negative relationship between age and work ability will be stronger, while under conditions of higher team cohesion, the negative relationship between age and work ability will be weaker.

H4B: Team cohesion will moderate the relationship between health and work ability. Under conditions of lower team cohesion, the negative relationship between poor health and work ability will be stronger, while under conditions of higher team cohesion, the negative relationship between poor health and work ability will be weaker.

\section{Individual-Level Moderators}

Organizational justice. As discussed in Chapter 4, organizational justice affects work-related outcomes in two main ways. First, it affects work-related attitudes and behaviors, such as organizational commitment and performance (Colquitt et al, 2001), by signaling to employees that they are valued and will be rewarded fairly for their efforts. Second, it affects both mental and physical health (Robbins et al., 2012) because perceived injustice is a stressor, which can result in strain. It can also affect health through its impact on health behaviors (e.g., smoking, drinking, inactivity). Justice is 
anticipated to interact with age and health because environments perceived to be higher in justice are more likely to distribute resources appropriately through fair practices to all employees, regardless of age or health status. For these reasons, I expect that organizational justice (both distributive and procedural) will serve as a resource in the JD-R model and will ameliorate the impact of age and poor health on work ability. H5A: Distributive organizational justice will moderate the relationship between age and work ability. Under conditions of lower organizational justice, the negative relationship between age and work ability will be stronger, while under conditions of higher organizational justice, the negative relationship between age and work ability will be weaker.

H5B: Distributive organizational justice will moderate the relationship between health and work ability. Under conditions of lower organizational justice, the negative relationship between health and work ability will be stronger, while under conditions of higher organizational justice, the negative relationship between health and work ability will be weaker.

H5C: Procedural organizational justice will moderate the relationship between age and work ability. Under conditions of lower organizational justice, the negative relationship between age and work ability will be stronger, while under conditions of higher organizational justice, the negative relationship between age and work ability will be weaker.

H5D: Procedural organizational justice will moderate the relationship between health and work ability. Under conditions of lower organizational justice, the 
negative relationship between health and work ability will be stronger, while under conditions of higher organizational justice, the negative relationship between health and work ability will be weaker.

Leader-Member exchange. In the previous chapter, I reviewed the ways in which leader-member exchange is likely to have a beneficial impact on work ability. Leader-member exchange is expected to act as a resource in this JD-R model. Specifically, subordinates in high-quality leader-member exchange relationships are better equipped to meet the demands of their jobs because they receive increased support, encouragement, and consideration from their supervisors (Howell \& Hall-Merenda, 1999). Leaders in high-quality leader-member exchange relationships are also more likely to be aware of their subordinates' needs, which would help them to adapt to the employees' changing needs and abilities as they age. Thus, I expect that leader-member exchange will buffer against the negative effects of age and decreased health on work ability.

H6A: Leader-member exchange will moderate the relationship between age and work ability. Under conditions of lower leader-member exchange, the negative relationship between age and work ability will be stronger, while under conditions of higher leader-member exchange, the negative relationship between age and work ability will be weaker.

H6B: Leader-member exchange will moderate the relationship between health and work ability. Under conditions of lower leader-member exchange, the negative relationship between poor health and work ability will be stronger, while 
under conditions of higher leader-member exchange, the relationship between poor health and work ability will be weaker.

The aforementioned hypotheses delineate the relationships I am testing in this dissertation. In the next chapter, I describe the context of this study, the sample, and the data collection method. Then, in the following chapters, I describe my data analyses, results, and implications for future research and practice. 


\section{Chapter 6: Method}

Data for this study were collected as part of a project of the Oregon Healthy Workforce Center, one of four Total Worker Health ${ }^{\mathrm{TM}}$ Centers of Excellence funded by the National Institute for Occupational Safety and Health (Grant: U19OH010154;

Principal Investigator, Dr. Leslie Hammer). The larger project investigated the effectiveness of a safety, work-life, and wellness intervention among a population of public-sector construction workers (working in two organizations) in a city in the Pacific Northwest. In particular, the intervention aimed to improve employee health and wellbeing through a three-component intervention. First, supervisors completed a computerbased training program designed to teach them how to be more supportive of their employees' work-life and safety concerns. Second, the supervisors tracked their implementation of the newly-learned behaviors with an iPod tracking program. Third, each work team participated in a four-hour Team Effectiveness Process training session designed to help them eliminate sources of overwork and improve their communication and group processes. As a Research Assistant on the project, I helped to design the study and questionnaires, administer the intervention program, and collect and analyze study data.

The study utilized a randomized controlled trial design; all existing work groups were randomized into treatment and control groups. Data were collected in 2013 via paper-and-pencil surveys at baseline, 6 months, and 12 months post-intervention. In this study, I am utilizing all 12-month data, with the exception of procedural and distributive justice. I am using 6-month measures of those constructs because they were not measured 
at the 12-month data collection. I am also only utilizing data from the employees and crew leaders (not the supervisors) to ensure measurement equivalence in scale scores. I thus controlled for intervention condition and organization in all analyses.

\section{Sample}

Participants were 274 employees and crew leaders working in 36 teams at two public, urban construction organizations. One organization focuses on construction and maintenance for the city's transportation and sewer systems, and the other focuses on construction and maintenance for the city's water systems. Participants completed the paper-and-pencil assessments on company time and were compensated for their time with a $\$ 25$ gift card at each data collection period in which they participated.

Demographic characteristics. The following statistics represent data collected 12-months post-intervention (the same time as the majority of the psychosocial variables utilized in this study). The average age of the sample was 44.8 ( $\mathrm{SD}=9.7)$, and the majority were White (80.4\%) and male (89.8\%). Regarding educational background, $40.6 \%$ had a high school diploma or less, $45 \%$ attended 1-3 years of college or technical school, $13.1 \%$ completed 4 years of college, and $1.3 \%$ attended graduate school. The majority of participants (64.1\%) were married, $14.2 \%$ were divorced or separated, $1.8 \%$ were widowed, $12.4 \%$ were living with their significant other, and $8.3 \%$ were single. The average job tenure was 11.4 years $(\mathrm{SD}=8.4)$.

\section{Measures}

Age. Chronological age was measured with one item: "What is your age?" 
Poor health. General health was measured with one item from the 12-item Short Form Health Survey (SF-12; Ware, Kosinski, \& Keller, 1996): "In general, would you say your health is..." Response options are "poor", "fair", "good", "very good", "excellent". This item is reverse-coded so that higher scores represent poorer health.

Team cohesion. Team cohesion was assessed with six items (Chin, Salisbury, Pearson, \& Stollak, 1999) on a 5-point response scale ("Strongly Disagree" to "Strongly Agree"). Sample items include, "I am happy to be part of this team" and "I feel that I am a member of this team". The reliability (Cronbach's alpha) of this scale in the current study was .93 .

Organizational justice. Distributive justice was measured with three items (Price $\&$ Mueller, 1986) on a 5-point response scale. A sample item is, "I feel fairly rewarded for the amount of effort I put forth." Procedural justice was also measured with three items (Moorman, 1991) on a 7-point response scale. A sample item is, "The organization provides opportunities to appeal or challenge the decisions made." The reliability for each of these scales in the current study was .92 .

Leader-member exchange. Leader-member exchange was assessed with seven items (Scandura \& Graen, 1984) on a 5-point response scale. Sample items include, “How well does your supervisor understand your job problems and needs?" and "Regardless of how much formal authority he/she has built into his/her position, what are the chances that your supervisor would use his/her power to help you solve problems in your work?" The reliability of this scale in the current study was .91 . 
Age diversity climate. Age diversity climate was measured with four items (Boehm, Kunze, \& Bruch, 2013) on a 7-point response scale. Sample items are "Our company makes it easy for people from diverse age groups to fit in and be accepted" and "Managers in our company demonstrate through their actions that they want to hire and retain an age-diverse workforce". Because this scale was originally developed and administered in German, I piloted it among 300 participants on Amazon's Mechanical Turk (MTurk) prior to inclusion on the Time 2 survey; the reliability (Cronbach's alpha) of the scale was .84. In the present study, the alpha was .87 .

Perceived work ability. Work ability was assessed with the two items from the Work Ability Index (Tuomi et al., 1997) utilized by Weigl and colleagues (2013): "How do you rate your current work ability with respect to the physical demands of your work?" and "How do you rate your current work ability with respect to the mental demands of your work?" Items are rated on a 5-point response scale $(1=$ very poor, $5=$ very good). Previous research has shown that shortened versions of the WAI are reliable, highly correlated with the overall scale score, and show convergent validity with measures of employee well-being (Ahlstrom et al., 2010; Weigl et al., 2013). Again, because these items were originally in German, I piloted them among 300 participants on MTurk prior to inclusion on the Time 2 survey; the reliability (Cronbach's alpha) of the 2-item scale was .78. In the present study, the alpha was .85 .

Please see the Questionnaire Measures section in Appendix $B$ for the full scales utilized in this study. The data analysis procedures for testing my study model (and ancillary analyses) and corresponding results are outlined in the following chapter. 


\section{Chapter 7: Results}

\section{Preliminary Analyses}

Before testing my hypotheses, a few preliminary analyses were conducted. I describe these below, and then discuss the results of my hypothesis testing.

Aggregation tests. The level at which a construct is measured should be guided by theory (Morgeson \& Hofmann, 1999; Walumbwa, Wang, Lawler, \& Su, 2004). Because age diversity climate and team cohesion are conceptualized as group-level constructs (Boehm, Kunze, \& Bruch, 2014; Chang \& Bordia, 2001), I planned to aggregate the measures of these constructs to the workgroup level. To test the appropriateness of such aggregation, I calculated the intraclass correlation coefficients (ICCs), looking at the reliability of scores within workgroups. The ICC for age diversity climate was .00, and the ICC for team cohesion was .05. These values are extremely low, and suggest that, in these data, group membership does not account for substantial variance in individual scores on these measures. Although age diversity climate and team cohesion are conceptualized as group-level constructs, they can also be examined at the individual perception (psychological) level. Because the data did not warrant aggregation of team cohesion or age diversity climate to the group level, I utilized only individual scores on these scales in the analyses that follow.

Control variable selection. Intervention group (treatment versus control) and organization (Organization A versus Organization B) were used as control variables in all analyses. Additional control variables of job tenure, gender, and hours worked per week were also selected based on prior research on work ability, and bivariate correlations 
between control variables and outcome variables in this study. (See correlation matrix, Table 2).

\section{Hypothesis Testing}

Table 2 shows means, standard deviations, and intercorrelations of study variables. In support of Hypothesis 1, increasing age is significantly negatively related to work ability $(r=-.20, p<.01)$. In support of Hypothesis 2 , poor health is also significantly negatively related to work ability $(r=-.41, p<.01)$. At the correlational level, individual age diversity climate perceptions $(r=.21, p<.01)$ and individual team cohesion perceptions $(r=.29, p<.01)$ are significantly positively related to work ability. However, procedural justice, distributive justice, and leader-member exchange were not significantly related to work ability.

The results of the regression analyses conducted to test hypotheses 3 and 4 are in Table 3. Hypothesis 3a stated that age diversity climate would moderate the relationship between age and work ability, such that under conditions of lower age diversity climate, the negative relationship between age and work ability would be stronger, while under conditions of higher age diversity climate, the negative relationship between age and work ability would be weaker. This hypothesis was not supported $(B=-.03, t(201)=-.84$, $\left.p=.40, \Delta R^{2}=.01\right)$. Hypothesis $3 \mathrm{~b}$ stated that age diversity climate would moderate the relationship between health and work ability, such that under conditions of lower age diversity climate, the negative relationship between poor health and work ability would be stronger, while under conditions of higher age diversity climate, the negative relationship between poor health and work ability would be weaker. The interaction 
between age diversity climate and poor health was significant at the $p<.10$ level $(B=$ $\left..07, t(192)=1.77, p=.08, \Delta R^{2}=.01\right)$ in the expected direction. Although this interaction was "borderline" significant, I chose to graph it because this is the first time this interaction has been tested. As can be seen in Figure 3, the negative relationship between poor health and work ability was weaker under conditions of higher (more positive) age diversity climate.

Hypothesis 4a stated that team cohesion would moderate the relationship between age and work ability, such that under conditions of lower team cohesion, the negative relationship between age and work ability would be stronger, while under conditions of higher team cohesion, the negative relationship between age and work ability would be weaker. This hypothesis was not supported $\left(B=.06, t(190)=1.50, p=.13, \Delta R^{2}=.01\right)$. Hypothesis $4 \mathrm{~b}$ stated that team cohesion would moderate the relationship between health and work ability, such that under conditions of lower team cohesion, the negative relationship between poor health and work ability would be stronger, while under conditions of higher team cohesion, the negative relationship between poor health and work ability would be weaker. The interaction between team cohesion and health was significantly related to work ability $\left(B=.11, t(202)=2.70, p<.01, \Delta R^{2}=.03\right)$ in the expected direction. Therefore, hypothesis $4 \mathrm{~b}$ was fully supported. As demonstrated in Figure 4, the negative relationship between poor health and work ability is weaker when team cohesion is higher.

The results of the regression analyses conducted to test hypotheses 5 and 6 are in Table 4. According to Hypothesis 5a, it was expected that distributive organizational 
justice would moderate the relationship between age and work ability, such that under conditions of lower organizational justice, the negative relationship between age and work ability would be stronger, while under conditions of higher distributive justice, the negative relationship between age and work ability would be weaker. This hypothesis was not supported $\left(B=.07, t(192)=1.50, p=.14, \Delta R^{2}=.00\right)$. Hypothesis $5 \mathrm{~b}$ stated that distributive organizational justice would moderate the relationship between health and work ability, such that under conditions of lower organizational justice, the negative relationship between health and work ability would be stronger, while under conditions of higher organizational justice, the negative relationship between health and work ability would be weaker. This hypothesis was also unsupported $(B=.05, t(192)=1.13, p$ $\left.=.26, \Delta R^{2}=.01\right)$. Hypotheses $5 \mathrm{c}$ and $5 \mathrm{~d}$ proposed the same moderating role for procedural organizational justice. Neither Hypothesis $5 \mathrm{c}(B=-.02, t(184)=-.47, p=$ $\left..64, \Delta R^{2}=.00\right)$ nor $5 \mathrm{~d}\left(B=.03, t(187)=.58, p=.56, \Delta R^{2}=.00\right)$ were supported.

According to Hypothesis 6a, leader-member exchange would moderate the relationship between age and work ability, such that under conditions of lower leadermember exchange, the negative relationship between age and work ability would be stronger, while under conditions of higher leader-member exchange, the negative relationship between age and work ability would be weaker. Hypothesis $6 \mathrm{~b}$ stated that leader-member exchange would moderate the relationship between health and work ability, such that under conditions of lower leader-member exchange, the negative relationship between poor health and work ability would be stronger, while under conditions of higher leader-member exchange, the relationship between poor health and 
work ability would be weaker. Hypothesis 6 a was not supported $(B=-.03, t(202)=-.87$, $\left.p=.39, \Delta R^{2}=.01\right)$, but Hypothesis $6 \mathrm{~b}$ was supported at the $p<.10$ level $(B=.07, t(195)$ $=1.81, p=.07, \Delta R^{2}=.03$ ) in the expected direction. As can be seen in Figure 5, the negative relationship between poor health and work ability was weaker under conditions of higher leader-member exchange.

\section{Ancillary Analyses}

The majority of the moderation hypotheses were unsupported. However, given a number of significant bivariate correlations between study variables, I wanted to further investigate the main effects of the psychosocial variables utilized in this study on work ability. Significant interactions can be difficult to detect in regression analyses, particularly when investigating somewhat nuanced and subtle constructs, such as selfreported psychosocial aspects of the work environment. Yet, particularly because the correlational analyses demonstrated that age diversity climate and team cohesion positively and significantly related to work ability, I decided to run a set of ancillary analyses to help understand the relationships between the study variables without trying to detect interactions. Therefore, I ran a set of multilevel regression analyses in order to determine if each of the psychosocial predictor variables (age diversity climate, team cohesion, leader-member exchange, procedural justice, and distributive justice) would significantly relate to work ability when controlling for age and health.

For simplicity, I controlled only for organization and treatment condition in these ancillary analyses. For example, to investigate the effect of age diversity climate on work ability, I entered organization indicator, treatment condition, age, health, and age 
diversity climate as the independent variables predicting work ability, the dependent variable. As with the analyses I conducted to test my original set of hypotheses, I utilized multilevel regression modeling to account for the nesting of individuals within workgroups. I ran similar, separate regression models for each of the psychosocial variables in the study to determine if they explained additional variance in work ability beyond that explained by age and health.

The results of these analyses are presented in Table 5. Leader-member exchange $\left(B=.02, t(208)=.59 p=.56, \Delta R^{2}=.00\right)$, procedural justice $(B=.02, t(194)=.55, p=$ $\left..58, \Delta R^{2}=.01\right)$, and distributive justice $\left(B=.03, t(196)=.74, p=.46, \Delta R^{2}=.01\right)$ were not significantly related to work ability when controlling for age and health. However, individual perceptions of age diversity climate $\left(B=.08, t(198)=1.99, p<.05, \Delta R^{2}=.01\right)$ and team cohesion $\left(B=.15, t(206)=3.97, p<.01, \Delta R^{2}=.05\right)$ were both significantly and positively related to work ability, even after controlling for age and health. This is a new and exciting finding in the work ability literature, because it suggests that even in spite of increasing age and declining health of workers, organizations can help improve their employees' work ability by fostering environments with high team cohesion and a positive age diversity climate.

Finally, to test for the unique effects of the predictors, I entered all of the predictors as a block controlling for intervention condition and organization. These results are presented in Table 6 . Work ability was significantly related to age $(B=-.13$, $t(208)=-3.08, p<.01)$, poor health $(B=-.20, t(208)=-4.95, p<.01)$, and individual perceptions of team cohesion $(B=.20, t(208)=3.86, p<.01)$. Leader-member exchange 
was also related to work ability at the $p<.10$ level $(B=-.10, t(208)=-1.80, p<.10)$

though contrary to expectations, the relationship was negative. In this model, procedural justice, distributive justice, and age diversity climate were not significantly related to work ability. 


\section{Chapter 8: Discussion}

This study contributes to our understanding of the effects of psychosocial workplace characteristics on employees' work ability. It also helps to better integrate the work ability construct into the Industrial and Organizational Psychology literature by building on the work of Weigl and colleagues (2013) and McGonagle and colleagues (in press) to understand the antecedents of work ability within a Job Demands-Resources model. Aside from the relationship between team cohesion and health, the remainder of the interaction hypotheses were unsupported at the $p<.05$ significance level. In other words, the psychosocial variables I examined did not significantly interact with age and health with regard to their effects on work ability to the extent expected. However, the correlational analyses and ancillary analyses showed that both age diversity climate and team cohesion were significantly and positively related to employees' work ability, even after controlling for age and health. This is an exciting finding, with potentially meaningful applications for practice. By understanding that age diversity climate and team cohesion are significantly related to improved work ability even under conditions of increased age and/or poor health, organizations can help employees to meet the mental and physical demands of their jobs by fostering these social-environmental aspects of the workplace (positive age diversity climate and high team cohesion). In short, these results suggest that employees' perceived social environment is related to employees' work ability.

\section{Age}


In this study, age was conceptualized as a "personal vulnerability" (Schaufeli \& Taris, 2014), meaning that it was an individual characteristic that was expected to relate negatively to work ability. The aging process is complex, and age can act as an advantage or a detriment depending on the outcome examined. However, it was expected to act as a personal demand in the context of this study because age has generally demonstrated negative relationships with work ability in previous research and because of the largelyphysical nature of the work performed by employees in this sample. Consistent with my hypothesis, age did show a significant, negative relationship with work ability in this study. This demonstrated negative relationship between age and work ability makes sense, given the nature of construction work. Compared to other industries and types of jobs, construction workers have relatively low autonomy and thus, potentially less opportunities to capitalize on the knowledge they have accumulated.

\section{Health}

Poor health was also expected to act as a personal vulnerability in this study. Both mental and physical health have demonstrated significant main effects on work ability in previous longitudinal research (Ilmarinen et al., 1997; van de Vijfeijke et al., 2013). Health problems can have an impact on performance and work ability through its relationship with pain (which makes it difficult for employees to focus and perform work tasks effectively) and absenteeism and presenteeism. In this sample, poor health was significantly and negatively related to work ability, as hypothesized. This suggests that organizations should be concerned about their employees' mental and physical health if they want to support their ability to meet job demands. 


\section{Psychosocial Workplace Characteristics}

Leader-member exchange. According to leader-member exchange theory, followers in high-quality leader-member exchange relationships demonstrate improved performance because their leaders provide increased support, encouragement, and consideration (Howell \& Hall-Merenda, 1999). It was expected that high-quality leadermember exchange would positively relate to work ability, as workers in these relationships would (in theory) be better equipped to meet their job demands because of the support they receive from their supervisor. Leader-member exchange was not, however, significantly related to work ability in this sample. This may be attributable to the type of work done by the participants in this sample. The interaction between leadermember exchange and poor health, however, was significantly related to work ability at the $p<.10$ level. The negative relationship between poor health and work ability was weaker under conditions of higher leader-member exchange. This suggests that leadermember exchange may have the potential to ameliorate or buffer the negative impact of poor health on work ability. Therefore, supervisors who have positive individual relationships with their subordinates may be able to help their employees to meet their job demands successfully in the face of health issues.

The fact that leader-member exchange did not show a stronger relationship with work ability in this dissertation may be due to the nature of the sample. This study utilized a sample of construction workers who perform mostly physical labor. Their supervisors, who coordinate and assign jobs, are not usually present at the worksites where the employees conduct their work. Therefore, it is possible that the employees in 
this sample may not have enough daily contact with their supervisors to really benefit from the relationship in terms of increased work ability.

Further, mean ratings of leader-member exchange were just above the mid-point (3.25 on a 5-point scale) in this study, suggesting that employees generally feel neutral as opposed to positive about the unique relationship they have with their supervisor. This could be attributable to the perceived differences between employees and supervisors in construction (and in the two organizations utilized in this study specifically). Similarity, especially in terms of personality, has been demonstrated to be a key predictor of the development of high-quality leader-member exchange relationships (Bauer \& Green, 1996). In the sample utilized in this dissertation, there seemed to be an "us versus them" mentality between front-line employees who actually carry out the construction work in the field, and the supervisors, who work from the main office and have "white collar" desk jobs (based on field observations by the research team who collected this data). Also, the actual construction workers in this sample are unionized, while the supervisors are not, which seems to create an even greater divide between the two groups. It is possible that if employees and supervisors perceived themselves to be more like one another, this would aid in the development of higher-quality leader-member exchange relationships which could potentially have more of a positive impact on work ability.

Organizational justice. Organizational justice (both procedural and distributive), which refers to employees' perceptions of fairness in organizations, was expected to relate positively to work ability in this study. In previous research, organizational justice has been shown to relate to a variety of positive behavioral and attitudinal outcomes, 
including job satisfaction, reduced withdrawal, and enhanced performance (Colquitt et al., 2001). It was expected that organizational justice would be related positively to work ability in this study because of its influence on attitudes such as belongingness (e.g., Armstrong-Stassen \& Schlosser, 2011) as well as its demonstrated relationship with health (e.g., Robbins et al., 2012). However, neither procedural nor distributive justice were significantly related to work ability in this study. It is possible that, as with leadermember exchange, the physical distance between front-line employees and their supervisors and management prevented the existence of meaningful relationships between justice and work ability. In order for employees to be positively affected by the perceived fairness of processes and outcomes, they need to be aware of what those processes and outcomes are. Working mostly offsite, this sample of construction workers may have been too far removed from the management's decision-making for it to affect their ability to meet their job demands.

Age diversity climate. Age diversity climate, which refers to employees' collective impression that their organization favors an age-diverse workforce and takes steps to actively recruit, promote, and retain employees of all age groups, was expected to buffer against the negative effects of increased age and poor health on work ability. In this study, I utilized individual perceptions of age diversity climate rather than workgroup averages because my aggregation statistics did not warrant analysis at the group level. Still, because positive age diversity climate is characterized by high social exchange relationships (Boehm et al., 2014), higher perceptions of age diversity climate were 
anticipated to increase work ability because of the associated social support and motivation inherent in social exchange relationships.

While age diversity climate perceptions did not significantly interact with age to affect work ability, the interaction between age diversity climate perceptions and health was significant at the $p<.10$ level. The relationships were in the hypothesized direction, demonstrating that the negative relationship between poor health and work ability was weaker under conditions of higher age diversity climate. This means that age diversity climate may have the potential to buffer against the negative effects of poor health on employees' work ability. Further, age diversity climate perceptions did significantly and positive relate to work ability after controlling for age and health in the ancillary analyses. This is a critical finding, as it suggests that age diversity climate is actually linked to increased perceptions of being able to meet one's mental and physical health demands even when controlling for the established work ability predictors of age and health.

The fact that age diversity climate is linked to improved work ability points to the importance of the social environment in determining the extent to which employees can meet the demands of their job. This is particularly important, considering that most of the research on work ability to date has focused on either physical workplace factors (such as physical workload and ergonomics) or characteristics of the individual employee (such as health or functional capacity). The results of this study demonstrate that age diversity climate is not only relevant to employees' feelings of respect and belonging, but also to their perception that they can meet their actual job demands. 
This is consistent with the work of Boehm and colleagues (2014), which has demonstrated that positive age diversity climate (which is fostered largely through ageinclusive HR practices) is linked to enhanced firm performance. The authors highlight the importance of the social aspect of age diversity climate, suggesting that companies not only invest in age-inclusive HR practices, but also actively discuss them, increase employees' awareness of them, and make those practices a key component of their "corporate DNA".

Team cohesion. Team cohesion, which refers to the degree to which members are attracted to their team and desire to remain in it, was expected to buffer against the negative effect of increased age and poor health on work ability. This hypothesis was rooted in Social Exchange Theory (Lewis \& Weigert, 1985), according to which positive feelings, perceptions, and expectations about the goodwill of other team members foster an obligation on the part of employees to reciprocate. This has been shown to lead to greater effort, and has been linked to enhanced performance (Evans \& Dion, 1992). While team cohesion did not significantly interact with age to predict work ability, it did significantly interact with poor health with regard to work ability as hypothesized. The relationship between poor health and work ability was negative, but this negative relationship was weaker under higher conditions of team cohesion.

This finding suggests that organizations may be able to help their employees to successfully meet their job demands in spite of health problems by developing and supporting cohesive work teams. In accordance with Social Exchange Theory (Lewis \& Weigert, 1985), employees who enjoy being part of their work team and are proud of 
their team membership are more likely to help one another. Further, members of cohesive teams can provide each other not only with instrumental support, but also emotional support, helping to reduce the negative impact of workplace and personal stressors on work ability. Leaders can help to support their teams and improve team cohesion by fostering an environment in which team members are rewarded for effective team performance, are treated fairly, and respect one another.

In the ancillary analyses, team cohesion was also shown to relate positively and significantly to work ability, after controlling for age and health. This suggests that, similar to age diversity climate, team cohesion is important for work ability, even after considering the major established (negative) predictors of increased age and health problems. This is consistent with previous research that has demonstrated a positive relationship between team cohesion and performance (e.g., Evans \& Dion, 1992). Team cohesion likely impacts performance through its effects on motivation and social support. The positive affect associated with enjoying membership in one's team can lead to a greater interest in participating in tasks that help both individual team members and the team as a whole perform more effectively.

\section{Potential Limitations}

As with any study, this dissertation does have some limitations. First, all data utilized were self-reported by study participants. This may lead to common method bias. However, it is important to note that the work ability literature has suggested that subjective measurement of the construct is actually important to predicting individual and organizational outcomes. Second, the specific nature of this sample limits the 
generalizability of the results. Construction is a unique industry; it is largely male, heavy in physical labor, and often involves at least somewhat remote working arrangements (in which employees and supervisors do not share the same work space). Another potential limitation is that this study was cross-sectional; thus, direction of causality of the observed relationships cannot be ascertained. Further, the correlation between the two items used to measure work ability (ability to meet mental demands and ability to meet physical demands) was .73 . Thus, it is unclear if participants were really able to differentiate between the two components of work ability examined. Lastly, the ICCs for the group-level variables, age diversity climate and team cohesion, did not warrant aggregation to the group level in this study. Therefore, I was unable to measure the effects of group-level averages of these constructs on individual work ability outcomes. Future studies would benefit from examining the effects of aggregate age diversity climate and team cohesion on individual outcomes, if possible.

\section{Implications for Understanding the Work Ability Construct}

This study helps to further integrate the construct of work ability into the $\mathrm{I} / \mathrm{O}$ and OHP literatures. Until recently, the research that was done on work ability lacked a theoretical foundation and focused mostly on physical workplace characteristics and/or health and demographic characteristics of individual employees. This work, conducted mostly in the occupational medicine field in Europe, is certainly valuable. It has identified characteristics, particularly from the perspectives of industrial hygiene, ergonomics, and medicine, that are related to individuals' work ability, which has been tied to important outcomes such as receipt of disability pension and retirement age. 
However, examining work ability from an I/O and OHP perspective has added value. Examining psychosocial predictors of work ability within an established theoretical framework helps in identifying an important set of characteristics that can likely be impacted by organizations. Testing these relationships within a theoretical framework enhances our understanding of the mechanisms through which these characteristics affect one another.

Studies by Weigl and colleagues (2014) and McGonagle and colleagues (in press) were two of the first to examine work ability through an I/O and OHP lens. Weigl and colleagues showed that the negative relationship between age and work ability was weakest when employees had greater autonomy and implemented selection, optimization, and compensation (SOC) strategies. This means that autonomy and SOC strategies can buffer against the negative effects of age on work ability. These findings are of practical value for both researchers and practitioners, because they suggest that designing jobs to increase autonomy and encouraging employees to use SOC strategies can help older employees to be successful in meeting the demands of their jobs.

McGonagle and colleagues utilized a Job Demands-Resources model to examine the relationship between job demands and resources with work ability, as well as the relationship between work ability and the outcomes of absence, disability leave, and retirement status. In a series of three studies, they found that health and sense of control were consistently and most strongly related to work ability (compared to other job demands and resources, such as role overload, time pressure, and autonomy). Palermo and colleagues (2013) also examined psychosocial aspects of the work environment and 
found that organizational nurturance and vocational strain related to work ability through their effects on job satisfaction.

These studies have been instrumental in creating a foundation for understanding psychosocial characteristics that can impact employees' work ability. However, we are just beginning to scratch the surface in terms of understanding how we can utilize $\mathrm{I} / \mathrm{O}$ and OHP methods to determine the most consequential predictors of work ability that can be used to improve employees' ability to meet their job demands through the lifespan. McGonagle and colleagues (in press) have called for the examination of other work environment characteristics that may impact work ability; this dissertation has responded to that call. This study has identified team cohesion and age diversity climate, social aspects of the work environment that appear to impact employees' work ability beyond the effect of increased age and poor health.

\section{Implications for Future Research}

Particularly because the study of work ability is still quite new in the fields of Industrial and Organizational Psychology and Occupational Health Psychology, there are many promising areas for future research. First, the use of objective measures (particularly of employee health) has the potential to enhance our understanding of the work ability construct. When all variables in a study are self-report, it is likely that the results will to some degree be affected by common method variance or shared variance due to measurement method (Podsakoff, MacKenzie, Lee, \& Podsakoff, 2003). Selfreported measures of health can also be affected by confounding factors, such as respondent affect and/or reading level. Because of the biases inherent in self-report 
measures, objective health measures can add substantially to the validity of results concerning the effects of organizational experiences on employees (Bakker, Killmer, Siegrist, \& Schaufeli, 2000).

In a similar vein, other-reports of different study constructs would also be useful in future research (and likely easier to obtain than objective health measures). Although other-reports of health may not be practical because it may be hard to ascertain someone else's health status, particularly regarding mental and emotional health, other-reports of work ability would likely be very useful. Work ability is similar to performance, in the sense that it refers to an employees' ability to meet their job demands. In many work situations, other-reports of performance are utilized in making workplace decisions. Promotions, raises, transfers, and employee terminations are almost always decided by other-reports of an employees' performance (most often, the supervisors'). While a person's own perceptions of their work ability likely affect their attitudes and well-being, others' perceptions of their work ability likely affect employment decisions that significantly affect their lives. In this sense, other-reports of work ability may not only be helpful for reducing common method variance, but also may have great practical relevance. Similarly, other-reports of psychosocial constructs, such as social characteristics of the work group or work environment (like team cohesion or age diversity climate) would also help to reduce common method bias and possibly provide a more objective understanding of employees' work settings.

The current study did not take into account the employees' particular jobs or differences between their various jobs. This likely has implications for understanding the 
work ability construct and its practical applications. For instance, if someone perceives their work ability to be low or declining, and they are in a job that has relatively low cognitive and/or physical demands, they may need to transition out of the workforce and either enter retirement or collect a disability pension. However, if a worker perceives their current work ability to be low, but they are in a job that is high in cognitive and/or physical demands, it is possible that they could continue to work successfully if transitioned to a job with more manageable demands. Future research would benefit from examining work ability in the context of the employees' jobs. One way to do this would be to categorize participants' jobs according to the job classification system utilized on O*NET.

As mentioned earlier, the sample utilized in this study is very specific - aging construction workers in a particular region of the United States. The nature of construction work is somewhat unique compared to many other industries. It is largely physical in nature, and employees spend most of their time traveling to various work sites throughout the city, away from the main offices where their supervisors are located. The employees' jobs also seem relatively high in interdependence. Team members are required to work together and coordinate the performance of their tasks. This particular sample is also mostly white and male. Therefore, future research is needed in order to determine the extent to which the findings of this dissertation generalize to other industries, types of jobs, and demographic groups. To this end, the psychosocial variables which did not demonstrate significant relationships with work ability in this study (i.e., 
leader-member exchange, organizational justice) should be examined in other contexts before it is determined that they do not have the potential to affect work ability.

Another promising avenue for future work ability research is the investigation of other psychosocial variables that may have a greater impact on work ability than those examined in this study. In particular, the construct of social support would likely relate to work ability, and could possibly buffer against the negative effects of increased age and poor health on work ability. In building the hypotheses for this dissertation, I explained that leader-member exchange, team cohesion, and age diversity climate were likely to counteract the negative effects of increased age and poor health on work ability partially because of their established relationships with social support. I believed that the social support inherent in these constructs would provide employees with the assistance they needed to meet the demands of their jobs. To this end, it is very possible that measuring social support directly (as opposed to related social workplace constructs) would lead to greater observed relationships with work ability. This would also fit well with the Job Demands-Resources model in which I couched my hypotheses, as social support has already been demonstrated to buffer against the negative effects of job demands in that model (Karasek \& Theorell, 1990).

As the construct of work ability becomes more integrated into the I/O and OHP literatures, research on the psychometric properties of various work ability scales is also needed. To date, very little work has been done demonstrating the reliability and validity of the different work ability measures, including the most commonly-used WAI. Further, although there is one chapter of this dissertation dedicated to reviewing the extant 
literature on work ability, more work is needed in order to organize and synthesize the research on work ability that has been conducted to date. Specifically, a meta-analysis examining the antecedents and outcomes of work ability would be extremely valuable to increasing our understanding of the prior research and identifying key areas for future studies.

Another important avenue for future research is to examine the outcomes of work ability, such as disability leave and actual retirement. Some studies have already shown that work ability is related to retirement intentions (e.g., Heponiemi et al., 2008; McGonagle et al., in press). Further, Feldt and colleagues (2009) showed that work ability is related to a person's actual age at retirement. However, more studies on actual retirement (as opposed to just retirement intentions) are needed. In particular, longitudinal studies examining both antecedents and outcomes of work ability would be useful. The stronger the demonstrated connection between work ability and behavioral outcomes of interest, the easier it will be to convince policy makers and organizational leaders to support employees' work ability throughout the lifespan.

Lastly, future research should examine the effect of interventions designed to improve work ability, or prevent the decline of work ability as employees age and potentially experience health issues (Truxillo, Cadiz, \& Hammer, in press). As we further integrate the work ability construct into the I/O and OHP literatures and understand the workplace characteristics that predict high work ability, it is important that we utilize this information to make a practical difference in employees' work experiences. It will be particularly fruitful to combine what has already been learned from the occupational 
medicine literature in Europe regarding physical and ergonomic workplace characteristics that affect work ability with the growing body of knowledge about psychosocial characteristics from the I/O and OHP literatures to create effective work ability interventions.

\section{Implications for Practice}

This study replicates the established finding that age and health are significantly related to work ability. Therefore, it is important for organizations to consider how to best support their employees throughout the lifespan, particularly as they get older and potentially experience health issues. Although increased age has generally been shown to relate negatively to work ability in previous work ability research, the findings have been inconsistent. This study shows that in this sample of construction workers, age is significantly and negatively related to work ability. The negative relationship between age and work ability makes sense, given the physical nature of construction work. Compared to other industries and types of jobs, employees have relatively low autonomy and potentially less opportunity to capitalize on the knowledge they have accumulated.

Even among healthy individuals, physical strength is generally greatest at age 2030 ; it gradually declines between ages 30 and 50, and then deteriorates more quickly after age 50 (Millanvoye, 1998). Therefore, in construction jobs which are high in physical labor, it is almost inevitable that increased age will lead to decreased work ability unless organizations take an active role in creating a work environment that will support aging employees' changing needs and abilities. Organizations can help their employees to thrive as they age by assessing and redesigning the jobs of older workers (Truxillo, 
Cadiz, \& Rineer, 2012). For example, construction organizations may be able to capitalize on the experience and knowledge of their older workers by providing them more opportunities to provide support and share knowledge with newer and/or younger employees (Truxillo, Cadiz, \& Rineer, 2014). Also, allowing workers more autonomy (to the extent possible) can also give older employees room to implement more selection, optimization, and compensation strategies, which have been shown to buffer against the negative relationship between age and work ability (Weigl et al., 2013; Truxillo, Cadiz, Rineer, Zaniboni, \& Fraccaroli, 2012).

The relationship between age and health is also important in understanding work ability. In the sample utilized in this study, increased age and poor health were positively related, though the correlation was not significant. However, in general, health tends to decline with age. As previously mentioned, age is related to declines in bone density, balance, exercise capacity, hearing ability, and visual acuity, and increases in conditions such as coronary artery disease (Silverstein, 2008). Increased age is also related to an increased prevalence of work-limiting disabilities (National Research Council, 2004). It is important that employers support the health of their workers of all ages; however, this becomes increasingly important as employees age and become more likely to experience poorer health. Organizations should be aware of the physical changes associated with age and support employees through the aging process. This can be done through many different ways; examples include job redesign efforts (e.g., Truxillo, Cadiz, \& Rineer, 2012), investment in health prevention and promotion programs, and offering sufficient 
health care benefits to employees to ensure that they can address their mental and physical health needs.

It is also noteworthy that health was a stronger predictor of work ability than was age, though both were statistically significant. In the regression models that were run to test the original set of hypotheses, health was significantly related to work ability (after controlling for age) in each of the ten models run. However, after controlling for health, age was only significantly related to work ability in three of the ten models; and even then, the magnitude of the relationships was small.

The fact that health seems to be more strongly and consistently related to work ability than age is consistent with past research, and is also promising for organizations. Obviously, organizations cannot change a person's age, but there are organization-based health interventions that can help promote health and prevent against illness (Hymel et al., 2011). There are a variety of evidence-based health programs and interventions of varying complexity and magnitude that can support employees in sustaining or improving their mental and physical health (e.g., Institute of Medicine Committee to Assess Worksite Preventive Health Program Needs, 2005). This dissertation (and prior research on work ability) suggests that organizations would be wise to implement such programs, not only to improve employees' welfare, but also because better health is related to improved work ability.

The fact that age diversity climate and team cohesion emerged as being significantly, and positively related to work ability even after controlling for age and health also has critical implications for organizations. These findings help to provide 
additional leverage to organizations looking to increase their employees' work ability. Organizations can improve their age diversity climate by ensuring that their policies and procedures are supportive of employees of all life stages, and that these policies and procedures are actually implemented fairly across age groups (Boehm et al., 2014).

Supervisors and managers can also help to improve team cohesion among their workgroups by supporting team-building trainings and activities and overseeing teamwork in ways that facilitate team performance and positive team morale. For example, team coordination and adaptation training has been found to be quite effective for improving team performance (Salas, Nichols, \& Driskell, 2007). Regarding team building, trainings that emphasize role clarity have been shown relate to enhanced performance (Salas, Rozell, Mullen, \& Driskell, 1999).

It is important to note that in many of today's work environments, teams are permeable and changing. Employees often belong to multiple teams, and teams may gain and lose members over time. In addition, individuals within teams change and develop, and the demands placed on teams vary as work contexts evolve. Organizations can help support their teams as they adapt and at various stages of development through transformational leadership, which has been shown to relate positively to team effectiveness and productivity. Such guidance from leadership is especially important when tasks are highly interdependent (Burke et al., 2006), as is the case with construction and in many other industries.

\section{Conclusion}


This study helps to further integrate work ability into our field and theoretically ground the construct using the Job Demands-Resources model (Demerouti, Bakker, Nachreiner, \& Schaufeli, 2001). This dissertation examined psychosocial characteristics of the work environment (age diversity climate, team cohesion, organizational justice, and leader-member exchange) that were expected to buffer against the negative effects of increased age and poor health (personal vulnerabilities) on work ability. While the majority of the hypothesized interaction relationships were not supported, ancillary analyses showed that both team cohesion and age diversity climate relate positively to work ability, even after controlling for age and health. This highlights the importance of social-contextual aspects of the work environment in helping employees to meet the mental and physical demands of their jobs throughout the lifespan. 
Table 1. Examples of Work Ability Measurement Tools and Strategies

\begin{tabular}{|c|c|c|c|c|c|}
\hline Measure & $\begin{array}{l}\text { Number of } \\
\text { Questions }\end{array}$ & Constructs Measured & $\begin{array}{l}\text { Qualitative } \\
\text { or } \\
\text { Quantitative }\end{array}$ & Range of Scores & How Scored \\
\hline $\begin{array}{l}\text { Work Ability Index } \\
\text { (Tuomi, Ilmarinen, } \\
\text { Jahkola, Katajarinne, \& } \\
\text { Tulkki, 1998) }\end{array}$ & $\begin{array}{l}7 \text { multi- } \\
\text { item } \\
\text { questions }\end{array}$ & $\begin{array}{l}\text {-present work ability } \\
\text { compared to lifetime best } \\
\text {-work ability in relation to } \\
\text { mental and physical job } \\
\text { demands } \\
\text {-number of diseases } \\
\text {-work impairment due to } \\
\text { diseases } \\
\text {-sickness absence } \\
\text {-projected work ability } 2 \\
\text { years from present } \\
\text {-mental resources }\end{array}$ & Quantitative & $\begin{array}{l}\text { Overall: } 7-49 \\
\text {-Current work ability } \\
\text { compared with lifetime best } \\
\text { (range: } 0-10 \text { ) } \\
\text {-Work ability in relation to } \\
\text { job demands (2-10) } \\
\text {-Number of diseases (1-7) } \\
\text {-Estimated work impairment } \\
\text { due to diseases (1-6) } \\
\text {-Sickness leave during last } 12 \\
\text { months (1-5) } \\
\text {-Own prognosis of work } \\
\text { ability } 2 \text { years from now (1- } \\
7 \text { ) } \\
\text {-Mental resources (1-4) }\end{array}$ & $\begin{array}{l}- \text { Sum of scores on the } 7 \\
\text { questions } \\
\text { Poor }=7-27 \\
\text { Moderate }=28-36 \\
\text { Good }=37-43 \\
\text { Excellent }=44-49\end{array}$ \\
\hline $\begin{array}{l}\text { Work Ability Score } \\
\text { (Tuomi, Ilmarinen, } \\
\text { Jahkola, Katajarinne, \& } \\
\text { Tulkki, 1998; } \\
\text { Ahlstrom, Grimby- } \\
\text { Ekman, Hagberg, \& } \\
\text { Delve, 2010) }\end{array}$ & 1 & $\begin{array}{l}\text {-present work ability } \\
\text { compared to lifetime best }\end{array}$ & Quantitative & $0-10$ & $\begin{array}{l}\text {-higher score indicates } \\
\text { higher work ability }\end{array}$ \\
\hline $\begin{array}{l}\text { Work Ability Estimate } \\
\text { (Ilmarinen, Gould, } \\
\text { Jarvikoski, \& Jarvisalo, } \\
\text { 2008) }\end{array}$ & 1 & $\begin{array}{l}\text {-the extent to which one is } \\
\text { generally fit to work } \\
\text { versus disabled }\end{array}$ & Quantitative & $\begin{array}{l}\text {-this one-item measure has } \\
\text { three possible response } \\
\text { options: 1) completely fit for } \\
\text { work, 2) partially disabled for } \\
\text { work, and 3) completely } \\
\text { disabled for work }\end{array}$ & $\begin{array}{l}\text {-the Work Ability Estimate } \\
\text { is treated as a categorical } \\
\text { variable; an individual is } \\
\text { simply categorized as } \\
\text { "completely fit for work", } \\
\text { "partially disabled for } \\
\text { work", or "completely } \\
\text { disabled for work" } \\
\text { depending on their response }\end{array}$ \\
\hline
\end{tabular}




\begin{tabular}{|c|c|c|c|c|c|}
\hline $\begin{array}{l}\text { Two-Item Work Ability } \\
\text { Scale (Weigl, Muller, } \\
\text { Hornung, Zacher, \& } \\
\text { Angerer, 2013) }\end{array}$ & 2 & $\begin{array}{l}\text {-work ability in relation to } \\
\text { mental and physical job } \\
\text { demands }\end{array}$ & Quantitative & $\begin{array}{l}\text {-Work ability in relation to } \\
\text { physical job demands (range } \\
=1 \text { [very poor] to } 5 \text { [very } \\
\text { good]) } \\
\text {-Work ability in relation to } \\
\text { physical job demands (range } \\
=1 \text { [very poor] to } 5 \text { [very } \\
\text { good]) }\end{array}$ & $\begin{array}{l}\text {-scale score is the mean of } \\
\text { the two items, with higher } \\
\text { scores signifying higher } \\
\text { work ability }\end{array}$ \\
\hline $\begin{array}{l}\text { Number of Days of } \\
\text { Sick Leave } \\
\text { (Lindberg, Vingård, } \\
\text { Josephson, \& } \\
\text { Alfredsson, 2006) }\end{array}$ & N/A & -sickness absence & Quantitative & $\begin{array}{l}-\min =0, \max =\text { a person's } \\
\text { number of scheduled work } \\
\text { days in a given time frame }\end{array}$ & -count \\
\hline $\begin{array}{l}\text { Work Ability Interview } \\
\text { (Tengland, 2013) }\end{array}$ & Varies & $\begin{array}{l}\text { Can be tailored for each } \\
\text { interview, but suggested } \\
\text { constructs (as per } \\
\text { Tengland, 2013) include: } \\
\text {-occupation } \\
\text {-training, education, } \\
\text { experience } \\
\text {-present work goals/tasks } \\
\text {-resources available to } \\
\text { accomplish work } \\
\text { goals/tasks } \\
\text {-degree of disability per } \\
\text { task/goal } \\
\text {-causes of diminished } \\
\text { work ability, including } \\
\text { health, motivation, etc. } \\
\text {-treatment sought } \\
\text {-possible changes to the } \\
\text { self or work environment } \\
\text { that might improve work } \\
\text { ability }\end{array}$ & Qualitative & N/A & -subjective assessment \\
\hline
\end{tabular}


Table 2. Means, Standard Deviations, and Intercorrelations among Study Variables

\begin{tabular}{|c|c|c|c|c|c|c|c|c|c|c|c|c|c|c|}
\hline Variable & M & SD & 1 & 2 & 3 & 4 & 5 & 6 & 7 & 8 & 9 & 10 & 11 & 12 \\
\hline 1. Work Ability & 4.27 & .64 & $(.85)$ & & & & & & & & & & & \\
\hline 2. Health & 2.63 & .86 & $-.41 * *$ & - & & & & & & & & & & \\
\hline 3. Age & 44.25 & 10.04 & $-.20 * *$ & .12 & - & & & & & & & & & \\
\hline 4. Leader-Member Exchange & 3.25 & .85 & .11 & $-.15^{*}$ & -.03 & $(.91)$ & & & & & & & & \\
\hline 5. Procedural Justice & 3.38 & 1.46 & .07 & -.08 & .02 & $.36 * *$ & $(.92)$ & & & & & & & \\
\hline 6. Distributive Justice & 2.99 & .99 & -.02 & .07 & .12 & $.31 * *$ & $.48 * *$ & $(.92)$ & & & & & & \\
\hline 7. Team Cohesion & 3.70 & .75 & $.29 * *$ & $-.14^{*}$ & .02 & $.54 * *$ & $.31 * *$ & $.26^{* *}$ & $(.93)$ & & & & & \\
\hline 8. Age Diversity Climate & 4.76 & 1.21 & $.21 * *$ & $-.17 *$ & $-.14 *$ & $.48 * *$ & $.28^{* *}$ & $.21^{* *}$ & $.40^{* *}$ & $(.87)$ & & & & \\
\hline 9. Treatment Condition & .64 & .48 & -.03 & -.11 & -.06 & -.03 & .02 & -.05 & .09 & .00 & - & & & \\
\hline 10. Organizational Indicator & .35 & .48 & .03 & -.06 & -.11 & -.02 & .11 & $-.12 *$ & -.06 & -.01 & .10 & - & & \\
\hline 11. Tenure & 10.37 & 7.19 & $-.21 * *$ & .12 & $.44 * *$ & -.02 & $-.17 *$ & -.05 & -.11 & $-.26 * *$ & -.07 & -.13 & - & \\
\hline 12. Gender & 1.10 & .31 & -.12 & .13 & .04 & -.01 & .10 & .01 & -.12 & .01 & $-.12 *$ & .04 & .06 & - \\
\hline 13. Hours worked/week & 40.29 & 9.92 & -.04 & -.13 & .01 & .02 & $.14^{*}$ & .13 & .02 & .06 & -.02 & -.07 & -.08 & -.07 \\
\hline
\end{tabular}

Notes. Cronbach's alphas for scales noted on the diagonal. Treatment Condition refers to whether individuals were assigned to the treatment or control intervention group. Organization Indicator is a dummy code that indicates whether employees worked at Organization A or Organization B. Gender was dummy coded as 1 = male; 2 = female. "Health" has been reverse-coded such that higher numbers represent poorer health. $* \mathrm{p}<.05 ; * * \mathrm{p}<.01$ 
Table 3.

Mixed Effects Model Estimates of Main and Moderating Effects of Age Diversity Climate and Team Cohesion on the Relationships Between Age and Work Ability and Health and Work Ability.

\begin{tabular}{|c|c|c|c|c|c|c|c|c|}
\hline \multirow[t]{2}{*}{ Moderator: } & \multicolumn{4}{|c|}{$\begin{array}{l}\text { Age Diversity } \\
\text { Climate }\end{array}$} & \multicolumn{4}{|l|}{$\begin{array}{l}\text { Team } \\
\text { Cohesion }\end{array}$} \\
\hline & Est. (SE) & $\Delta \mathrm{R}^{2}$ & Est. (SE) & $\Delta \mathrm{R}^{2}$ & Est. (SE) & $\Delta \mathrm{R}^{2}$ & Est. (SE) & $\Delta \mathrm{R}^{2}$ \\
\hline IV: & Age & & Poor Health & & Age & & Poor Health & \\
\hline \multicolumn{9}{|l|}{ Fixed Effects } \\
\hline Intercept & $4.86 *(.25)$ & & $4.88 *(.25)$ & & $4.72 *(.25)$ & & $4.78 *(.25)$ & \\
\hline Controls & & $.16^{*}$ & & $.06^{*}$ & & $.16^{*}$ & & $.06^{*}$ \\
\hline Age & N/A & & $-0.06(.04)$ & & $\mathrm{N} / \mathrm{A}$ & & $-.08+(.04)$ & \\
\hline Health & $-.24 *(.04)$ & & N/A & & $-.24 *(.04)$ & & N/A & \\
\hline Treatment & $-.07(.09)$ & & $-.06(.09)$ & & $-.07(.09)$ & & $-.07(.08)$ & \\
\hline Org Indicator & $-.06(.09)$ & & $-.06(.09)$ & & $-.03(.09)$ & & $-.02(.08)$ & \\
\hline Tenure & $-.01(.01)$ & & $-.01(.01)$ & & $-.01(.01)$ & & $-.01(.01)$ & \\
\hline Gender & $-.16(.13)$ & & $-.18(.13)$ & & $-.08(.13)$ & & $-.09(.13)$ & \\
\hline Hours/Week & $-.01+(.00)$ & & $-.01+(.00)$ & & $-.01(.00)$ & & $-.01+(.00)$ & \\
\hline Main Effects & & $.03 *$ & & $.13^{*}$ & & $.05 *$ & & $.15^{*}$ \\
\hline IV & $.01(.04)$ & & $-.24 *(.04)$ & & $-.09(.04)$ & & $-.24 *(.04)$ & \\
\hline Moderator & $.07+(.04)$ & & $.08(.04)$ & & $.15(.04)$ & & $.14(.04)$ & \\
\hline Interaction & & .01 & & .01 & & .01 & & $.03 *$ \\
\hline IV*Moderator & $-.03(.04)$ & & $.07+(.04)$ & & $.06(.04)$ & & $.11 *(.04)$ & \\
\hline \multicolumn{9}{|l|}{ Random Effects } \\
\hline Residual & $.31 *(.03)$ & & $.31 *(.03)$ & & $.30 *(.03)$ & & $.30 *(.03)$ & \\
\hline Intercept Var & $.01(.02)$ & & $.01(.02)$ & & $.00(.00)$ & & $.00(.00)$ & \\
\hline
\end{tabular}

Notes: Treatment Condition refers to whether individuals were assigned to the treatment or control intervention group. Organization Indicator is a dummy code that indicates whether employees worked at Organization A or Organization B. Gender was dummy coded as $1=$ male; $2=$ female. "Health" has been reverse-coded such that higher numbers represent poorer health. ${ }^{*} p<.05 .,+p<.10$. 
Table 4.

Mixed Effects Model Estimates of Main and Moderating Effects of Organizational Justice and Leader-Member Exchange on the Relationships Between Age and Work Ability and Health and Work Ability.

\begin{tabular}{|c|c|c|c|c|c|c|c|c|c|c|c|c|}
\hline \multirow[t]{2}{*}{ Moderator: } & \multicolumn{4}{|c|}{$\begin{array}{l}\text { Distributive } \\
\text { Justice }\end{array}$} & \multicolumn{4}{|l|}{$\begin{array}{l}\text { Procedural } \\
\text { Justice }\end{array}$} & \multicolumn{4}{|l|}{$\begin{array}{l}\text { Leader- } \\
\text { Member } \\
\text { Exchange }\end{array}$} \\
\hline & Est. (SE) & $\Delta \mathrm{R}^{2}$ & Est. (SE) & $\Delta \mathrm{R}^{2}$ & Est. (SE) & $\Delta \mathrm{R}^{2}$ & Est. (SE) & $\Delta \mathrm{R}^{2}$ & Est. (SE) & $\Delta \mathrm{R}^{2}$ & Est. (SE) & $\Delta R^{2}$ \\
\hline IV: & Age & & Poor Health & & Age & & Poor Health & & Age & & $\begin{array}{l}\text { Poor } \\
\text { Health }\end{array}$ & \\
\hline $\begin{array}{l}\text { Fixed Effects } \\
\text { Intercept }\end{array}$ & $4.86 *(.26)$ & & $4.84(.26)$ & & $4.82 *(.26)$ & & $4.84 *(.26)$ & & $4.86 *(.26)$ & & $4.90 *(.26)$ & \\
\hline Controls & & $.16^{*}$ & & $.06 *$ & & $.16^{*}$ & & $.06^{*}$ & & $.16^{*}$ & & $.06^{*}$ \\
\hline Age & $\mathrm{N} / \mathrm{A}$ & & $-.11 *(.05)$ & & $\mathrm{N} / \mathrm{A}$ & & $-.10 *(.05)$ & & $\mathrm{N} / \mathrm{A}$ & & $-.07(.04)$ & \\
\hline Health & $-.23 *(.04)$ & & $\mathrm{N} / \mathrm{A}$ & & $-.22 *(.04)$ & & $\mathrm{N} / \mathrm{A}$ & & $-.25 *(.04)$ & & $\mathrm{N} / \mathrm{A}$ & \\
\hline Treatment & $-.07(.09)$ & & $-.07(.09)$ & & $-.07(.09)$ & & $-.08(.09)$ & & $-.06(.09)$ & & $-.05(.09)$ & \\
\hline Org Indicator & $-.06(.09)$ & & $-.06(.09)$ & & $-.05(.09)$ & & $-.05(.09)$ & & $-.07(.09)$ & & $-.06(.09)$ & \\
\hline Tenure & $-.01(.01)$ & & $-.01(.01)$ & & $-.01(.01)$ & & $-.01(.01)$ & & $-.01(.01)$ & & $-.01+(.01)$ & \\
\hline Gender & $-.19(.13)$ & & $-.17(.13)$ & & $-.18(.13)$ & & $-.19(.13)$ & & $-.14(.13)$ & & $-.17(.13)$ & \\
\hline Hours/Week & $-.01(.00)$ & & $-.01(.00)$ & & $-.01(.00)$ & & $-.01(.00)$ & & $-.01+(.00)$ & & $-.01+(.00)$ & \\
\hline Main Effects & & .03 & & $.12^{*}$ & & .03 & & $.11^{*}$ & & .01 & & $.11^{*}$ \\
\hline IV & $-.10 *(.05)$ & & $-.23 *(.04)$ & & $-.11(.05)$ & & $-.22 *(.04)$ & & $-.07(.05)$ & & $-.25 *(.04)$ & \\
\hline Moderator & $.04(.04)$ & & $.04(.04)$ & & $.02(.04)$ & & $.03(.04)$ & & $.01(.04)$ & & $.01(.04)$ & \\
\hline Interaction & & .00 & & .01 & & .00 & & .00 & & .01 & & .03 \\
\hline IV*Moderator & $.07(.04)$ & & $.05(.05)$ & & $-.02(.05)$ & & $.03(.04)$ & & $-.03(.04)$ & & $.07+(.04)$ & \\
\hline Random Effects & & & & & & & & & & & & \\
\hline Residual & $.30 *(.03)$ & & $.30(.03)$ & & $.30 *(.03)$ & & $.30 *(.03)$ & & $.32 *(.04)$ & & $.31 *(.03)$ & \\
\hline Intercept Var & $.00(.00)$ & & $.00(.02)$ & & $.01(.02)$ & & $.00(.02)$ & & $.01(.02)$ & & $.01(.02)$ & \\
\hline
\end{tabular}

Notes: Treatment Condition refers to whether individuals were assigned to the treatment or control intervention group. Organization Indicator is a dummy code that indicates whether employees worked at Organization A or Organization B. Gender was dummy coded as $1=$ male; $2=$ female. 
Table 5.

Mixed Effects Model Estimates of Main Effects of Psychosocial Variables on Work Ability Controlling for Age and Health

\begin{tabular}{|c|c|c|c|c|c|c|c|c|c|c|}
\hline \multirow[t]{2}{*}{ Psychosocial Predictor } & \multicolumn{2}{|c|}{$\begin{array}{l}\text { Age Diversity } \\
\text { Climate }\end{array}$} & \multicolumn{2}{|l|}{$\begin{array}{l}\text { Team } \\
\text { Cohesion }\end{array}$} & \multicolumn{2}{|l|}{$\begin{array}{l}\text { Distributive } \\
\text { Justice }\end{array}$} & \multicolumn{2}{|l|}{$\begin{array}{l}\text { Procedural } \\
\text { Justice }\end{array}$} & \multicolumn{2}{|l|}{$\begin{array}{l}\text { Leader- } \\
\text { Member } \\
\text { Exchange }\end{array}$} \\
\hline & Est. (SE) & $\Delta \mathrm{R}^{2}$ & Est. (SE) & $\Delta \mathrm{R}^{2}$ & Est. (SE) & $\Delta \mathrm{R}^{2}$ & Est. (SE) & $\Delta \mathrm{R}^{2}$ & Est. (SE) & $\Delta \mathrm{R}^{2}$ \\
\hline IV: & Age & & Age & & Age & & Age & & Age & \\
\hline \multicolumn{11}{|l|}{ Fixed Effects } \\
\hline Intercept & $4.27 *(.08)$ & & $4.29 *(.07)$ & & $4.27 *(.08)$ & & $4.27 *(.07)$ & & $4.28 *(.08)$ & \\
\hline Controls & & .00 & & .00 & & .00 & & .00 & & .00 \\
\hline Treatment & $-.02(.10)$ & & $-.05(.08)$ & & $-.01(.09)$ & & $-.03(.09)$ & & $-.03(.09)$ & \\
\hline Org Indicator & $-.02(.10)$ & & $.00(.08)$ & & $-.03(.09)$ & & $-.02(.09)$ & & $-.02(.09)$ & \\
\hline Main Effects & & $.16^{*}$ & & $.16^{*}$ & & $.16^{*}$ & & $.16^{*}$ & & $.16^{*}$ \\
\hline Age & $-.09 *(.04)$ & & $-.11 *(.04)$ & & $-.13^{*}(.00)$ & & $-.13 *(.04)$ & & $-.10 *(.04)$ & \\
\hline Health & $-.23(.04)$ & & $-.23 *(.04)$ & & $-.21(.05)$ & &.$- .22 *(.04)$ & & $-.24 *(.04)$ & \\
\hline $\begin{array}{l}\text { Psychosocial } \\
\text { Predictor }\end{array}$ & $.08 *(.04)$ & $.01^{*}$ & $.15 *(.04)$ & $.05^{*}$ & $.03(.04)$ & .01 & $.02(.04)$ & .01 & $.02(.04)$ & .01 \\
\hline \multicolumn{11}{|l|}{ Random Effects } \\
\hline Residual & $.32 *(.04)$ & & $.31 *(.03)$ & & $.30 *(.03)$ & & $.31 *(.03)$ & & $.32 *(.04)$ & \\
\hline Intercept Var & $.02(.02)$ & & $.00(.02)$ & & $.00(.02)$ & & $.00(.02)$ & & $.01(.02)$ & \\
\hline
\end{tabular}

Notes: Treatment Condition refers to whether individuals were assigned to the treatment or control intervention group. Organization Indicator is a dummy code that indicates whether employees worked at Organization A or Organization B. "Health" has been reverse-coded such that higher numbers represent poorer health.

$* p<.05 .,+p<.10$. 
Table 6.

Model Estimates of Main Effects of Concurrent Predictors of Work Ability

\begin{tabular}{|c|c|c|}
\hline IV: & Est. (SE) & $\Delta \mathrm{R}^{2}$ \\
\hline Intercept & $4.26 *(.07)$ & \\
\hline Controls & & .00 \\
\hline Treatment & $-.04(.08)$ & \\
\hline Org Indicator & $.02(.08)$ & \\
\hline Main Effects & & $.24^{*}$ \\
\hline Age & $-.13 *(.04)$ & \\
\hline Health & $-.20 *(.04)$ & \\
\hline $\begin{array}{l}\text { Leader-Member } \\
\text { Exchange }\end{array}$ & $-.10+(.05)$ & \\
\hline Procedural Justice & $-.01(.05)$ & \\
\hline Distributive Justice & $.00(.05)$ & \\
\hline Team Cohesion & $.19 *(.05)$ & \\
\hline Age Diversity Climate & $.02(.04)$ & \\
\hline
\end{tabular}

Notes: Treatment Condition refers to whether individuals were assigned to the treatment or control intervention group. Organization Indicator is a dummy code that indicates whether employees worked at Organization A or Organization B. "Health" has been reverse-coded such that higher numbers represent poorer health.

$* p<.05 .,+p<.10$. 
Figure 1. Proposed Model

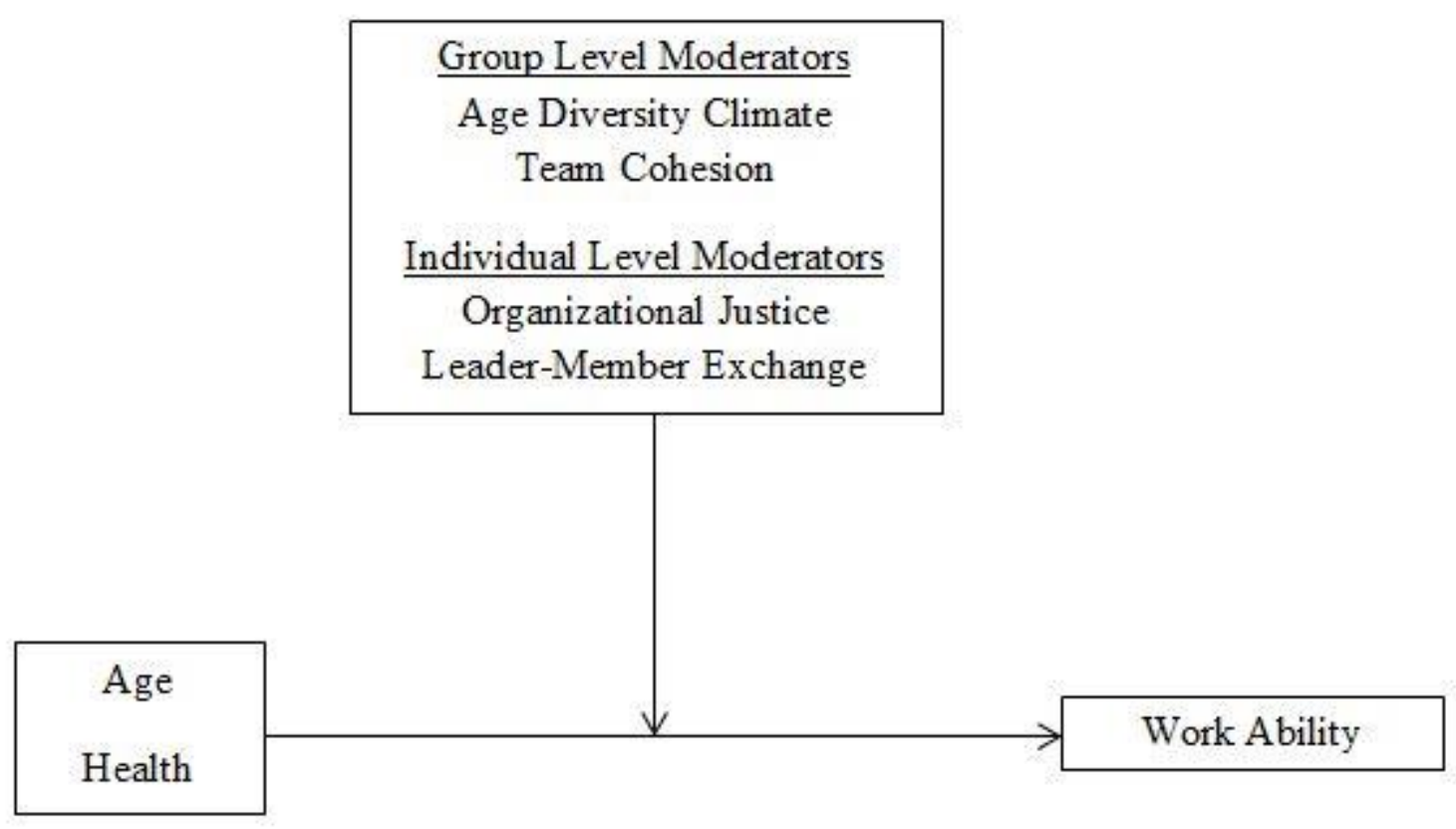


Figure 2. Work Ability House.

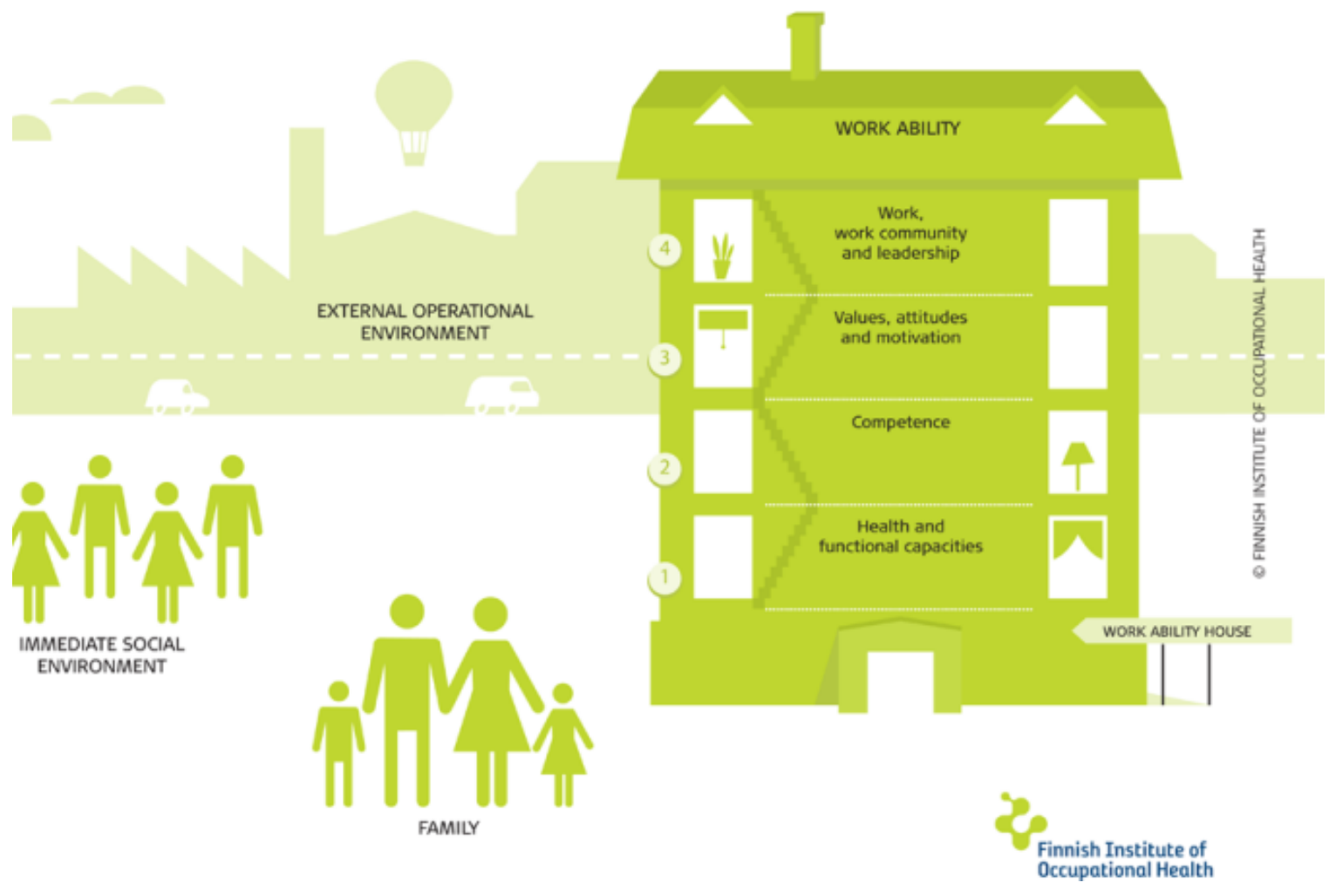


Figure 3. Interaction between Age Diversity Climate and Health on Work Ability ( $p<$ $.10)$.

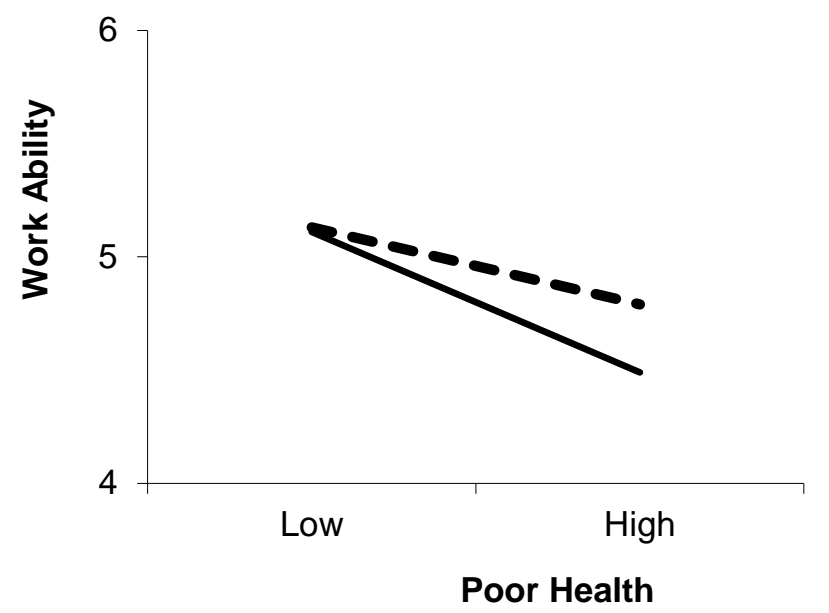


Figure 4. Interaction between Team Cohesion and Health on Work Ability.
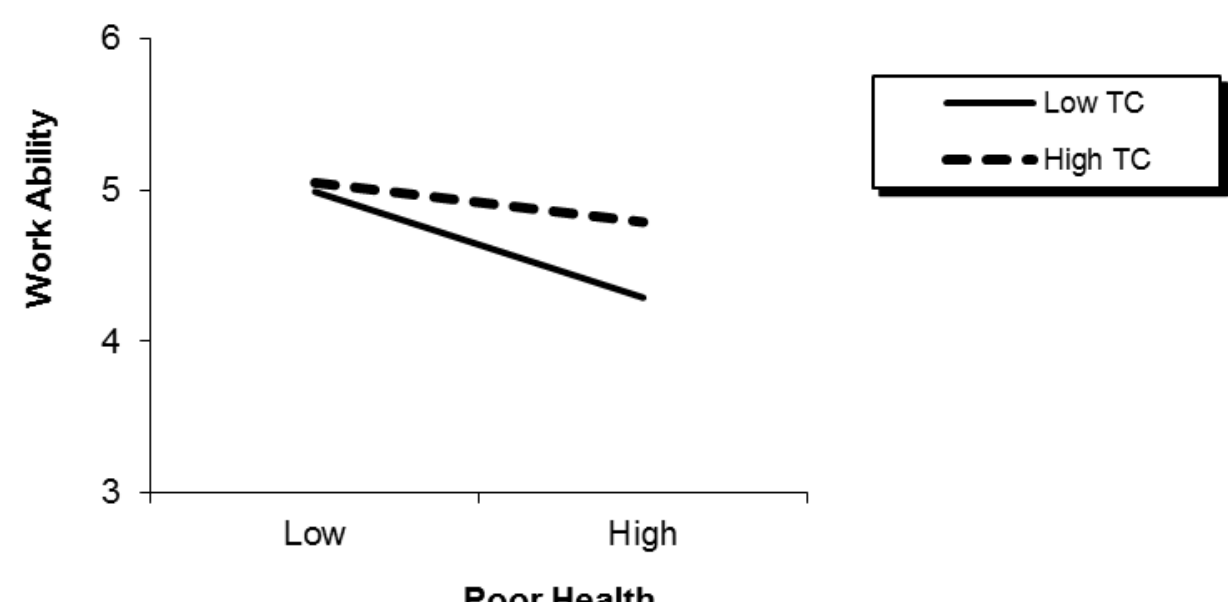

Poor Health 
Figure 5. Interaction between Leader-Member Exchange and Health on Work Ability ( $p$ $<.10)$.

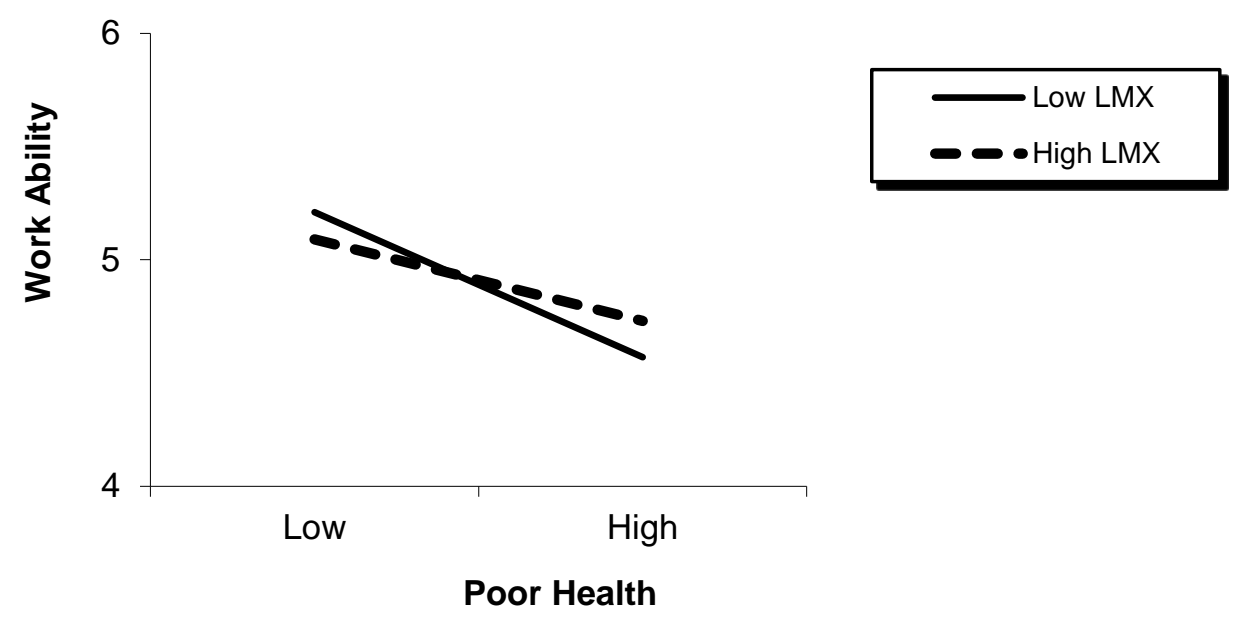




\section{References}

AARP (2002). Staying ahead of the curve: The AARP Work and Career Study: A National Survey Conducted for AARP by Roper ASW.

Ackerman, P. L. (2000). Domain-specific knowledge as the "dark matter" of adult intelligence Gf/Gc, personality and interest correlates. The Journals of Gerontology Series B: Psychological Sciences and Social Sciences, 55, 69-84.

Adams, D. (1971). Correlates of satisfaction among the elderly. The Gerontologist, 6468.

Ahlstrom, L., Grimby-Ekman, A., Hagberg, M., \& Dellve, L. (2010). The work ability index and single-item question: associations with sick leave, symptoms, and health-a prospective study of women on long-term sick leave. Scandinavian Journal of Work, Environment \& Health, 36, 404-412.

Alavinia, S. M., Van Den Berg, T. I., Van Duivenbooden, C., Elders, L. A., \& Burdorf, A. (2009). Impact of work-related factors, lifestyle, and work ability on sickness absence among Dutch construction workers. Scandinavian Journal of Work, Environment \& Health, 35, 325-333.

Alavinia, S. M., De Boer, A. G. E. M., Van Duivenbooden, J. C., Frings-Dresen, M. H. W., \& Burdorf, A. (2009). Determinants of work ability and its predictive value for disability. Occupational Medicine, 59, 32-37.

Allen, T.D. (2007). Mentoring relationships from the perspective of the mentor. In B.R. Ragins \& K.E. Kram (Eds.) The handbook of mentoring at work: theory, research, and practice (pp. 123-147). Thousand Oaks, CA: Sage Publications. 
Allen, T. D., Herst, D. E., Bruck, C. S., \& Sutton, M. (2000). Consequences associated with work-to-family conflict: a review and agenda for future research. Journal of Occupational Health Psychology, 5, 278-308

Armstrong-Stassen, M., \& Schlosser, F. (2011). Perceived organizational membership and the retention of older workers. Journal of Organizational Behavior, 32, 319344.

Aryee, S., Budhwar, P. S., \& Chen, Z. X. (2002). Trust as a mediator of the relationship between organizational justice and work outcomes: Test of a social exchange model. Journal of Organizational Behavior, 23, 267-285.

Bakker, A. B., \& Demerouti, E. (2007). The job demands-resources model: State of the art. Journal of Managerial Psychology, 22, 309-328.

Bakker, A. B., Demerouti, E., \& Euwema, M. C. (2005). Job resources buffer the impact of job demands on burnout. Journal of Occupational Health Psychology, 10, 170180.

Bakker, A. B., Demerouti, E., \& Verbeke, W. (2004). Using the job demands-resources model to predict burnout and performance. Human Resource Management, 43, $83-104$.

Bakker, A. B., Hakanen, J. J., Demerouti, E., \& Xanthopoulou, D. (2007). Job resources boost work engagement, particularly when job demands are high. Journal of Educational Psychology, 99, 274-284.

Bakker, A. B., Killmer, C. H., Siegrist, J., \& Schaufeli, W. B. (2000). Effort-reward imbalance and burnout among nurses. Journal of Advanced Nursing, 31, 884-891. 
Baltes, P. B., \& Baltes, M. M. (1990). Psychological perspectives on successful aging: The model of selective optimization with compensation. In P. B. Baltes \& M. M. Baltes (Eds.), Successful aging: Perspectives from the behavioral sciences (pp. 134). New York: Cambridge University Press.

Baltes, B. B., \& Finkelstein, L. M. (2011). Contemporary empirical advancements in the study of aging in the workplace. Journal of Organizational Behavior, 32, 151154.

Barnett, R. C., Marshall, N. L., \& Pleck, J. H. (1992). Men's multiple roles and their relationship to men's psychological distress. Journal of Marriage and the Family, $54,358-367$.

Bauer, T. N., \& Green, S. G. (1996). Development of leader-member exchange: A longitudinal test. Academy of Management Journal, 39, 1538-1567.

Beal, D. J., Cohen, R. R., Burke, M. J., \& McLendon, C. L. (2003). Cohesion and performance in groups: a meta-analytic clarification of construct relations. Journal of Applied Psychology, 88, 989-1004.

Bennett, J. B., \& Lehman, W. E. (1998). Workplace drinking climate, stress, and problem indicators: Assessing the influence of teamwork (group cohesion). Journal of Studies on Alcohol and Drugs, 59, 608-618.

Blanchard-Fields, F., Stein, R., \& Watson, T. L. (2004). Age differences in emotionregulation strategies in handling everyday problems. The Journals of Gerontology Series B: Psychological Sciences and Social Sciences, 59, 261-269.

Blau P. (1964). Exchange and power in social life. New York, NY: Wiley. 
Bliese, P. D. (2000). Within-group agreement, non-independence, and reliability: implications for data aggregation and analysis. In K. J. Klein, \& S. W. J. Kozlowski (Eds.), Multi-level theory, research and methods in organizations: Foundations, extensions, and new directions (pp. 349-381). San Francisco, CA: Jossey-Bass.

Böhm, S. A., Kunze, F., \& Bruch, H. (2014). Spotlight on Age-Diversity Climate: The Impact of Age-Inclusive HR Practices on Firm-Level Outcomes. Personnel Psychology, 67, 667-704.

Brandon, E. (2010, November 15). Why the retirement age is increasing. US News \& World Report. Retrieved from: http://money.usnews.com/money/retirement/articles/2010/11/15/why-theretirement-age-is-increasing.

Burke, C. S., Stagl, K. C., Klein, C., Goodwin, G. F., Salas, E., \& Halpin, S. M. (2006). What type of leadership behaviors are functional in teams? A meta-analysis. The Leadership Quarterly, 17, 288-307.

Byrne, Z. S., \& Hochwarter, W. A. (2006). I get by with a little help from my friends: The interaction of chronic pain and organizational support on performance. Journal of Occupational Health Psychology, 11, 215.

Camerino, D., Conway, P. M., Van der Heijden, B. I. J., Estryn-Behar, M., Consonni, D., Gould, D., \& Hasselhorn, H. M. (2006). Low-perceived work ability, ageing and intention to leave nursing: a comparison among 10 European countries. Journal of Advanced Nursing, 56, 542-552. 
Carstensen, L. L. (1991). Socioemotional selectivity theory: Social activity in life-span context. Annual Review of Gerontology and Geriatrics. 17, 195-217.

Cartwright, D. (1968). The nature of group cohesiveness. Group Dynamics: Research and Theory, 91, 91-109.

Centers for Disease Control and Prevention (2012). Older employees in the workplace: Issue Brief No. 1. Retrieved from: http://www.cdc.gov/nationalhealthyworksite/docs/Issue_Brief_No_1_Older_Empl oyees_in the Workplace 7-12-2012_FINAL(508).pdf

Chang, A., \& Bordia, P. (2001). A multidimensional approach to the group cohesiongroup performance relationship. Small Group Research, 32, 379-405.

Chin, W.W., Salisbury, D.W., Pearson, A.W., \& Stollak, M.J. (1999). Perceived cohesion in small groups. Small Group Research, 30, 751-766.

Choi, S. D. (2009). Safety and ergonomic considerations for an aging workforce in the US construction industry. Work: A Journal of Prevention, Assessment and Rehabilitation, 33, 307-315.

Cohen, S., \& Herbert, T. B. (1996). Health psychology: Psychological factors and physical disease from the perspective of human psychoneuroimmunology. Annual Review of Psychology, 47, 113-142.

Cohen, S., \& Wills, T. A. (1985). Stress, social support, and the buffering hypothesis. Psychological Bulletin, 98, 310-357. 
Colquitt, J. A., Conlon, D. E., Wesson, M. J., Porter, C. O., \& Ng, K. Y. (2001). Justice at the millennium: a meta-analytic review of 25 years of organizational justice research. Journal of Applied Psychology, 86, 425-445.

CPWR. (2013). The Construction Chart Book: The US construction industry and its workers. Silver Spring, MD: CPWR—The Center for Construction Research and Training. p. 9-10.

Cropanzano, R., Bowen, D. E. and Gilliland, S. W. (2007). The management of organizational justice. Academy of Management Perspectives, 21, 34-48.

Cropanzano, R., Prehar, C. A., \& Chen, P. Y. (2002). Using social exchange theory to distinguish procedural from interactional justice. Group \& Organization Management, 27, 324-351.

Dansereau Jr, F., Graen, G., \& Haga, W. J. (1975). A vertical dyad linkage approach to leadership within formal organizations: A longitudinal investigation of the role making process. Organizational Behavior and Human Performance, 13, 46-78.

De Zwart, B. C. H., Frings-Dresen, M. H. W., \& Van Duivenbooden, J. C. (2002). Testretest reliability of the Work Ability Index questionnaire. Occupational Medicine, 52, 177-181.

Deci, E. L., \& Ryan, R. M. (1985). The general causality orientations scale: Selfdetermination in personality. Journal of Research in Personality, 19, 109-134.

Demerouti, E., Bakker, A. B., Nachreiner, F., \& Schaufeli, W. B. (2001). The job demands-resources model of burnout. Journal of Applied psychology, 86, 499512. 
Dulebohn, J. H., Bommer, W. H., Liden, R. C., Brouer, R. L., \& Ferris, G. R. (2012). A Meta-Analysis of Antecedents and Consequences of Leader-Member Exchange Integrating the Past With an Eye Toward the Future. Journal of Management, 38, 1715-1759.

Eskelinen, L., Kohvakka, A., Merisalo, T., Hurri, H. \& Wagar, G. (1991). Relationship between the self-assessment and clinical assessment of health status and work ability. Scandinavian Journal of Work, Environment and Health, 17, 40-47.

Erez, A., \& Isen, A. M. (2002). The influence of positive affect on the components of expectancy motivation. Journal of Applied Psychology, 87, 1055-1067.

Evans, C. R., \& Dion, K. L. (1991). Group cohesion and performance a metaanalysis. Small Group Research, 22, 175-186.

Feldt., T., Hyvonen, K., Makikangas, A., Kinnumem, U., \& Kokko, K. (2009). Development trajectories of Finnish managers' work ability over a 10-year follow-up period. Scandinavian Journal of Work, Environment \& Health, 35, 3747.

Freund, A. M., \& Baltes, P. B. (2002). Life-management strategies of selection, optimization and compensation: Measurement by self-report and construct validity. Journal of Personality and Social Psychology, 82, 642-662.

Gelfand, M.J., Nishii, L.H., Raver, J., \& Schneider, B. (2005). Discrimination in organizations: An organizational level systems perspective. In Dipboye R, Colella A (Eds.), Discrimination at work: The psychological and organizational bases (pp. 89-116). Mahwah, NJ: Erlbaum. 
Goedhard, R. G., \& Goedhard, W. J. (2005, June). Work ability and perceived work stress. In International Congress Series (Vol. 1280, pp. 79-83). Elsevier.

Goedhard, W.J., Rijpstra, T.S., \& Puttiger, P.H. (1998). Age, absenteeism, and physical fitness in relation to work ability. Gerontechnology: A Sustainable Investment in the Future, 48, 254-257.

Goetzel, R. Z., Long, S. R., Ozminkowski, R. J., Hawkins, K., Wang, S., \& Lynch, W. (2004). Health, absence, disability, and presenteeism cost estimates of certain physical and mental health conditions affecting US employers. Journal of Occupational and Environmental Medicine, 46, 398-412.

Gould, R., Koskinen, S., Seitsamo, J., Tuomi, K., Polvinen, A., \& Sainio, P. (2008). Data and Methods. In R. Gould, J. Ilmarinen, J. Jarvisalo, \& S. Koskinen, (Eds.). Dimensions of work ability: Results of the Health 2000 Survey (pp. 25-32). Helsinki: Finnish Centre of Pensions, The Social Insurance Institution, National Public Health Institute, Finnish Institute of Occupational Health.

Gould, R., \& Polvinen, A. (2008). Factors Affecting Work Ability: Attitudes Towards Work. In R. Gould, J. Ilmarinen, J. Jarvisalo, \& S. Koskinen, (Eds.). Dimensions of work ability: Results of the Health 2000 Survey (pp. 95-98). Helsinki: Finnish Centre of Pensions, The Social Insurance Institution, National Public Health Institute, Finnish Institute of Occupational Health.

Graen, G. B., \& Uhl-Bien, M. (1995). Relationship-based approach to leadership: Development of leader-member exchange (LMX) theory of leadership over 25 
years: Applying a multi-level multi-domain perspective. The Leadership Quarterly, 6, 219-247.

Greenberg, J. (2006). Losing sleep over organizational injustice: attenuating insomniac reactions to underpayment inequity with supervisory training in interactional justice. Journal of Applied Psychology, 91, 58-69.

Greenberg, J. (1987). A taxonomy of organizational justice theories. Academy of Management Review, 12, 9-22.

Greenhaus, J. H., \& Powell, G. N. (2006). When work and family are allies: A theory of work-family enrichment. Academy of Management Review, 31, 72-92.

Hackman, J. R., \& Oldham, G. R. (1975). Development of the Job Diagnostic Survey. Journal of Applied Psychology, 60, 159-170.

Hakanen, J. J., Bakker, A. B., \& Schaufeli, W. B. (2006). Burnout and work engagement among teachers. Journal of School Psychology, 43, 495-513.

Hamilton, N., Karoly, P., \& Kirtzman, H. (2004). Self-regulation and chronic pain: The role of emotion. Cognitive Therapy \& Research, 28, 559-576.

Haslam, C., Atkinson, S., Brown, S. S., \& Haslam, R. A. (2005). Anxiety and depression in the workplace: effects on the individual and organisation (a focus group investigation). Journal of Affective Disorders, 88, 209-215.

Heponiemi, T., Kouvonen, A., Vänskä, J., Halila, H., Sinervo, T., Kivimäki, M., \& Elovainio, M. (2008). Health, psychosocial factors and retirement intentions among Finnish physicians. Occupational Medicine, 58, 406-412. 
Hobfoll, S. E. (2001). The influence of culture, community, and the nested-self in the stress process: advancing conservation of resources theory. Applied Psychology, 50, 337-421.

Hobfoll, S. E. (1989). Conservation of resources: A new attempt at conceptualizing stress. American Psychologist, 44, 513-524.

Horn, J. L., \& Cattell, R. B. (1967). Age differences in fluid and crystallized intelligence. Acta Psychologica, 26, 107-129.

Howell, J. M., \& Hall-Merenda, K. E. (1999). The ties that bind: The impact of leadermember exchange, transformational and transactional leadership, and distance on predicting follower performance. Journal of Applied Psychology, 84, 680-694.

Hymel, P. A., Loeppke, R. R., Baase, C. M., Burton, W. N., Hartenbaum, N. P., Hudson, T. W., ... \& Larson, P. W. (2011). Workplace health protection and promotion: a new pathway for a healthier-and safer-workforce. Journal of Occupational and Environmental Medicine, 53, 695-702.

Hurwitz, E. L., Morgenstern, H., \& Chiao, C. (2005). Effects of recreational physical activity and back exercises on low back pain and psychological distress: findings from the UCLA Low Back Pain Study. American Journal of Public Health, 95(10), 1817-1824.

Ilgen, D. R., Hollenbeck, J. R., Johnson, M., \& Jundt, D. (2005). Teams in organizations: From input-process-output models to IMOI models. Annu. Rev. Psychol., 56, 517543. 
Ilmarinen, J. (2009). Work ability-a comprehensive concept for occupational health research and prevention. Scandinavian Journal of Work, Environment \& Health, 35, 1-5.

Ilmarinen, J. (2007). The work ability index (WAI). Occupational Medicine, 57, 160.

Ilmarinen, J. E. (2001). Aging workers. Occupational and Environmental Medicine, 58, 546-546.

Ilmarinen, J., Gould, R., Jarvikoski, A., \& Jarvisalo, J. (2008). Diversity of work ability. In R. Gould, J. Ilmarinen, J. Jarvisalo, \& S. Koskinen, (Eds.). Dimensions of work ability: Results of the Health 2000 Survey (pp. 13-24). Helsinki: Finnish Centre of Pensions, The Social Insurance Institution, National Public Health Institute, Finnish Institute of Occupational Health.

Ilmarinen, J., Tuomi, K., \& Klockars, M. (1997). Changes in the work ability of active employees over an 11-year period. Scandinavian Journal of Work Environment and Health, 23, 49-57.

Ingledew, D. K., Hardy, L., \& Cooper, C. L. (1997). Do resources bolster coping and does coping buffer stress? An organizational study with longitudinal aspect and control for negative affectivity. Journal of Occupational Health Psychology, 2, 118.

Institute of Medicine Committee to Assess Worksite Preventive Health Program Needs for NASA Employees (2005). Integrating Employee Health-A Model Program for NASA. Washington, DC: The National Academies Press. 
James, L. R., Demaree, R. G., \& Wolf, G. (1993). An assessment of within-group interrater agreement. Journal of Applied Psychology, 78, 306-309.

Järvikoski A, Härkäpää K, \& Mannila S (2001). Multidimensional work ability concept and maintenance of work ability. Rehabilitation, 3, 3-11.

Johnson, J. V., \& Hall, E. M. (1988). Job strain, work place social support, and cardiovascular disease: a cross-sectional study of a random sample of the Swedish working population. American Journal of Public Health, 78, 1336-1342.

Kahn, R. L., \& Byosiere, P. (1992). Stress in organizations. In M. D. Dunnette \& L. M. Hough (Eds.), Handbook of industrial and organizational psychology (Vol. 3, pp. 571- 650). Palo Alto, CA: Consulting Psychologists Press.

Kanfer, R. \& Ackerman, P.L. (2004). Aging, work motivation, and adult development. Academy of Management Review, 29, 440-458.

Karasek, R.A. (1979). Job demands, job decision latitude, and mental strain: Implications for job redesign. Administrative Science Quarterly, 24, 285-308.

Karasek, R. A., \& Theorell, T. (1990). Healthy work: Stress, productivity, and the reconstruction of working life. New York: Basic Books.

Kinsella, K., \& Wan, H. (2008). An aging world: 2008, US Dept. of Commerce, Economics and Statistics Administration, US Census Bureau.

Kivimäki, M., Ferrie, J. E., Brunner, E., Head, J., Shipley, M. J., Vahtera, J., \& Marmot, M. G. (2005). Justice at work and reduced risk of coronary heart disease among employees: the Whitehall II Study. Archives of Internal Medicine, 165, 22452251. 
Kopelman, R. E., Brief, A. P., \& Guzzo, R. A. (1990). The role of climate and culture in productivity in B. Schneider (Ed.) Organizational Climate and Culture, 282-318.

Koskinen, S., Martelin, T., Sainio, P, \& Gould, R. (2008). Factors Affecting Work Ability: Health. In R. Gould, J. Ilmarinen, J. Jarvisalo, \& S. Koskinen, (Eds.). Dimensions of work ability: Results of the Health 2000 Survey (pp. 65-79). Helsinki: Finnish Centre of Pensions, The Social Insurance Institution, National Public Health Institute, Finnish Institute of Occupational Health.

Kujala, V., Tammelin, T., Remes, J., Vammavaara, E., Ek, E., \& Laitinen, J. (2006). Work ability index of young employees and their sickness absence during the following year. Scandinavian Journal of Work Environment and Health, 32, 7584.

Kunze, F., Boehm, S., \& Bruch, H. (2013). Organizational Performance Consequences of Age Diversity: Inspecting the Role of Diversity-Friendly HR Policies and Top Managers' Negative Age Stereotypes. Journal of Management Studies, 50, 413442.

Kunze, F., Böhm, S. A., \& Bruch, H. (2011). Age diversity, age discrimination climate and performance consequences - a cross organizational study. Journal of Organizational Behavior, 32, 264-290.

Lerner, D., Adler, D. A., Chang, H., Berndt, E. R., Irish, J. T., Lapitsky, L., ... \& Rogers, W. H. (2004). The clinical and occupational correlates of work productivity loss among employed patients with depression. Journal of Occupational and Environmental Medicine, 46, S46-S55. 
Lewis, J. D., \& Weigert, A. (1985). Trust as a social reality. Social Forces, 63, 967-985.

Liden, R. C., \& Maslyn, J. M. (1998). Multidimensionality of leader-member exchange: An empirical assessment through scale development. Journal of Management, 24, 43-72.

Liira, J., Matikainen, E., Leino-Arjas, P., Malmivaara, A., Mutanen, P., Rytkönen, H., \& Juntunen, J. (2000). Work ability of middle-aged Finnish construction workers-a follow-up study in 1991-1995. International Journal of Industrial Ergonomics, 25, 477-481.

Lindberg, P., Vingård, E., Josephson, M., \& Alfredsson, L. (2006). Retaining the ability to work-associated factors at work. The European Journal of Public Health, 16, 470-475.

Loeppke, R. R., Schill, A. L., Chosewood, L. C., Grosch, J. W., Allweiss, P., Burton, W. N., ... \& Larson, P. W. (2013). Advancing workplace health protection and promotion for an aging workforce. Journal of Occupational and Environmental Medicine, 55, 500-506.

Mach, M., Dolan, S., \& Tzafrir, S. (2010). The differential effect of team members' trust on team performance: The mediation role of team cohesion. Journal of Occupational and Organizational Psychology, 83, 771-794.

Mäkitalo, J., \& Palonen, J. (1994). What is the capacity for work: A medical balance model and integrated understanding of type. People and Work, 8, 155-162.

Martelin, T., Sainio, P., Koskinen, S., \& Gould, R. (2008). Work Ability in Different Population Groups: Employment Status. In R. Gould, J. Ilmarinen, J. Jarvisalo, \& 
S. Koskinen, (Eds.). Dimensions of work ability: Results of the Health 2000 Survey (pp. 45-47). Helsinki: Finnish Centre of Pensions, The Social Insurance Institution, National Public Health Institute, Finnish Institute of Occupational Health.

McKay, P. F., Avery, D. R., \& Morris, M. A. (2008). Mean racial-ethnic differences in employee sales performance: The moderating role of diversity climate. Personnel Psychology, 61, 349-374.

McAdams, D. P., de St Aubin, E. D., \& Logan, R. L. (1993). Generativity among young, midlife, and older adults. Psychology and Aging, 8, 221-230.

McGonagle, A.K., Fisher, G.G., Barnes-Farrell, J.L., and Grosch, J.W. (in press). Individual and work factors related to perceived work ability and labor force outcomes. Journal of Applied Psychology.

Meijman, T.F. and Mulder, G. (1998), "Psychological aspects of workload", in Drenth, P.J., Thierry, H. and de Wolff, C.J. (Eds), Handbook of Work and Organizational Psychology, 2nd ed., Erlbaum, Hove, pp. 5-33.

Michalisin, M. D., Karau, S. J., \& Tangpong, C. (2007). Leadership's activation of team cohesion as a strategic asset: an empirical simulation. Journal of Business Strategies, 24, 1-26.

Millanvoye, M. (1998). Ageing of the organism before sixty years of age. In: J.C., Marquie, D. Paumes Cau-Bareille, \& S. Volkoff, (Eds.) Working with age (pp 133-161). London: Taylor \& Francis Inc. 
Monteiro, M. S., Ilmarinen, J., \& Filho, H. R. C. (2006). Work ability of workers in different age groups in a public health institution in Brazil. International Journal of Occupational Safety and Ergonomics, 12, 417-427.

Moorman. R. H. (1991). Relationship between organizational justice and organizational citizenship behavior. Do fairness perceptions influence employee citizenship? Journal of Applied Psychology, 76, 845 - 855.

Mor Barak, E. M., Cherin, D. A., \& Berkman, S. (1998). Organizational and personal dimensions in diversity climate ethnic and gender differences in employee perceptions. The Journal of Applied Behavioral Science, 34, 82-104.

Morgeson, F.P. \& Humphrey S.E. (2006). The Work Design Questionnaire (WDQ): Developing and validating a comprehensive measure for assessing job design and the nature of work. Journal of Applied Psychology, 91, 1321-1399.

National Research Council, Committee on the Health and Safety Needs of Older Workers (2004). Health and safety needs of older workers. Washington, D.C.: The National Academics Press.

Ng, T. \& Feldman, D. C. (2010). The relationships of age with job attitudes: A metaanalysis. Personnel Psychology, 63, 677-718.

Ng, T. W., \& Feldman, D. C. (2008). The relationship of age to ten dimensions of job performance. Journal of Applied Psychology, 93, 392-423.

Nygård, C. H., Eskelinen, L., Suvanto, S., Tuomi, K., \& Ilmarinen, J. (1991). Associations between functional capacity and work ability among elderly municipal employees. Scand J Work Environ Health, 17, 122-127. 
Palermo, J., Fuller-Tyszkiewicz, M., Walker, A., \& Appannah, A. (2013). Primary-and secondary-level organizational predictors of work ability. Journal of Occupational Health Psychology, 18, 220-229.

Pensola, T., \& Jarvikoski, A. (2008). Work Ability in Different Population Groups: Marital Status. In R. Gould, J. Ilmarinen, J. Jarvisalo, \& S. Koskinen, (Eds.). Dimensions of work ability: Results of the Health 2000 Survey (pp. 54-56). Helsinki: Finnish Centre of Pensions, The Social Insurance Institution, National Public Health Institute, Finnish Institute of Occupational Health.

Podsakoff, P. M., MacKenzie, S. B., Lee, J. Y., \& Podsakoff, N. P. (2003). Common method biases in behavioral research: a critical review of the literature and recommended remedies. Journal of Applied Psychology, 88, 879-903.

Pohjonen, T. (2001). Perceived work ability of home care workers in relation to individual and work-related factors in different age groups. Occupational Medicine, 51, 209-217.

Price J. L. \& Mueller, C. W. (1986). Distributive justice. In Handbook of Organizational Measurement (pp. 122-127), Price JL, Mueller C. W. (eds). Pitman: Marshfield, MA.

Rineer, J., Truxillo, D.M., Hammer, L.B., \& Bodner, T. (2012). Social job characteristics and older workers: Effects on job satisfaction and job tension. Master's thesis, Portland State University, Portland, OR, USA.

Robbins, J. M., Ford, M. T., \& Tetrick, L. E. (2012). Perceived unfairness and employee health: a meta-analytic integration. Journal of Applied Psychology, 97, 235-272. 
Rohmert W, Rutenfranz J (1983) Erholung und pause. In: Lehmann G, Rohmert W, Rutenfranz J (Eds.) Praktische Arbeitsphysiologie. Thieme, Stuttgart, pp 86-93.

Rupp, D. E., \& Cropanzano, R. (2002). The mediating effects of social exchange relationships in predicting workplace outcomes from multifoci organizational justice. Organizational Behavior and Human Decision Processes, 89, 925-946.

Sainio, P., Koskinen, S., Martelin, T., \& Gould, R. (2008). Factors Affecting Work Ability: Functional Capacity. In R. Gould, J. Ilmarinen, J. Jarvisalo, \& S. Koskinen, (Eds.). Dimensions of work ability: Results of the Health 2000 Survey (pp. 80-90). Helsinki: Finnish Centre of Pensions, The Social Insurance Institution, National Public Health Institute, Finnish Institute of Occupational Health.

Salas, E., Nichols, D. R., \& Driskell, J. E. (2007). Testing three team training strategies in intact teams A meta-analysis. Small Group Research, 38, 471-488.

Salas, E., Rozell, D., Mullen, B., \& Driskell, J. E. (1999). The effect of team building on performance: An integration. Small Group Research, 30, 309-329.

Scandura, T. A., \& Graen, G. B. (1984). Moderating effects of initial leader-member exchange status on the effects of a leadership intervention. Journal of Applied Psychology, 69, 428-436.

Schaie, K. W., \& Willis, S. L. (1993). Age difference patterns of psychometric intelligence in adulthood: Generalizability within and across ability domains. Psychology and Aging, 8, 44-55. 
Schaufeli, W. B., \& Taris, T. W. (2014). A critical review of the Job Demands-Resources Model: Implications for improving work and health. In Bridging occupational, organizational and public health (pp. 43-68). Springer Netherlands.

Shultz, K. S., \& Wang, M. (2007). The influence of specific physical health conditions on retirement decisions. The International Journal of Aging and Human Development, 65, 149-161.

Seitsamo, J., Tuomi, K., Ilmarinen, J., \& Gould, R. (2008). Factors Affecting Work Ability: Work and the Work Environment. In R. Gould, J. Ilmarinen, J. Jarvisalo, \& S. Koskinen, (Eds.). Dimensions of work ability: Results of the Health 2000 Survey (pp. 99-108). Helsinki: Finnish Centre of Pensions, The Social Insurance Institution, National Public Health Institute, Finnish Institute of Occupational Health.

Settersten, R. \& Mayer, K. (1997). The Measurement of Age, Age Structuring, and the Life Course. Annual Review of Sociology, 23, 233-261.

Shore, L.M., Randel A.E., Chung B.E., Dean M.A., Ehrhart K.H., \& Sing, G. (2011). Inclusion and diversity in work groups: A review and model for future research. Journal of Management, 37, 1262-1289.

Siegrist, J. (1996). Adverse health effects of high-effort/low-reward conditions. Journal of Occupational Health Psychology, 1, 27-41.

Silverstein, M. (2008). Meeting the challenges of an aging workforce. American Journal of Industrial Medicine, 51, 269-280. 
Soto, C. J., John, O. P., Gosling, S. D., \& Potter, J. (2011). Age differences in personality traits from 10 to 65: Big Five domains and facets in a large cross-sectional sample. Journal of Personality and Social Psychology, 100, 330-348.

Stanford Center on Longevity (2013). The aging US workforce: A chartbook of demographic shifts. Stanford, CA: Hayutin, A., Beals, M., \& Borges, E.

Tajfel, H. (1982). Social psychology of intergroup relations. Annual Review of Psychology, 33, 1-39.

Takeuchi R, Lepak DP, Wang H, Takeuchi K. (2007). An empirical examination of the mechanisms mediating between high performance work systems and the performance of Japanese organizations. Journal of Applied Psychology, 92, 10691083.

Tengland, P. A. (2013). A qualitative approach to assessing work ability. Work: A Journal of Prevention, Assessment and Rehabilitation, 44, 393-404.

Truxillo, D.M., Cadiz, D.M., \& Hammer, L.B. (in press). Supporting the aging workforce: a research review and recommendations for workplace intervention research. Annual Review of Organizational Psychology and Organizational Behavior.

Truxillo, D., Cadiz, D., \& Rineer, J. (2014). The Aging Workforce: Implications for Human Resource Management. Oxford Research Review. http://www.oxfordhandbooks.com/view/10.1093/oxfordhb/9780199935406.001.0 001/oxfordhb-9780199935406-e-004

DOI: 10.1093/oxfordhb/9780199935406.013.004 
Truxillo, D., Cadiz, D., \& Rineer, J. (2012). Job design for an aging workforce. In J. Houdmont, S. Leka, \& R. Sinclair (Eds.), Contemporary Occupational Health Psychology: Global Perspectives on Research and Practice, Volume 2, WileyBlackwell.

Truxillo, D.M., Cadiz, D.M., Rineer, J.R., Zaniboni, S., \& Fraccaroli, F. (2012). A lifespan perspective on job design: Fitting the job and the worker to promote job satisfaction, engagement, and performance. Organizational Psychology Review, 2, 340-360.

Tuomi, K., Ilmarinen, J., Eskelinen, L., Järvinen, E., Toikkanen, J., \& Klockars, M. (1991). Prevalence and incidence rates of diseases and work ability in different work categories of municipal occupations. Scand J Work Environ Health, 17, 6774.

Tuomi, K., Vanhala, S., Nykyri, E., \& Janhonen, M. (2004). Organizational practices, work demands and the well-being of employees: a follow-up study in the metal industry and retail trade. Occupational Medicine, 54, 115-121.

Tuomi, K., Ilmarinen, J., Seitsamo, J., Huuhtanen, P., Martikainen, R., Nygard, C.H., \& Klockars, M. (1997). Summary of the Finnish research project (1981-1992) to promote the health and work ability of aging workers. Scandinavian Journal of Work, Environment and Health, 23, 66-71.

Tuomi, K., Huuhtanen, P., Nykyri, E., \& Ilmarinen, J. (2001). Promotion of work ability, the quality of work and retirement. Occupational Medicine, 51, 318-324. 
US Census Bureau (2012). US Census Bureau projections show a slower growing, older, more diverse nation a half century from now. Retrieved from: www.census.gov/newsroom/releases/archives/population/cb12-243.html.

van den Berg, T. I., Elders, L. A., de Zwart, B. C., \& Burdorf, A. (2009). The effects of work-related and individual factors on the Work Ability Index: a systematic review. Occupational \& Environmental Medicine, 66, 211-220.

Van der Doef, M., \& Maes, S. (1999). The job demand-control (-support) model and psychological well-being: a review of 20 years of empirical research. Work \& Stress, 13, 87-114.

van Emmerik, I. H., Bakker, A. B., \& Euwema, M. C. (2009). Explaining employees' evaluations of organizational change with the job-demands resources model. Career Development International, 14, 594-613.

Van Vegchel, N., De Jonge, J., Bosma, H., \& Schaufeli, W. (2005). Reviewing the effort-reward imbalance model: drawing up the balance of 45 empirical studies. Social Science \& Medicine, 60, 1117-1131.

Wang, M., \& Shultz, K. S. (2010). Employee retirement: A review and recommendations for future investigation. Journal of Management, 36, 172-206.

Ware, J., Kosinski, M., \& Keller, S.D. (1996). A 12-item short-form health survey: construction of scales and preliminary tests of reliability and validity. Med. Care, $34,220-233$.

Weigl, M., Müller, A., Hornung, S., Zacher, H., \& Angerer, P. (2013). The moderating effects of job control and selection, optimization, and compensation strategies on 
the age-work ability relationship. Journal of Organizational Behavior, 34, 607628.

Xanthopoulou, D., Bakker, A. B., Demerouti, E., \& Schaufeli, W. B. (2009). Reciprocal relationships between job resources, personal resources, and work engagement. Journal of Vocational Behavior, 74, 235-244.

Xanthopoulou, D., Bakker, A. B., Demerouti, E., \& Schaufeli, W. B. (2007). The role of personal resources in the job demands-resources model. International Journal of Stress Management, 14, 121-141.

Zaniboni, S., Truxillo, D. M., \& Fraccaroli, F. (2013). Differential effects of task variety and skill variety on burnout and turnover intentions for older and younger workers. European Journal of Work and Organizational Psychology, 22, 306317.

Zaniboni, S., Truxillo, D. M., Fraccaroli, F., McCune, E. A., \& Bertolino, M. (2011). Age moderates the effects of WDQfactors on job attitudes. In K. James and G. Burlacu (Chairs), Age and Career Development in a Changing World of Work. Paper presented at the 2011 SIOP Conference, Chicago, IL. 
Appendix A

Work Ability Index

Note: Number of points associated with each response is located at the end of each item starting with Question 3

\section{Current work ability compared with the lifetime best}

Assume that your work ability at its best has a value of 10 points. How many points would you give your current work ability? ( 0 means that you cannot currently work at all)

$10=$ completely work ability, $0=$ unable to work at present

\section{Work ability in relation to the demands of the job}

How do you rate your current work ability with respect to the physical demands of your work?

$5=$ very good, $1=$ very poor

How do you rate your current work ability with respect to the mental demands of your work?

5 = very good, 1 = very poor

\section{Number of current diseases diagnosed by a physician}

In the following list, mark your diseases or injuries. Also indicate whether a physician has diagnosed or treated these diseases. For each disease, therefore, there can be 2 (physician's diagnosis), 1 (own opinion), or no alternatives circled.

Injury from accidents

01 back 21

$02 \mathrm{arm} / \mathrm{hand} 21$

$03 \mathrm{leg} /$ foot 21

04 other part of body, where and what kind of injury? 21 
Musculoskeletal disease

05 disorder of the upper back or cervical spine, repeated instances of pain 21

06 disorder of the lower back, repeated instances of pain 21

07 (sciatica) pain radiating from the back into the leg 21

08 Musculoskeletal disorder affecting the limbs (hands, feet), repeated instances of pain 2 1

09 rheumatoid arthritis 21

10 other musculoskeletal disorder, what? 21

Cardiovascular diseases

11 hypertension (high blood pressure) 21

12 Coronary heart disease, chest pains during exercise (angina pectoris) 21

13 coronary thrombosis, myocardial infarction 21

14. cardiac insufficiency 21

15 other cardiovascular disease, what? 21

$\cdots$

Respiratory disease

16 repeated infections of the respiratory tract (also tonsillitis, acute sinusitis, acute bronchitis) 21

17 chronic bronchitis 21

18 chronic sinusitis 21

19 bronchial asthma 21

20 emphysema 21

21 pulmonary tuberculosis 21

22 other respiratory disease, what 21

...

Mental disorder

23 mental disease or severe mental health problem (for example, severe depression, mental disturbance) 21

24 slight mental disorder or problem (for example, slight depression, tension, anxiety, insomnia) 21

Neurological and sensory disease

25 problems or injury to hearing 21

26 visual disease or injury (other than refractive error) 21

27 neurological disease (for example stroke, neuralgia, migraine, epilepsy) 21

28 other neurological or sensory disease, what? 21

Digestive disease

29 gall stones or disease 21

30 liver or pancreatic disease 21

31 gastric or duodenal ulcer 21

32 gastritis or duodenal irritation 21

33 colonic irritation, colitis 21

34 other digestive disease, what? 21 
Genitourinary disease

35 urinary tract infection 21

36 kidney disease 21

37 genitals disease (for example fallopian tube infection in women or prostatic infection in men 21

38 Other genitourinary disease, what? 21

...

Skin diseases

39 allergic rash, eczema 21

40 other rash, what 21

41 other skin disease, what? 21

...

Tumor

42 benign tumor 21

43 malignant tumor (cancer), where? 21

...

Endocrine and metabolic diseases

44 obesity 21

45 diabetes 21

46 goiter or others thyroid disease 21

47 other endocrine or metabolic disease, what? 21

...

Blood diseases

48 anemia 21

49 other blood disorder, what? 21

...

Birth defects

50 birth defect, what? 21

Other disorder or disease

51 What? 21

...

\section{Estimated work impairment due to diseases}

Is your illness or injury a hindrance to your current job?

Circle more than one alternative if needed.

-There is no hindrance/I have no diseases 6

-I am able to do my job, but it causes some symptoms 5

-I must sometimes slow down my work pace or change my work methods 4

-I must often slow down my work pace or change my work methods 3

-Because of my disease, I feel I am able to do only part-time work 2

-In my opinion, I am entirely unable to work 1 


\section{Sick leave during the past year (12 months)}

How many whole days have you been off work because of a health problem (disease or health care or for examination) during the past year (12 months)?

none at all 5

at the most 9 days 4

10 - 24 days 3

25 - 99 days 2

100 - 365 days 1

\section{Own prognosis of work ability two years from now}

Do you believe that - from the standpoint of your health - you will be able to do your current job two years from now?

unlikely 1

no certain 4

relatively certain 7

\section{Mental resources}

Have you recently been able to enjoy your regular daily activities?

often 4

rather often 3

sometimes 2

rather seldom 1

never 0

Have you recently been active and alert?

often 4

rather often 3

sometimes 2

rather seldom 1

never 0

Have you recently felt yourself to be full of hope for the future?

continuously 4

rather often 3

sometimes 2

rather seldom 1

never 0 
Appendix B

Questionnaire Items

$\underline{\text { Age }}$

What is your age?

Health (Reverse-coded to represent poor health)

\begin{tabular}{|c|c|c|c|c|}
\hline OPoor & O Fair & O Good & OVery Good & OExcellent \\
\hline
\end{tabular}

\section{$\underline{\text { Team Cohesion }}$}

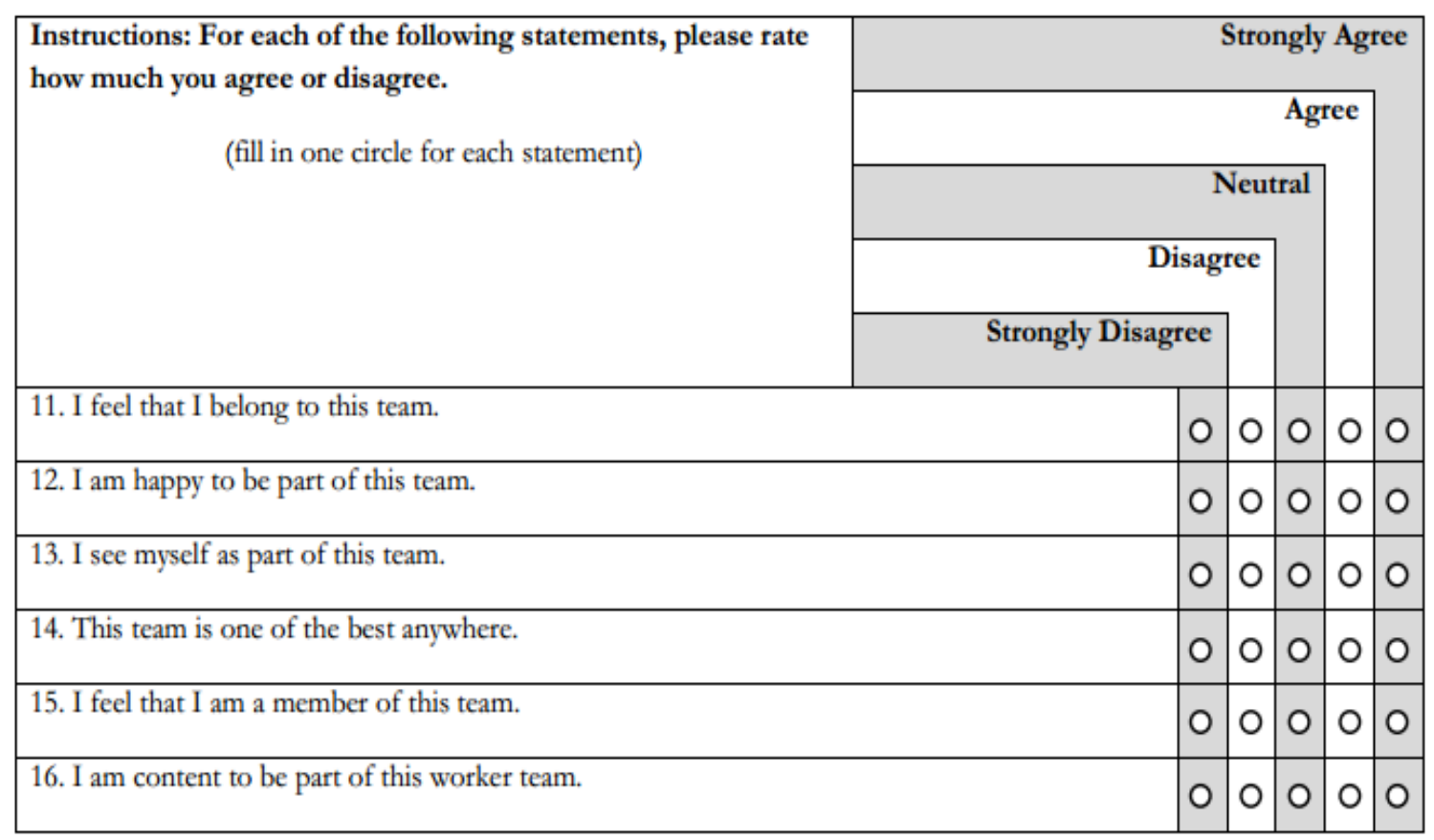




\section{Distributive Justice}

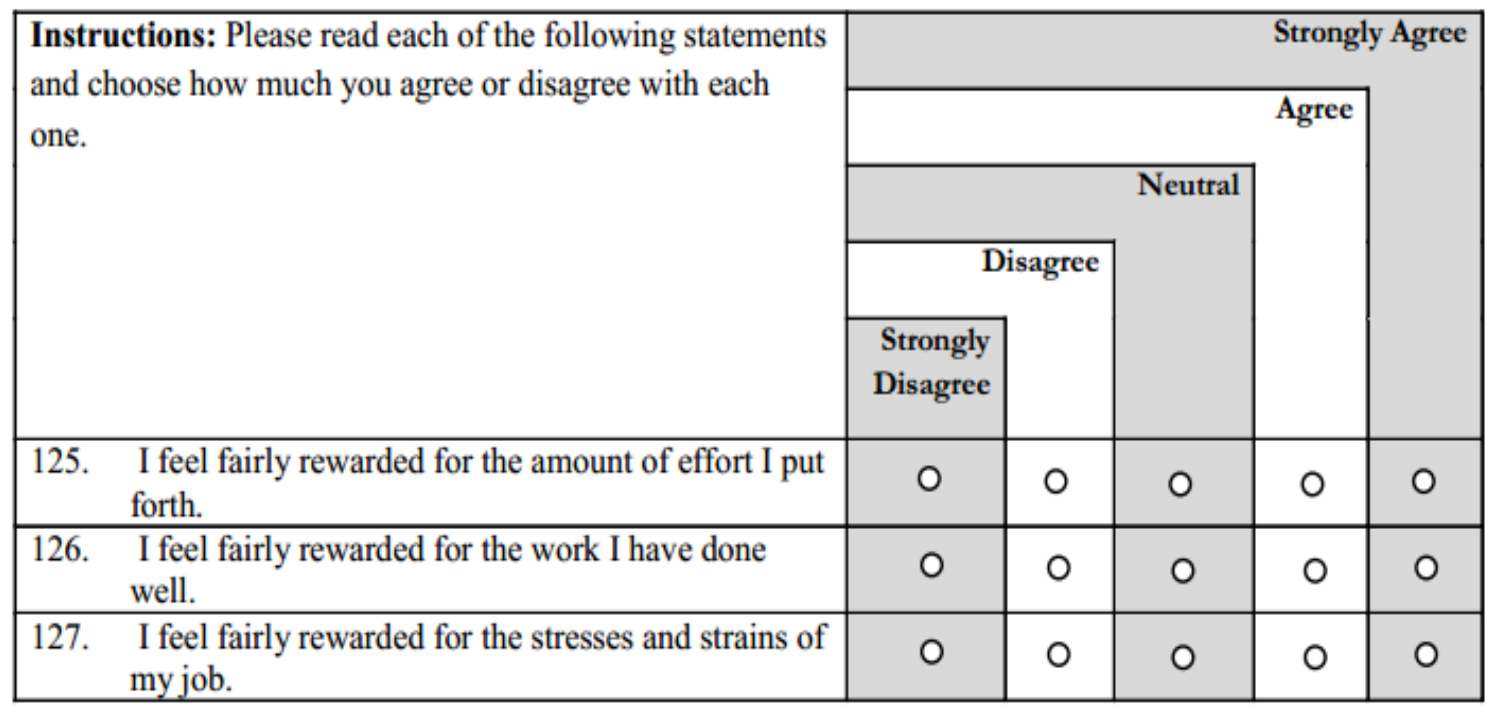

\section{$\underline{\text { Procedural Justice }}$}

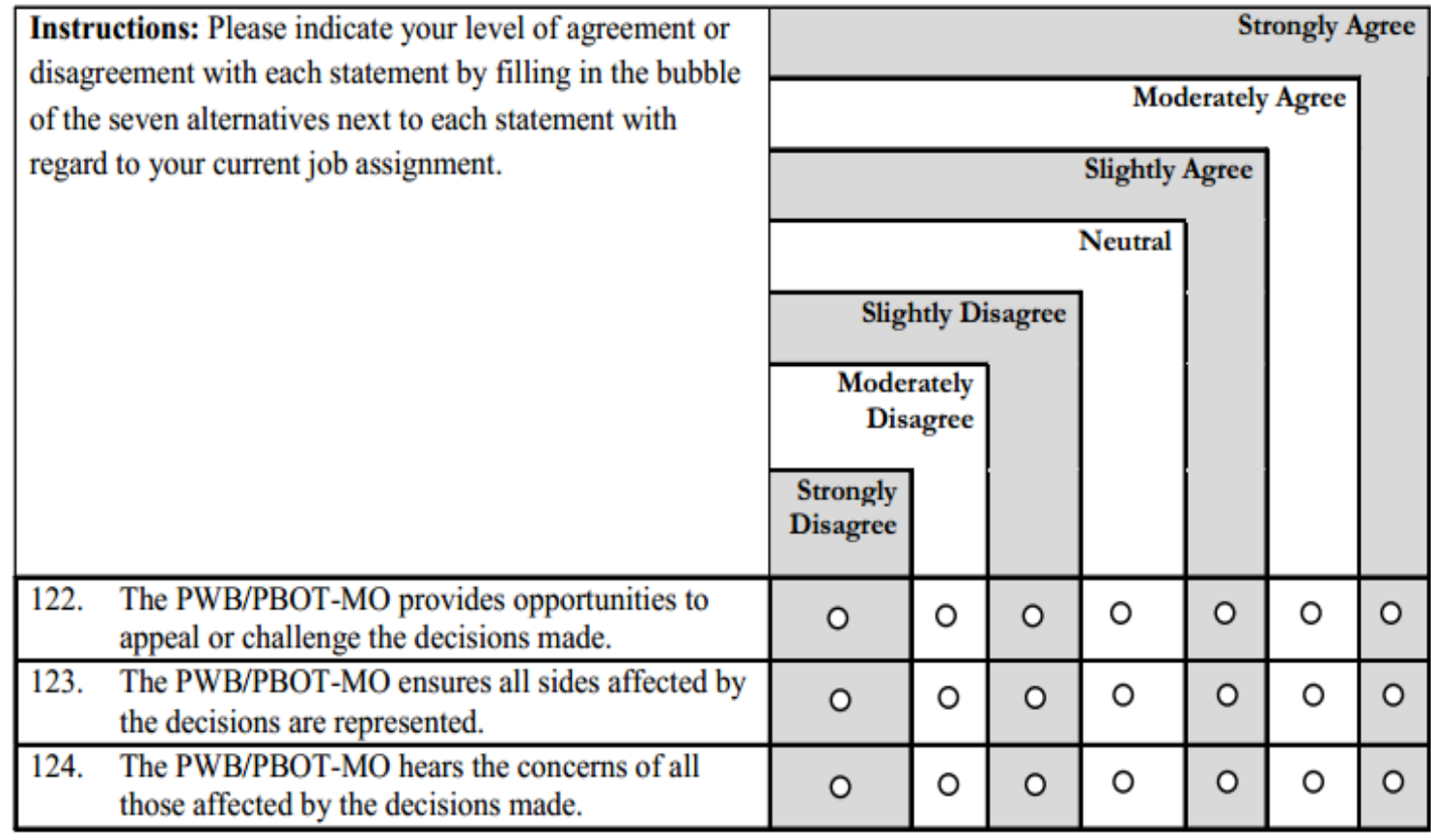


Leader-Member Exchange

128. Do you know where you stand with your supervisor?

O Rarely

O Occasionally

O Sometimes

O Fairly Often

O Very Often

129. How well does your supervisor understand your job problems and needs?

O Not a bit

O A little

O A fair amount

O Quite a bit

$O$ A great deal

130. How well does your supervisor recognize your potential?

O Not at all

O A little

O Moderately

O Mostly

O Fully 
131. Regardless of how much formal authority he/she has built into his/her position, what are the chances that your supervisor would use his/her power to help you solve problems in your work?

O None

O Small

O Moderately

O High

V Very high

132. Again, regardless of the amount of formal authority your supervisor has, what are the chances that he/she would "bail you out," at his/her expense?

O None

O Small

O Moderately

O High

O Very high

133. I have enough confidence in my supervisor that I would defend and justify his/her decision if he/she were not present to do so?

O Strongly disagree

O Disagree

O Neutral

O Agree

O Strongly agree

134. How would you characterize your working relationship with your supervisor?

Extremely ineffective

O Worse than average

O Average

O Better than average

O Extremely effective 


\section{$\underline{\text { Age Diversity Climate }}$}

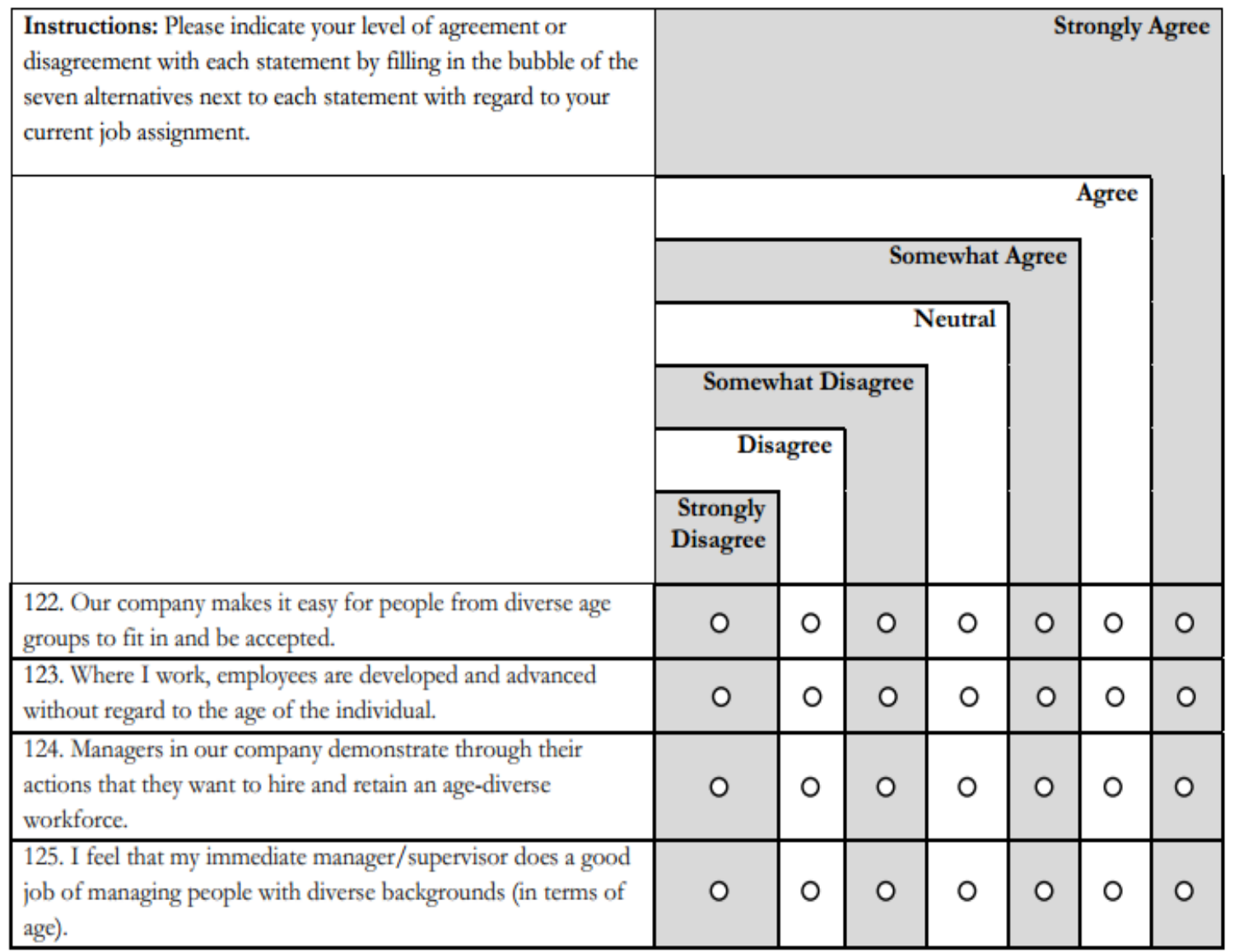

\section{Work Ability}

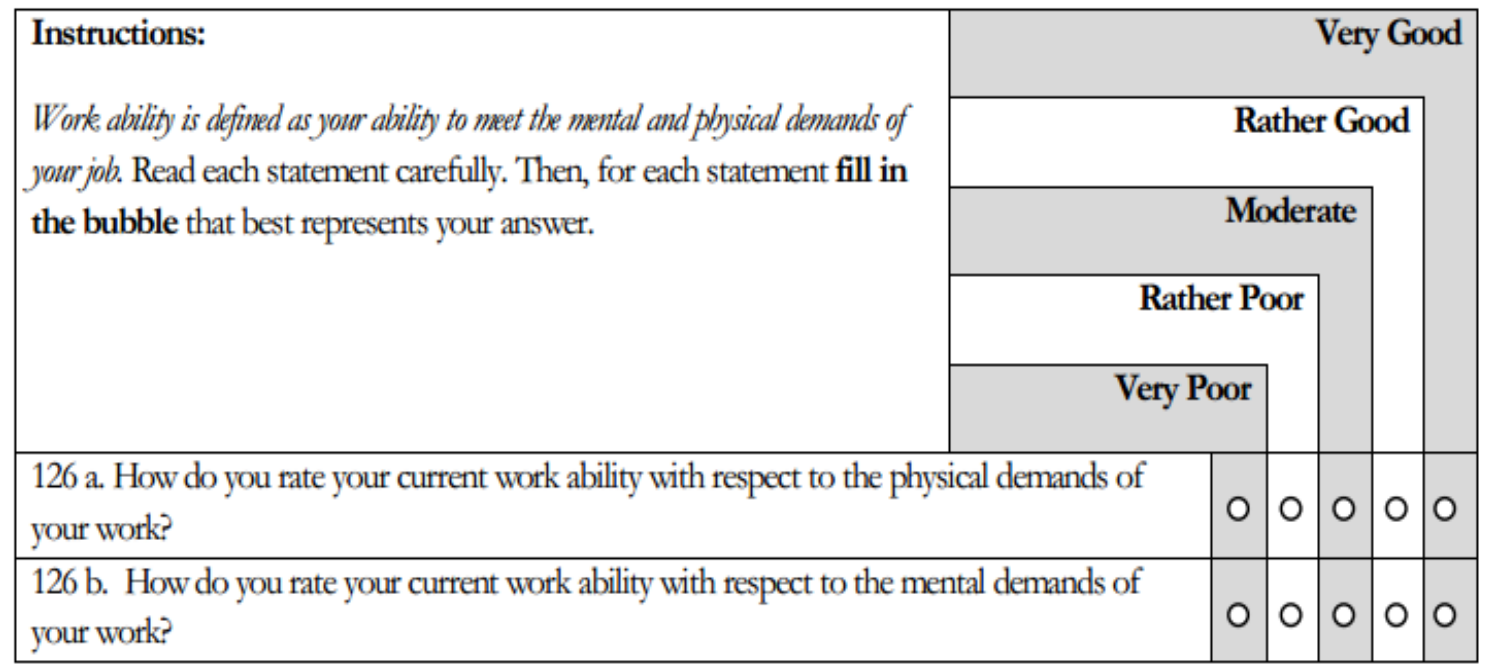

